bioRxiv preprint doi: https://doi.org/10.1101/2020.12.17.423314; this version posted December 19,2020 . The copyright holder for this preprint

(which was not certified by peer review) is the author/funder, who has granted bioRxiv a license to display the preprint in perpetuity. It is made available under aCC-BY-NC-ND 4.0 International license.

\title{
Co-opting regulation bypass repair (CRBR) as a gene correction strategy for monogenic
}

\section{diseases}

Jingjie Hu${ }^{1}$, Rebecca A. Bourne ${ }^{1}$, Barbara C. McGrath ${ }^{1}$, Alice Lin ${ }^{2}$, Zifei Pei ${ }^{1}$, and Douglas R.

Cavener $^{1}$

Affiliations:

${ }^{1}$ Department of Biology, The Pennsylvania State University, University Park, PA, 16802, USA

${ }^{2}$ Department of Biochemistry and Molecular Biology, The Pennsylvania State University, University

Park, PA, 16802, USA

Correspondence should be addressed to Douglas R. Cavener (망@psu.edu) 


\section{ABSTRACT}

With the development of CRISPR/Cas9-mediated gene editing technologies, correction of diseasecausing mutations has become possible. However, current gene correction strategies preclude mutation repair in post-mitotic cells of human tissues, and a unique repair strategy must be designed and tested for each and every mutation that may occur in a gene. We have developed a novel gene

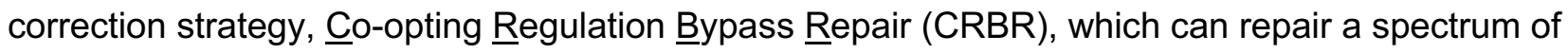
mutations in mitotic or post-mitotic cells and tissues. CRBR utilizes the non-homologous end-joining (NHEJ) pathway to insert a coding sequence (CDS) and transcription/translation terminators targeted upstream of any CDS mutation and downstream of the transcriptional promoter. CRBR gene repair results in simultaneous co-option of the endogenous regulatory region and bypass of the genetic defect. We demonstrated the potential of CRBR strategy for human gene therapy by rescuing a mouse model of the Wolcott-Rallison syndrome (WRS) with permanent neonatal diabetes caused by either large deletion or nonsense mutation in the PERK (EIF2AK3) gene. Additionally, we expressed a GFP CDS-terminator cassette that was integrated downstream of the human insulin promoter in cadaver pancreatic islets of Langerhans which paves the way for autologous cell-tissue replacement therapy for gene repair in beta cells. 


\section{$\underline{\text { Introduction }}$}

Conventional treatment of genetic diseases has relied upon long-term drug therapy or organ transplantation which necessitates the use of immunosuppressive drugs that lead to an increased risk of infections and cancer. Because these therapeutic approaches entail severe and debilitating sideeffects, strategies to permanently repair the underlying genetic defect have been sought. Gene therapy was pioneered through the use of viral expression vectors to overcome gene deficiency ${ }^{1-3}$, either by overexpressing a wild-type cognate to the deficient gene or with a heterologous gene that leads to metabolic compensation. Major drawbacks of viral vector gene expression are a lack of normal temporal, spatial and quantitative gene regulation and continued expression of the mutant gene.

The advent of CRISPR/Cas9 based technologies ${ }^{4-7}$ provided an immediate solution to the problems inherent in existing gene therapies, namely targeted correction of genetic disease-causing mutations. Expression of both Cas9 endonuclease and single guide RNA (sgRNA) in eukaryotic cells induces a double-strand break (DSB) at a target site in the genome. The DSB can be repaired by two major pathways: error-prone non-homologous end joining (NHEJ) or homology directed repair (HDR). Although the HDR pathway has been shown to repair genes precisely in mouse models of human disease $^{8-14}$, it is dependent upon cellular homologous recombination functions that are only expressed during cell division. Therefore, HDR is not capable of gene repair in post-mitotic cells ${ }^{15,16}$. Base editing approaches ${ }^{17-20}$ provide precise genome editing in post-mitotic tissues, but both HDR and base editing are limited because the components provided in trans must be engineered and tested for each specific mutation. Given that many single-gene genetic diseases ${ }^{21-23}$ may be caused by a spectrum of mutations throughout the coding sequence, a gene therapy method that utilizes a single design to repair any one of several possible mutations would be highly advantageous.

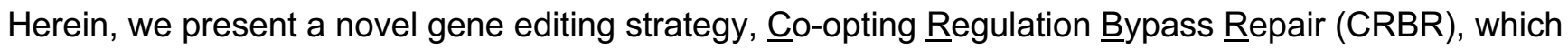
provides the means to repair a spectrum of mutations in mitotic or post-mitotic cells/tissues. CRBR is based on the efficient NHEJ repair pathway that is induced upon CRISPR/Cas9-mediated targeted 
DSB. Normally, NHEJ DSB repair results in the rejoining of two genomic DNA fragments cut by Cas9. However, if a heterologous DNA molecule is present, NHEJ repair can ligate the heterologous DNA to the cut ends of the genomic DNA, thereby inserting a large, heterologous DNA fragment at a specific sgRNA/Cas9 target site. Suzuki and coworkers ${ }^{24}$ showed that this mechanism can be used to insert a wild-type exon to repair a truncated exon with a specific splicing defect, but their method cannot be generalized to repair mutations within an exon or a spectrum of mutations. The CRBR strategy that we have developed enables targeted insertion of a normal coding sequence (CDS) and transcription/translation terminator cassette upstream of a deleterious disease-causing gene mutation. Expression of the CRBR cassette rescues gene deficiency by restoring normal expression of the wildtype CDS under its native promoter and other regulatory elements, such as enhancers, while bypassing the downstream mutated region. Because a single CRBR CDS-terminator cassette contains all of the coding sequence, it can therefore be used to rescue any coding sequence mutation, as well as splice-site mutations.

To test the efficacy of CRBR, we targeted two genes, eukaryotic translation initiation factor 2 alpha kinase 3 (PERK) and insulin (INS), which are both critically important for pancreatic beta cell functions and maintenance of glucose homeostasis. Using CRBR, we successfully integrated a complete PERK CDS-terminator cassette into the 5'UTR and showed that its expression rescued two independent Perk KO alleles in mice, one with a large three-exon deletion and the other with a nonsense mutation. Notably, all of the severe anomalies ${ }^{25,26}$ including neonatal diabetes, growth retardation, necrotic death of the exocrine pancreatic, and skeletal dysplasia were absent in the CRBR allele rescued Perk KO mice. We also demonstrated the potential of CRBR for human gene therapy by integrating a GFP CDS-terminator cassette downstream of the human insulin gene by both plasmid transfection and AAV transduction of human cadaver islets. We observed a large number of pancreatic beta cells within these islets that expressed high levels of GFP driven by the insulin promotor. It should now be possible to use CRBR gene repair to correct deficiencies in genes critical for insulin synthesis and secretion by autologous cell-tissue replacement therapy. 
$\underline{\text { Results }}$

\section{CRBR-mediated in vitro PERK CDS integration in Perk KO cell line}

The CRBR strategy features a genome editing process that generates a Cas9/sgRNA targeted DSB at a non-coding region in the genome, either within the 5'UTR or an intron. The same Cas9/sgRNA cut sites are engineered in the donor to promote the insertion of a wild-type coding sequence with transcription termination into the genomic DSB (Figure 1A). The CRBR-edited allele expresses the inserted CDS-terminator cassette under control of the endogenous promoter and bypasses expression of the downstream mutation.

We first tested the CRBR strategy in a Perk KO mouse embryonic fibroblast (MEF) cell line $\left(\right.$ Perk $^{\text {ex7- }}$ 9/_ex7-9 $)$ in which exons 7-9 have been deleted. A partial CDS $(\sim 2.2 \mathrm{~kb})$ containing the 3 ' end of intron 6 and exons 7-17 of rat Perk followed by a heterologous polyadenylation signal (bGHpA) was designed to integrate into the endogenous intron 6 to restore normal PERK expression. A Cas9/sgRNA target cut site identified within intron 6 was engineered into the donor plasmid with reverse orientation flanking the 3'in6-rPERKex7to17-bGHpA cassette (Figure 1B). The rPERKex7-17-2cut CRBR cassette can be integrated in two possible orientations: the correct 5'- $\underline{5^{\prime} / 3^{\prime}}-3^{\prime}$ orientation and the incorrect, "flipped" 5'- $\underline{3^{\prime} / 5^{\prime}}-3^{\prime}$ orientation. We designed the cassette cut sites in reversed orientation so that the correctly oriented integrants would not regenerate the cut sites whereas the incorrectly oriented integrants would restore it. Consequently, incorrectly oriented integrants could be re-excised for possible re-insertion in the correct orientation. Perk KO MEF cells co-transfected with the Cas9/sgRNA plasmid and the rPERKex7-17-2cut plasmid were positive for the 5' junction and 3' junction PCRs (Figure 1C), indicating the presence of correctly edited cells within the population. The chimeric mouse-rat Perk mRNA was also detected in this mixed cell population (Figure 1D).

This mixed population was then sorted into single cells and expanded to create 96 independent cell lines with two possible Perk alleles. Among the 96 single sorted cell lines, thirty-three cell lines were positive for the 5' junction PCR (Figure S1A). In order to test for functional PERK restoration in the 
CRBR-edited Perk KO MEF cells, we subjected these cell lines to thapsigargin treatment, which induces ER stress by PERK auto-phosphorylation and phosphorylation of its major substrate elF2 $\alpha$. Cell line \#3 had detectable levels of both PERK-P and elF2 $\alpha-P$, indicating that a functional chimeric PERK protein was expressed in this cell line (Figure 1E). CRBR-editing was confirmed in 7 other single sorted cell lines at the genome level (Figure S1B) but PERK protein expression could not be detected in these lines (data not shown). In these cases, we suspect that the 5 ' junction within the intron 6 of CRBR-edited Perk altered the splicing signal between the mouse exon 6 and rat exon 7-17 CDS of the cassette. Cell line \#3, which exhibited PERK expression, had an $11 \mathrm{bp}$ deletion at the 5' junction that removed an unintended cryptic splice-acceptor site (AG/G), which fortuitously reversed the splicing defect. The 5 ' junction of the other 7 non-expressing cell lines occurred as designed (either a clean joint or 1-2bp indels) but retained the splice-acceptor (Figure S1C). The resulting alternative mature transcript in these non-expressing cell lines contained an extra 135bp intronic sequence that encoded a stop codon, which likely resulted in nonsense-mediated mRNA decay. These results show that a CRBR-mediated partial-CDS gene editing can restore Perk gene expression and gene function in Perk KO cell line, but the introduction of cryptic splice sites must be avoided. 
bioRxiv preprint doi: https://doi.org/10.1101/2020.12.17.423314; this version posted December 19, 2020. The copyright holder for this preprint (which was not certified by peer review) is the author/funder, who has granted bioRxiv a license to display the preprint in perpetuity. It is made available under aCC-BY-NC-ND 4.0 International license.

A

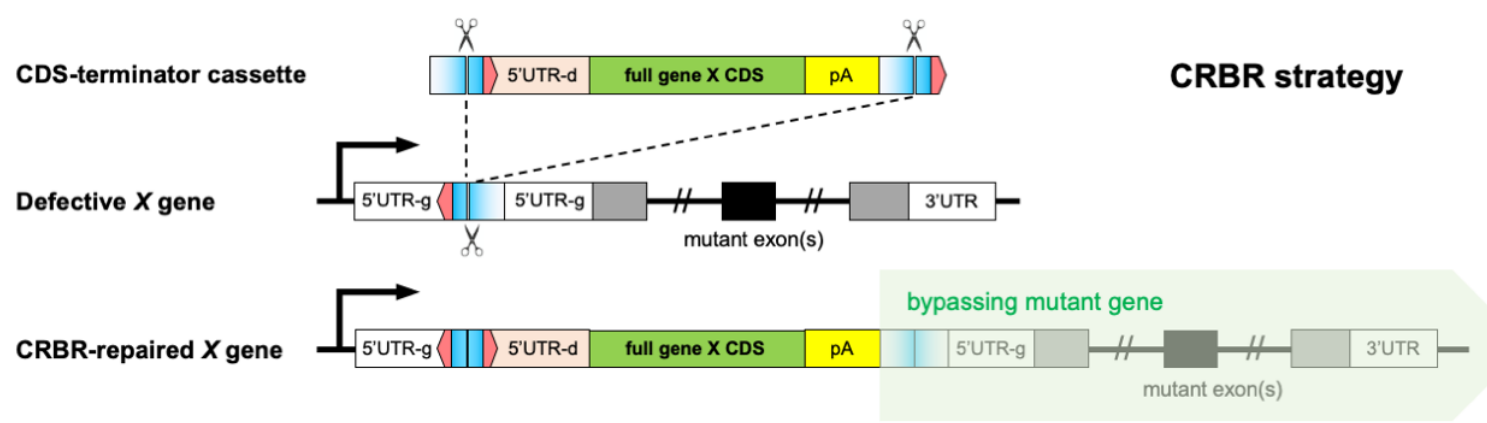

B

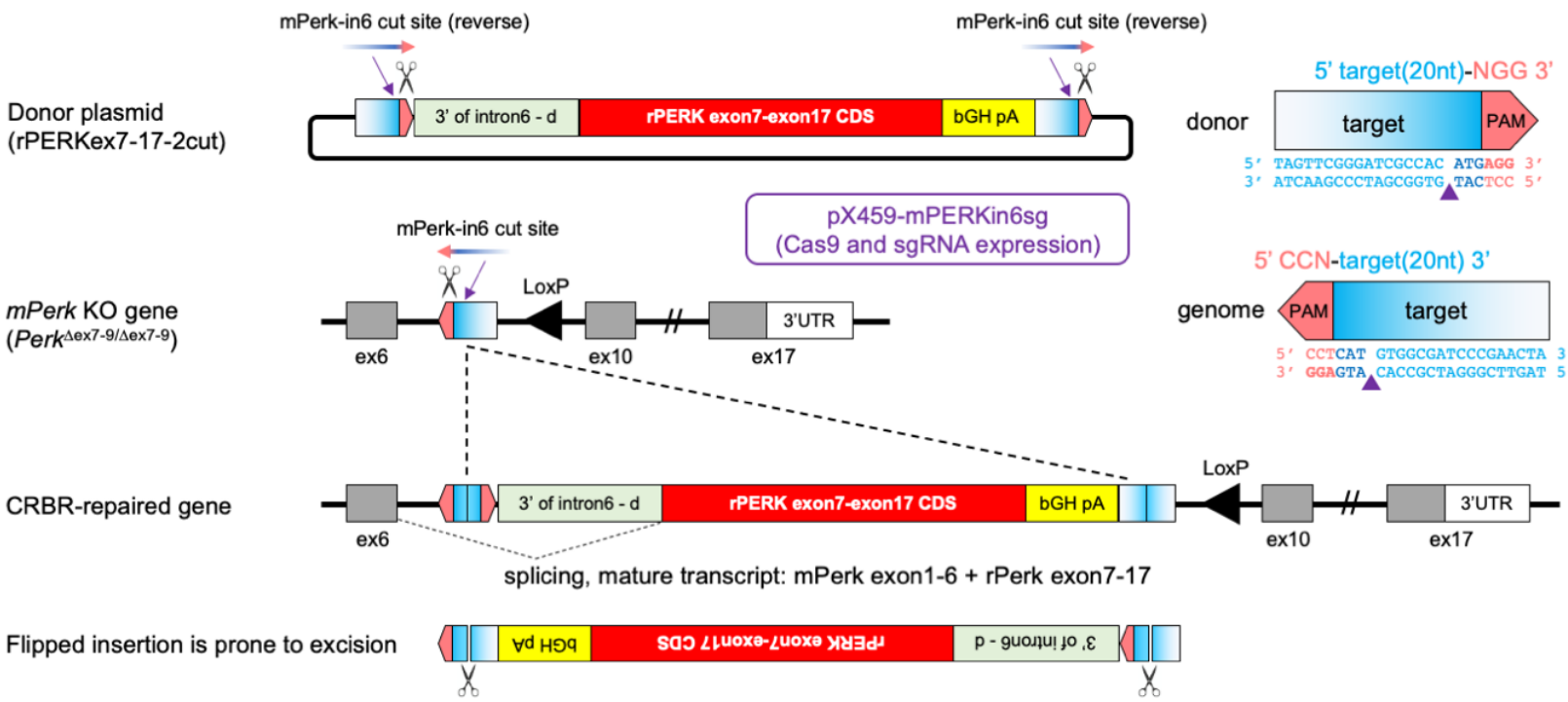

C

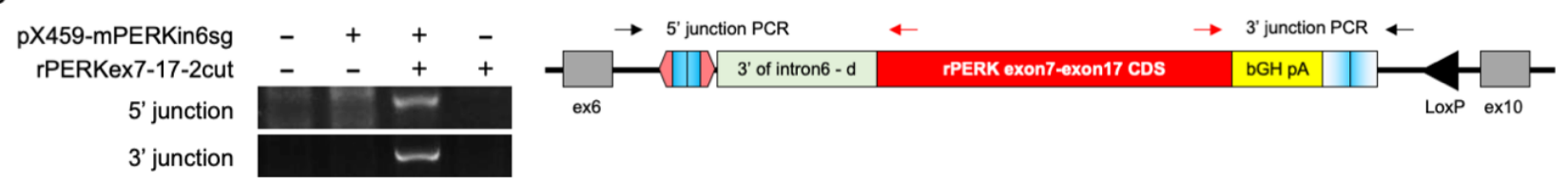

D

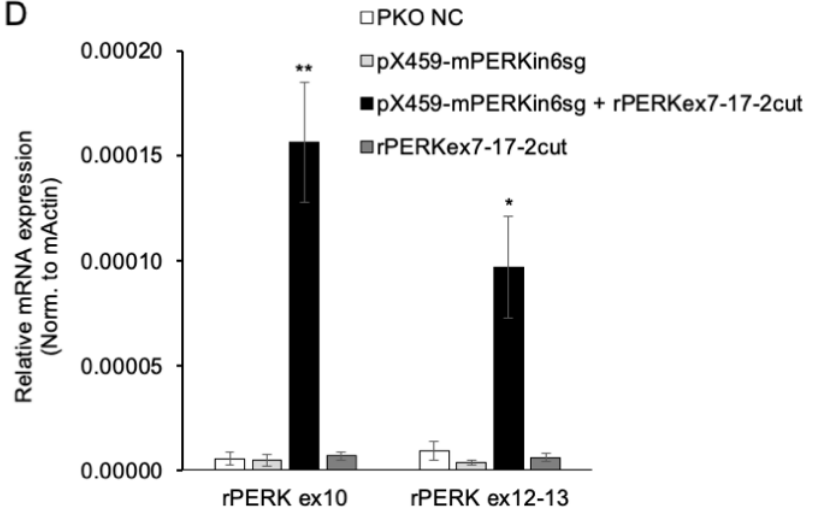

$\mathrm{E}$
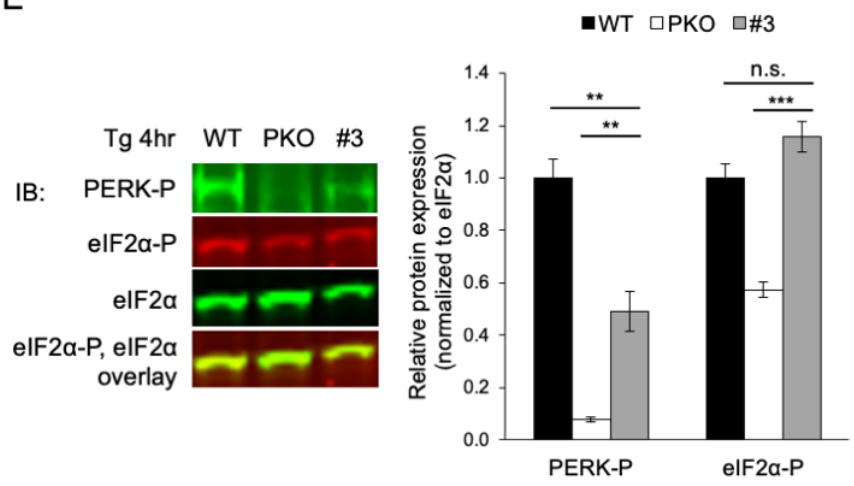

Figure 1. CRBR-mediated in vitro partial PERK CDS integration in Perk KO cell line. A. Schematic of CRBR strategy. CDS-terminator cassette is flanked by Cas9/gRNA target sites in reverse orientation as in the genome. Correct integration of the CRBR cassette is expressed under the native promoter, with the 5'UTR region having small changes resulted from residue target site 
from the donor. Salmon pentagon, PAM site (3nt). Rectangle with blue gradient, Cas9/gRNA targeted protospacer sequence (20nt); Cas9 cleavage locates at $17 \mathrm{nt}$ to the white side, $3 \mathrm{nt}$ to the blue side. 5'UTR-g, 5'UTR region in the genome. 5'UTR-d, 5'UTR region engineered in the donor.

B. Schematic of CRBR-PartialCDS strategy for Perk ${ }^{\Delta e x 7-9 / \Delta e x 7-9}$ genome. Donor plasmid provides a 3'intron6-rPERKex7-17CDS-bGHpA cassette that is flanked by Cas9/gRNA target sites in reverse orientation (5' 20nt-NGG 3') as identified within the mPerk intron 6 (5' CCN-20nt 3'). Expression of Cas9 and mPERKin6-sgRNA leads to the cleavage of the mPerk-in6 cut sites that are engineered in the donor to generate the CRBR cassette, and also a targeted DSB at genomic mPerk intron 6 . Correct integration of the CRBR cassette is retained while the incorrect integrant is prone to excision. Small changes at 5' junction should be spliced out with intron 6 and mature transcript results in a chimeric mouse-rat Perk sequence.

C and D. Perk ${ }^{\mathrm{sex} 7-9 / \Delta \mathrm{ex} 7-9}$ MEF cells $\left(3 \times 10^{6}\right.$ cells) were electroporated with $1.8 \mu \mathrm{g}$ of $\mathrm{pX} 459$ -

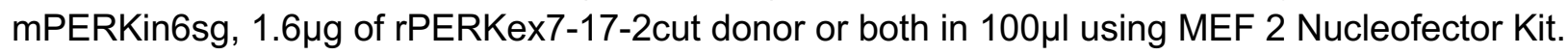
Puromycin $(1 \mu \mathrm{g} / \mathrm{ml})$ was used to enrich transfected cells (with pX459-mPERKin6sg treatment) for 3 days. (C) Genomic DNA was harvested 6d post transfection for 5' junction PCR and 3' junction PCR analysis. Primers were designed to flank the junction sites. (D) Chimeric mouse-rat Perk mRNA expression levels were quantified in sub-cultured Perk ${ }^{\Delta e x 7-9 / \Delta e x 7-9}$ (PKO) MEF cells (mixed cell population). Relative gene expression was normalized to mActin. Quantification represents $n=3$ per treatment. Statistical significance was calculated relative to the no treatment control, $\mathrm{pX} 459$ mPERKin6sg only and rPERKex7-17-2cut donor only; ${ }^{*} \mathrm{p}<0.05,{ }^{* *} \mathrm{p}<0.01$.

E. Protein expression levels were quantified in Perk ${ }^{+/+}$(WT) and Perk ${ }^{\Delta e x 7-9 / \Delta e x 7-9}$ (PKO) MEF cells and

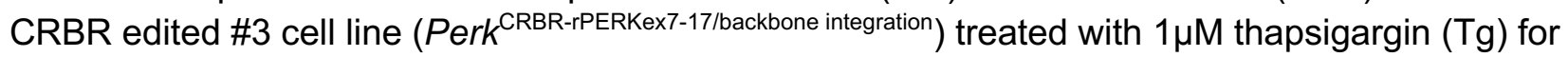
4hrs. Quantification represents $n=4$ per cell line. Relative protein expression was normalized to elF2 $\alpha$. Statistical significance was calculated relative to Perk WT or Perk ${ }^{\Delta \mathrm{ex} 7-9 / \Delta \mathrm{ex} 7-9}$ MEF cells; ${ }^{* *} \mathrm{p}<0.01$, ${ }^{* *} p<0.001$, n.s., not significant.

\section{rPERK-CRBR-edited Perk allele completely rescues Perk KO mice}

To circumvent the RNA splicing defects that might be generated during NHEJ-DSB repair at the 5' junction, we modified the CRBR strategy so that an entire fully-spliced rat PERK CDS carrying a cterminal myc tag was targeted to the 5'UTR of the mouse Perk gene. The rPERKmyc-2cut CRBR cassette consists of the intact mouse Perk 5'UTR, a rPERK CDS $(\sim 3.4 \mathrm{~kb})$ with a myc tag, bGHpA terminator, and a Cas9/sgRNA target site engineered in reverse orientation (Figure 2A). This modified CRBR strategy preserves the sequence of mouse Perk 5'UTR to ensure normal translation initiation. The Perk KO nonsense mutant MEF cell line $\left(\right.$ Perk $\left.^{\mathrm{C528X/C528X}}\right)$ co-transfected with the Cas9/sgRNA plasmid and the rPERKmyc-2cut plasmid was positive for both 5' junction and 3' junction PCRs

(Figure 2B), which confirmed the CRBR-Full-CDS integration at the intended target site in the genome in vitro. 


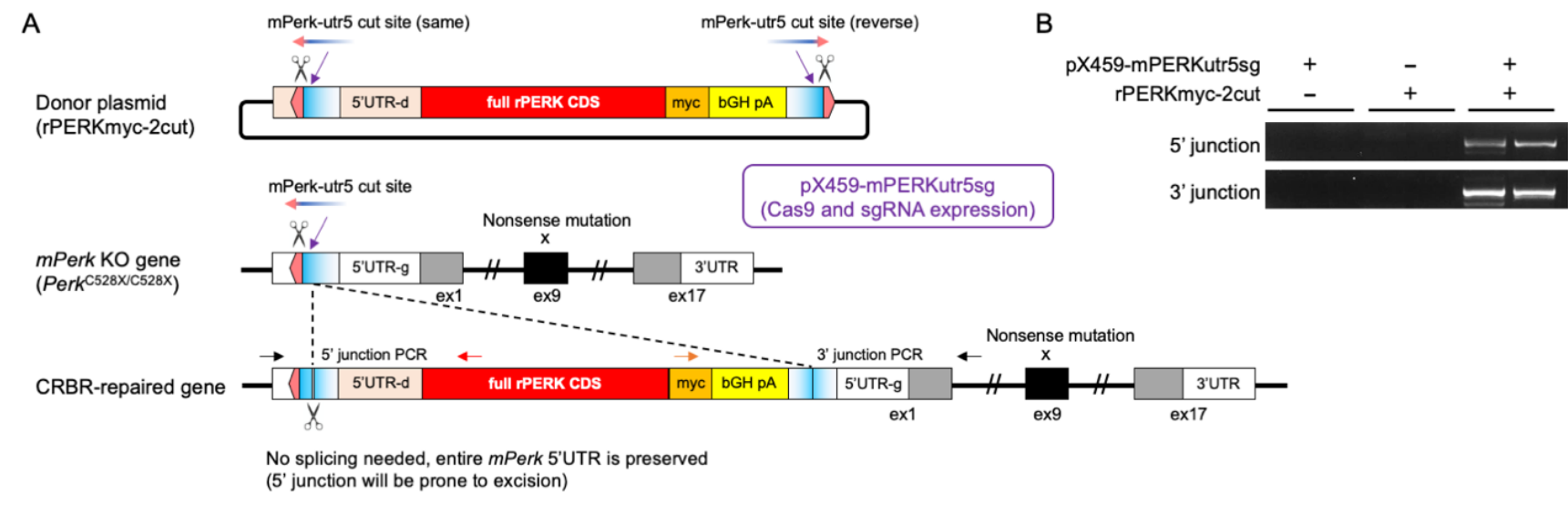

Figure 2. CRBR-mediated in vitro full PERK CDS integration in Perk KO cell line.

A. Schematic of CRBR-FullCDS strategy. Donor plasmid provides a full rPERKmyc CDS-bGHpA cassette that is flanked by a wild-type 5'UTR of mPerk and a Cas9/gRNA target site in reverse orientation as identified within the mPerk 5'UTR. Expression of Cas9 and mPERKutr5-sgRNA leads to the cleavage of the mPerk-utr5 cut sites that are engineered in the donor to generate the CRBR cassette, and also a targeted DSB at genomic mPerk 5'UTR. Correct integration of the CRBR cassette preserved the wild-type sequence of mPerk 5'UTR but also resume the mPerk-utr5 cut site that is prone to excision. Small indels could retain the integration of the rPERKmyc CRBR cassette and no splicing is required to achieve a mature transcript of rat Perk from the CRBR-edited genome. B. Perk ${ }^{\text {C528X/C528X }}$ MEF cells $\left(1 \times 10^{5}\right.$ cells) were electroporated with $1 \mu \mathrm{g}$ of $\mathrm{pX} 459-\mathrm{mPERKutr} 5 \mathrm{sg}, 1 \mu \mathrm{g}$ of rPERKmyc-2cut donor or both using the $10 \mu$ l Neon transfection system $(n=2)$. Genomic DNA was harvested 2d post transfection for 5' junction PCR and 3' junction PCR analysis. Primers were designed to flank the junction sites.

To demonstrate that the CRBR-edited allele can be expressed and regulated normally at the mRNA and protein level during development, we designed an in vivo proof-of-concept experiment to test if an engineered rPERK-CRBR-edited allele could rescue a Perk KO allele in mice. A key assumption of this strategy is that the integration of the CRBR cassette in a wild type Perk allele will generate a complete loss-of-function insertional mutation of the endogenous allele while simultaneously introducing a functional CRBR cassette under the endogenous promoter. The CRBR cassetteinsertional mutation can be genetically crossed to a mouse bearing any other type of Perk null mutation to generate offspring that carry the CRBR cassette-insertional mutation on one chromosome and a Perk null mutation on the other. If these mice express PERK only from the correctly targeted CRBR cassette and are phenotypically normal with respect to the WRS phenotype, the ability of CRBR to rescue PERK expression and function in vivo would be confirmed. 
The SpCas9 protein, mPERK-utr5-sgRNA, and the rPERKmyc-2cut plasmid were microinjected into zygotes to create transgenic mice with the rPERKmyc-CDS integrated into the 5'UTR of the wild-type mouse Perk allele. Out of the 21 transgenic mice generated, one was positive for both 5' and 3' junction PCRs. After further genotyping, this mouse turned out to be mosaic at the Perk locus (WT/4bpDel/rPERK-CRBR/flipped-backbone-CRBR), with the rPERK-CRBR allele having small indels in the 5'UTR region (Figure 3A). To validate the rPERK-CRBR allele is transmissible into the germline, the mouse carrying the mosaic alleles was crossed to wild-type mice to produce F1

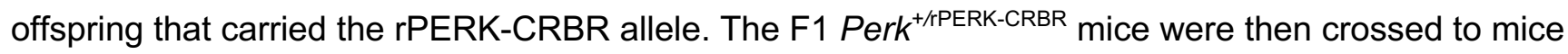
heterozygous for a Perk null allele $\left(P e r k^{\mathrm{C} 528 \mathrm{X} /+}\right.$ or $\left.P e r k^{\mathrm{sex} 7-9 /+}\right)$. Some of these F2 offspring were KO/rPERK-CRBR heterozygotes (Perk ${ }^{\text {C528X/rPERK-CRBR }}$ or Perk ${ }^{\text {Sex7-9/rPERK-CRBR }}$ ). Perk KO mice exhibit high neonatal lethality (50-99\%), and those mice that survive exhibit severe growth retardation, low pancreatic beta cell mass, exocrine pancreas atrophy, and extreme hyperglycemia by four weeks of age $^{26-29}$. The rPERK-CRBR allele showed complete phenotypic rescue of both the Perk nonsense null mutant ( $n>30$, Figure 3B-C) and the Perk $\Delta$ ex7-9 deletion mutant $(n>8$, data not shown) with respect to survivorship, growth, beta cell mass, exocrine pancreas viability, and glucose homeostasis.

Perk mRNA levels from both the rPERK-CRBR cassette and the endogenous mouse Perk were analyzed to determine if the CRBR-integrated $r$ Perk was expressed and if the CRBR insertion blocked expression of the downstream mPerk mRNA as expected from the experimental design. The rPERKCRBR cassette was robustly expressed in the pancreas and brain in genotypes carrying one or two rPERK-CRBR alleles and was absent in mice lacking the rPERK-CRBR cassette (Figure 3D). Similarly, mPerk expression was seen in genotypes carrying one or two copies of the wild-type mouse Perk allele, with reduced expression in genotypes carrying the C528X nonsense mutation. The reduction of mouse Perk mRNA in the latter is likely caused by nonsense-mediated mRNA decay (NMD). The insertion of the CRBR cassette in the wild-type mouse allele resulted in a $\sim 95 \%$ reduction in mouse Perk mRNA as can be seen when comparing mice homozygous for the rPERK-CRBR and wild-type alleles. Therefore, we estimate that $\sim 5 \%$ of the primary transcripts in the CRBR alleles are 
transcriptional read-through of the rPERKmyc-bGHpA terminator within the CRBR cassette resulting in low-level expression of the downstream mouse Perk sequence. This conclusion was confirmed by sequencing the cDNA. The small fraction of transcripts that leak through the bGH polyA terminator would be bicistronic, comprised of rPERK-myc and mPERK. It is very unlikely that the mPERK sequences within this hybrid CDS would be translated, however, because normal cap-dependent translation initiates only at the first CDS (i.e. rPERK-myc, would be translated). Any translation of the downstream mPERK CDS would require that the $40 \mathrm{~S}$ ribosome either remain on the mRNA after translation termination of the rPERK-myc CDS with subsequent translation re-initiation or bind internally upstream of mPERK CDS in a cap-independent mechanism ${ }^{30}$. Both of these possibilities are highly unlikely as they require specialized sequence contexts ${ }^{31}$ that are absent in this case.

Consistent with their phenotypic rescue, the C528X/CRBR and $\triangle$ ex7-9/CRBR mice expressed a substantial level of the rPerk mRNA derived from the CRBR cassette. Low-level detection of $m$ Perk mRNA in these mice was contributed by the KO mutant allele (leftover from NMD) and by the CRBR allele (leaky transcriptional read-through), neither of which are competent for normal translation. We conclude, therefore, that the CRBR rescue of Perk null mutations is due solely to the expression of the rPERK protein translated from rPERK-CRBR cassette. Cassette-derived rPERK protein expression was confirmed by immunoblotting with antibodies directed to the myc tag and both rat and mouse PERK (Figure 3E). Critically, the cassette-encoded myc-tagged rPERK showed strong expression in all genotypes bearing a rPERK-CRBR allele but not in other genotypes. Altogether, these results demonstrate that a CRBR-edited allele can rescue a null allele in a living organism. Additionally, they suggest the expression of the CDS-terminator cassette in a CRBR-repaired cell can be regulated normally under the endogenous promoter and provide therapeutic effect in vivo. 
bioRxiv preprint doi: https://doi.org/10.1101/2020.12.17.423314; this version posted December 19, 2020. The copyright holder for this preprint (which was not certified by peer review) is the author/funder, who has granted bioRxiv a license to display the preprint in perpetuity. It is made available under aCC-BY-NC-ND 4.0 International license.

A

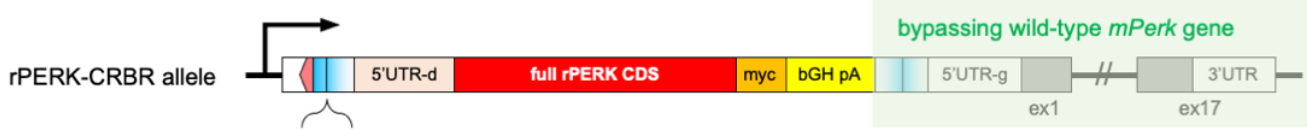

4 bp deletion $(-1$ to +3$)$ and $10 \mathrm{bp}$ insertion at $(+18)$ at the $5^{\prime}$ junction

B

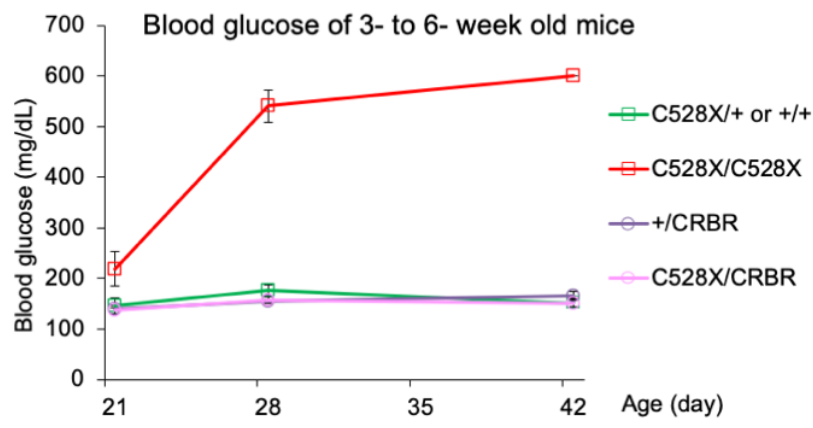

C
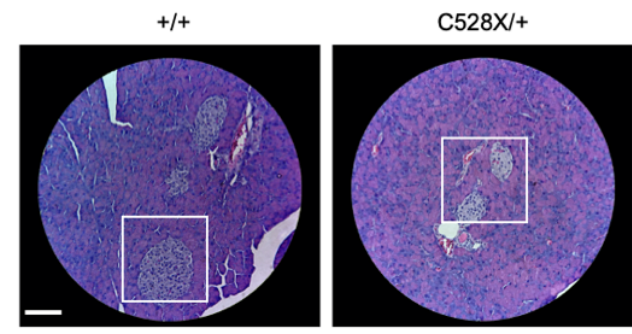

C528X/C528X
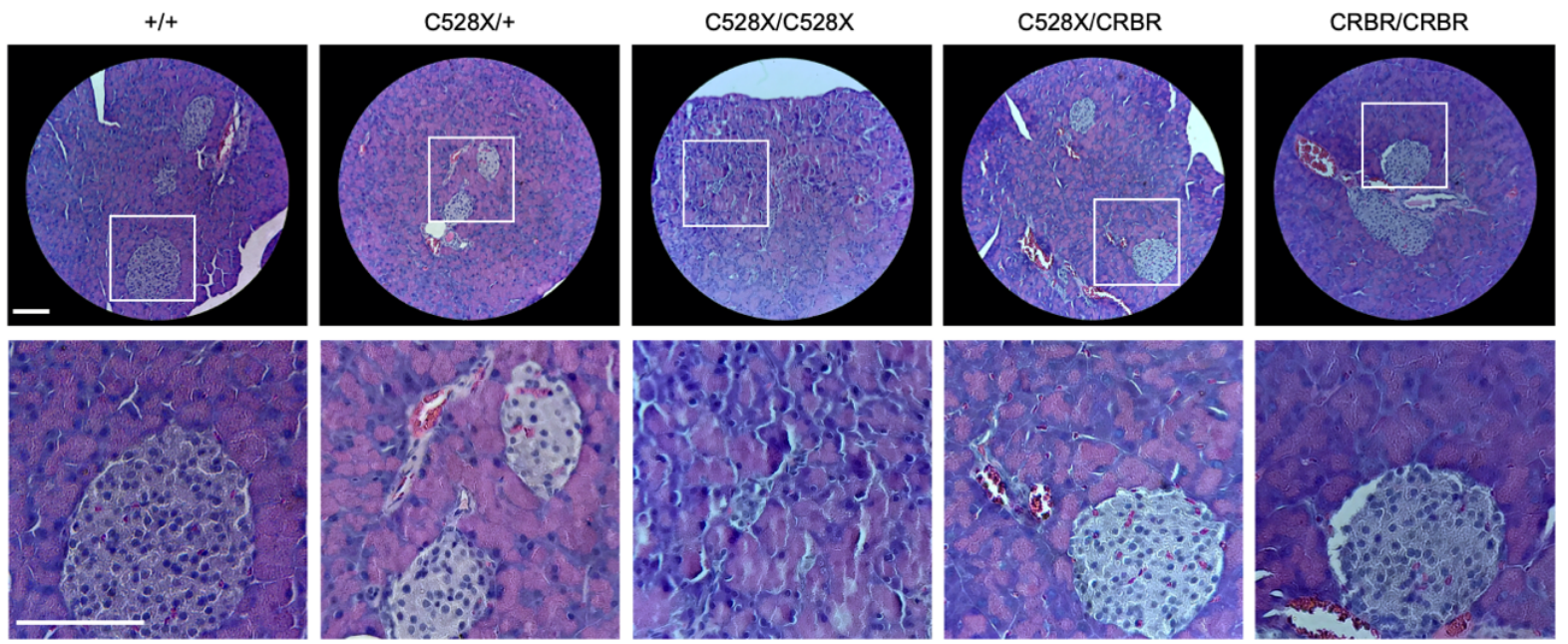

D
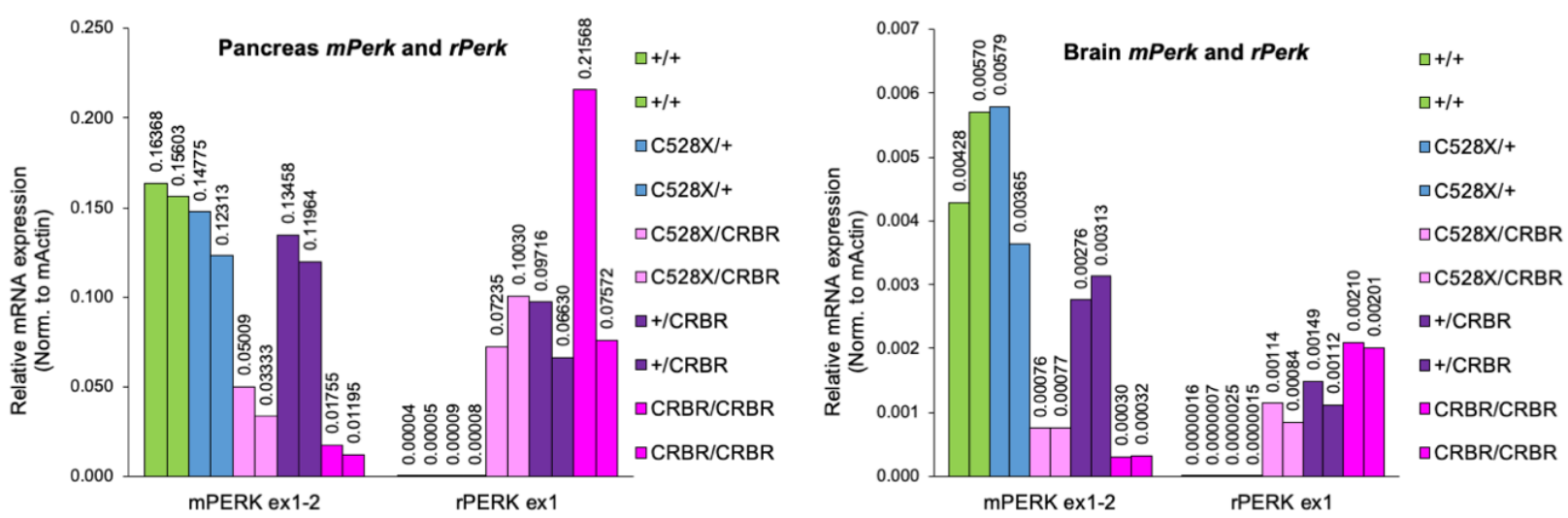

$\mathrm{E}$
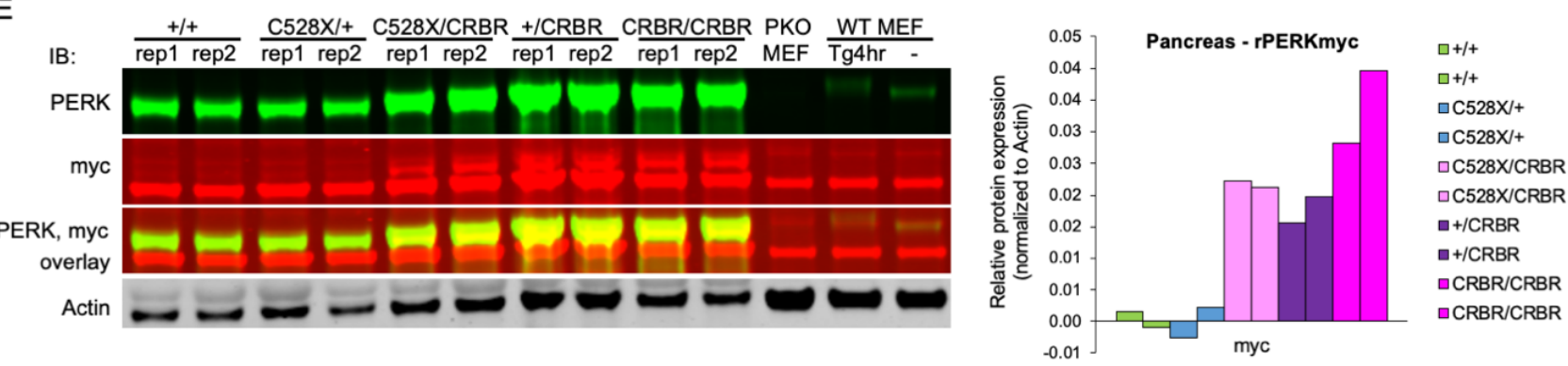
Figure 3. CRBR-edited Perk allele rescues Perk KO allele in a proof-of-concept mouse model. A. Schematic of rPERK-CRBR allele (in a wild-type mouse Perk background) from the transgenic mouse. Sequence of the 5' junction at 5'UTR, see Figure S9.

B. Blood glucose levels were monitored on P21, P28 and P42 mice with genotypes indicated in the

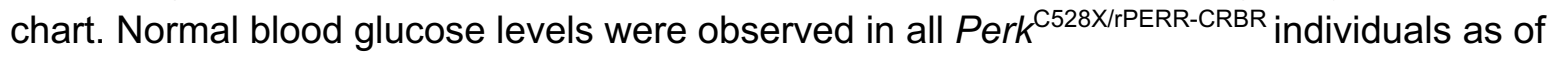
manuscript submission $(n>30)$, including ones presented here $(n=7)$. Student's $t$-test showed no significance difference of blood glucose between C528X/CRBR mice (pink, $n=7$ ) and littermate $+/$ CRBR mice (purple, $n=5$ ) or independent litters with at least one wild-type mouse Perk allele (C528X/+ or $+/+$, green, $n=6$ ) at all three age points. Only Perk KO mice (C528X/C528X, red, $n=8)$ become diabetic before P28 and exceeding the glucometer upper limit $(600 \mathrm{mg} / \mathrm{dL})$ by P35. C528X/CRBR or +/CRBR mice were offspring from Perk ${ }^{+/ r P E R R-C R B R}$ crossing to Perk ${ }^{\text {C528X/+ }}$ mice. Perk KO (C528X/C528X) or littermates (C528X/+ or +/+) were offspring from Perk ${ }^{\mathrm{C} 528 \mathrm{X} /+}$ mice self-crossing. These control glucose data points were from diabetic Perk KO mice that were injected with three dosages of CRBR AAV vector mixture, on P21, P28 and P35, but no reversal of the diabetic phenotypes; while C528X/+ or +/+ littermates were injected with saline.

C. Representative Hematoxylin and Eosin staining images from the pancreas of Perk ${ }^{+/+}(\mathrm{P} 62)$, Perk $^{\text {C528X/+ }}$ (P53), Perk ${ }^{\text {C528X/C528X }}$ (P34), Perk ${ }^{\text {C528X/rPERK-CRBR }}$ (P46) and Perk ${ }^{\text {rPERK-CRBR/rPERK-CRBR }}$ (P46) mice. The Perk ${ }^{\mathrm{C} 28 \mathrm{X} / \mathrm{C} 528 \mathrm{X}}$ pancreas has typical Perk KO defects such as very small islets with small beta cell mass, disorganized acinus structure, some degranulated cells (white), clear halo around nuclei and gaps between acinar cells, which are not seen in the pancreas of the Perk ${ }^{\text {C528X/rPERK-CRBR }}$

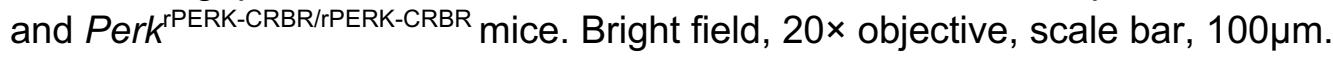

$\mathrm{D}$ and E. Two replicate mice with the same genotype were sacrificed at P38 $\left(\right.$ Perk $^{+/+}$, from Perk ${ }^{+/ \text {rPERK- }}$ ${ }_{\text {CRBR }}$ crossing), P58 and P30 (Perk ${ }^{\mathrm{C} 28 \mathrm{X} /+}$, from Perk ${ }^{\mathrm{C} 528 \mathrm{X} /+}$ cross Perk $\left.^{\mathrm{C} 528 \mathrm{X} / \mathrm{rPERK}-\mathrm{CRBR}}\right)$, and P46 $\left(\right.$ Perk $^{\text {C528X/rPERK-CRBR }}$, Perk $^{+/ \text {rPERK-CRBR }}$ and Perk ${ }^{\text {rPERK-CRBR/rPERK-CRBR }}$, from Perk ${ }^{\text {C528X/rPERK-CRBR }}$ cross $^{\text {Per }}$ Perk $^{+/ \text {PPERK-CRBR }}$ ) for pancreas and brain tissues. The mRNA expression levels (D) of endogenous $m$ Perk and $r$ Perk from CRBR-edited allele in pancreas and brain were quantified using $m P e r k$ - and $r$ Perk-specific primers and normalized to mActin. Both mPERK and rPERK protein expression levels in pancreas $(E)$ were measured by PERK antibody, while rPERK was also recognized by a myc tag antibody. Negative control, Perk ${ }^{\Delta e x 7-9 / \Delta \mathrm{ex7-9}}$ (PKO) MEF cells. Positive control for PERK, Perk ${ }^{+/+}$(WT) MEF cells treated with or without $1 \mu \mathrm{M}$ thapsigargin ( $\mathrm{Tg}$ ) for $4 \mathrm{hrs}$. Relative protein expression was normalized to Actin. rPERKmyc quantitation was further subtracted by the average background signal of the two Perk ${ }^{+/+}$replicates.

\section{CRBR-mediated in vitro and in vivo gene editing in mouse pancreatic beta cells}

To better assess and visualize the protein expression from a CRBR-edited allele, we applied a similar two-cut CRBR strategy to introduce a GFP CDS into the Insulin gene locus, the most highly expressed gene within pancreatic beta cells. Again, we designed the Cas9/sgRNA cut sites in the reverse orientation relative to the native cut site in the 5'UTR target site of the mouse Ins2 gene (Figure 4A) to increase the likelihood that the EGFP-CDS-pA cassette $(\sim 1.1 \mathrm{~kb})$ remained stably integrated. This design feature, however, did alter the 5'UTR from the wild-type sequence. To avoid 
potential interference with translation, we selected an integration site within a region that is not conserved among mammals, and we avoided introducing new ATG codons within the CRBR-edited 5'UTR that could incorrectly initiate translation of the resulting mRNA. We first tested this strategy in MIN6 mouse beta cells by co-transfecting them with the Cas9/sgRNA plasmid and the EGFP-2cut plasmid. EGFP-positive cells were visible by two days post-transfection and continued to increase in number until 15 days, whereas donor-only treated cells remained EGFP-negative over the same time period (Figure 4B). 5' and 3' junction analysis of the integrants confirmed CRBR-editing at the genome level (Figure 4C). Single cell sorting revealed that the mixed population contained $2.5 \%$ GFPpositive cells (Figure S2A); the low percentage of positive cells reflected the relatively poor transfection efficiency of MIN6 cells ( $25 \%)$.

A subset of GFP-positive cells was clonally isolated for further characterization (Figure S2B). Junction PCRs and sequence analyses showed that cell lines \#8, \#10, \#13 and \#14 had one CRBR-edited allele and one allele with small indels at the genomic cleavage site. The cell line \#15 had one CRBRedited allele and one whole donor plasmid integrated allele (Figure S2C). EGFP mRNA expression was confirmed in the sorted GFP-positive cell lines (Figure 4D). We also expected that the native mouse Ins2 expression would be reduced as a consequence of the insertion of the EGFP CRBR cassette. Indeed, we found that the mouse Ins2 mRNA levels were reduced compared to wild-type MIN6 cells (Figure 4E). These results suggest the CRBR-integrated EGFP-CDS-pA cassette is expressed and can bypass the endogenous mouse Ins 2 transcription. 
bioRxiv preprint doi: https://doi.org/10.1101/2020.12.17.423314; this version posted December 19, 2020. The copyright holder for this preprint (which was not certified by peer review) is the author/funder, who has granted bioRxiv a license to display the preprint in perpetuity. It is made available under aCC-BY-NC-ND 4.0 International license.

A

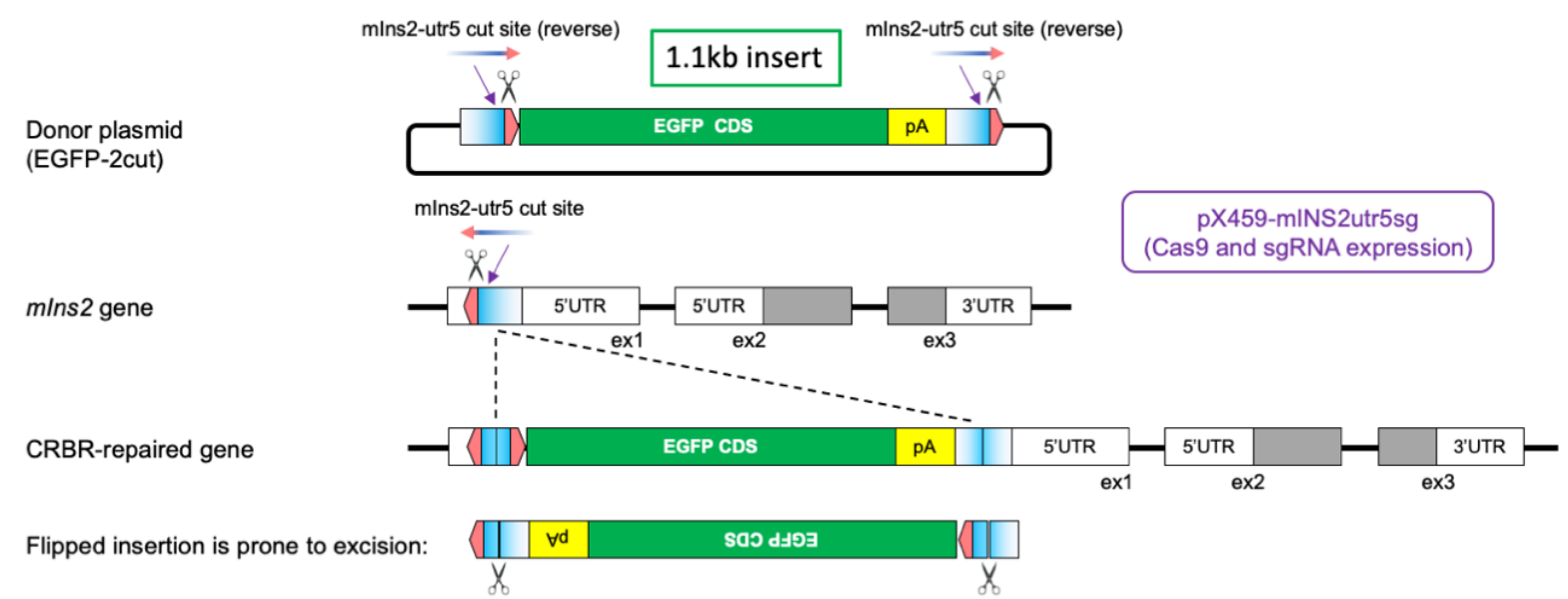

B

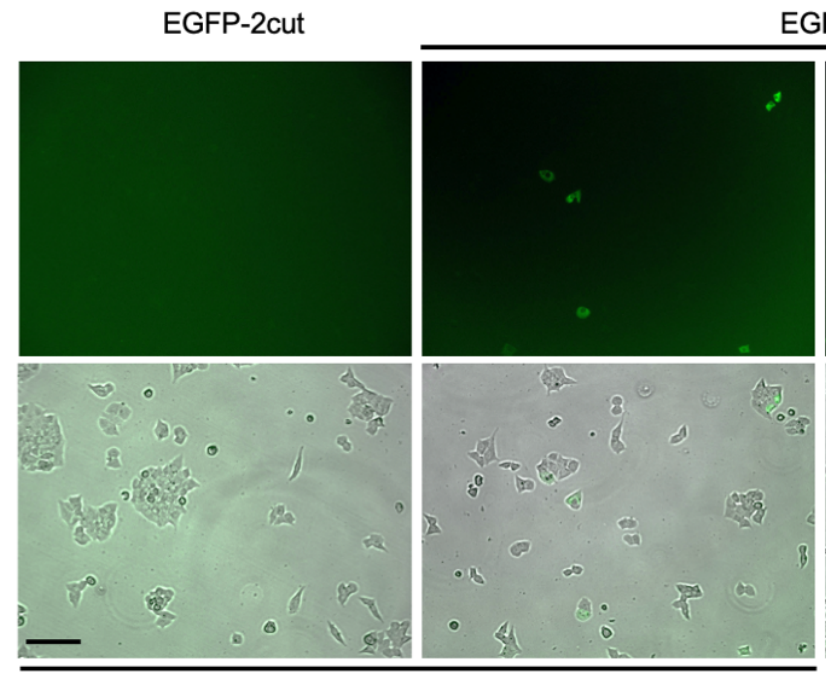

2d post transfection

EGFP-2cut + pX459-mINS2utr5sg

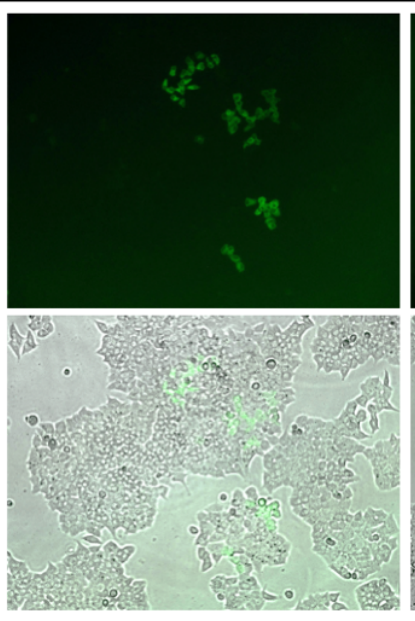

6d post transfection

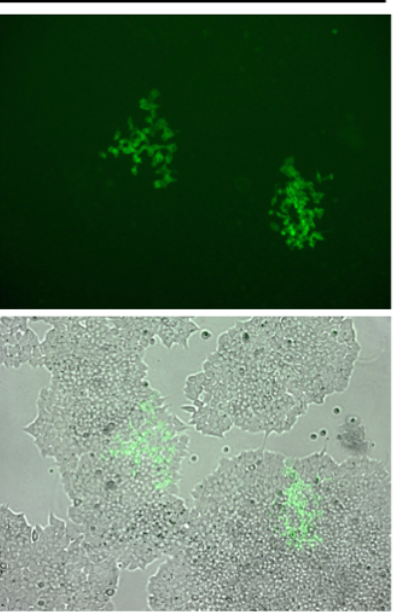

$15 d$ post transfection

C

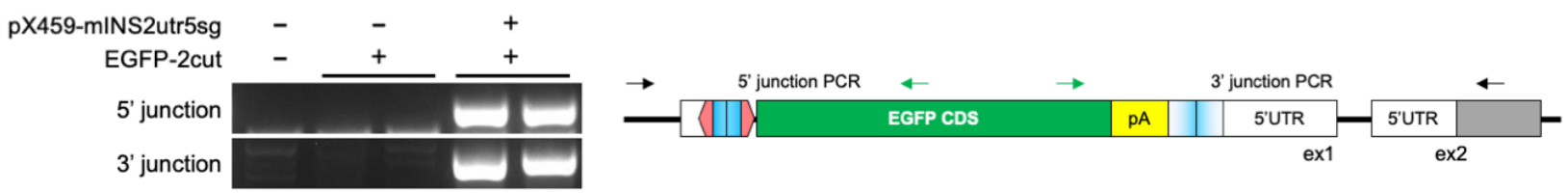

D

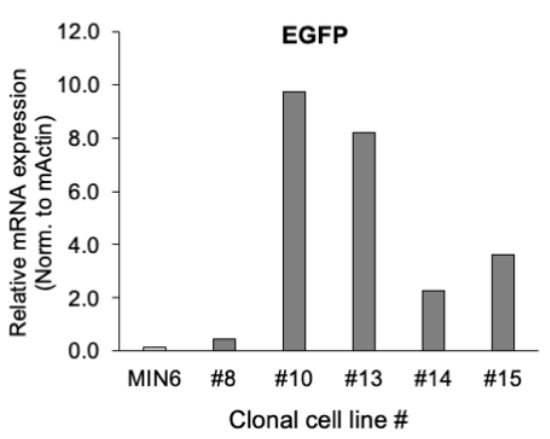

E

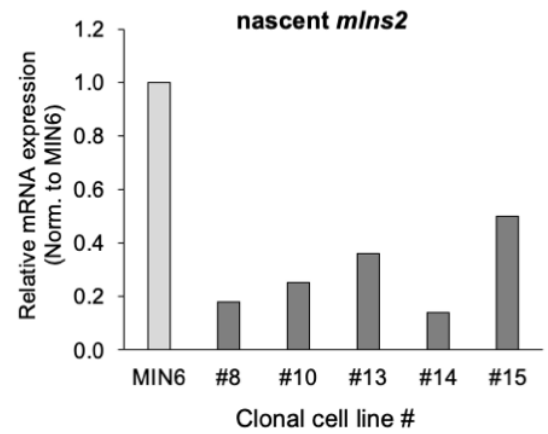

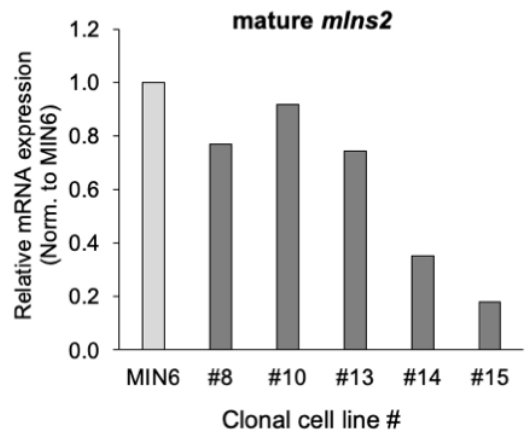

Figure 4. CRBR-mediated in vitro EGFP CDS integration in mouse Ins2 gene.

A. Schematic of CRBR-EGFP-2cut strategy for wild-type mlns2 genome. Donor plasmid provides an EGFP CDS-pA cassette that is flanked by Cas9/gRNA target sites in reverse orientation (5' 20nt-NGG 
3') as identified within the mIns2 5'UTR in exon 1 (5' CCN-20nt 3'). No mlns2 5'UTR sequence is engineered between the 5' cut site and the start codon of EGFP. Expression of Cas 9 and mINS2utr5sgRNA leads to the cleavage of the mIns2-utr5 cut sites that are engineered in the donor to generate the CRBR cassette, and also a targeted DSB at genomic mIns2 5'UTR. Correct integration of the CRBR cassette will be retained while incorrect integrant is prone to excision.

$B$ and C. MIN6 cells $\left(1 \times 10^{6}\right.$ cells) were electroporated with $1 \mu \mathrm{g}$ of EGFP-2cut donor with or without $1 \mu \mathrm{g}$ of $\mathrm{pX} 459-\mathrm{mINS} 2 \mathrm{utr5sg}$ in $100 \mu \mathrm{l}$ using Nucleofector $\mathrm{V}$ Kit. Cells were imaged (B) as live cultures $2 \mathrm{~d}, 6 \mathrm{~d}$, and $15 \mathrm{~d}$ post transfection at $10 \times$ objective, scale bar, 100 $\mathrm{mm}$. Genomic DNA (C) was harvested $6 \mathrm{~d}$ post transfection for 5' junction PCR and 3' junction PCR analysis. Primers were designed to flank the junction sites.

$D$ and E. EGFP mRNA expression levels from the CRBR-edited allele (D) were quantified in five sorted GFP-positive cells (\#8, 10,13,14, and 15) by normalizing to mActin. Nascent $m$ Ins2 and mature mIns2 mRNA expression levels $(E)$ were quantified by normalizing to mActin first, and then the relative fold change in expression was calculated relative to wild-type MIN6 cells.

To evaluate the capability of CRBR-mediated gene editing in the mouse pancreas in vivo, an AAV carrying the EGFP-CDS-pA cassette and U6-driven mINS2-utr5 sgRNA cassette (AAV-sgRNA-CDS) was systemically delivered to the Rosa26-CAG-Cas9-EGFP mouse strain, which constitutively expresses Cas9 nuclease throughout the body. Using a Cas9 expressing mouse strain reduces the variability of Cas9 delivery in trans via an additional viral vector. For comparison, we also delivered the same AAV-sgRNA-CDS into wild-type mice in combination with another AAV that supplies Cas9 (AAV-Cas9) (Figure 5A). Liver and pancreas tissues from P14 Cas9-EGFP mice were harvested 30day post retro-orbital (r.o.) injection of the AAV8-sgRNA-CDS. Junction PCRs and DNA sequence analyses revealed substantial CRBR-mediated gene editing at the genome level in the liver and a detectable level in the pancreas (Figure 5B). Some individuals had detectable EGFP transcription from the mouse Ins2 gene locus in the pancreas RNA (Figure 5C). The mouse Ins2 promoter is not active in the liver, and as expected, EGFP transcription from Ins2 gene locus in the liver was not observed.

Previous experiments ${ }^{32-34}$ suggested that AAV serotypes DJ and 8 would be the most appropriate for delivery into the pancreas. Eight-week old Cas9-EGFP mice were subjected to tail vein injection of AAV-sgRNA-CDS of either serotype DJ or 8. Both serotypes had substantial CRBR-mediated gene editing at the genome level in the liver, with AAV-DJ being more efficient (Figure 5D). Junction PCRs 
analysis indicated that the tail vein injected AAV8-sgRNA-CDS was capable of targeting the pancreas, with some individuals having detectable CRBR-editing at the genome level. However, similarly administered AAV-DJ-sgRNA-CDS showed no indication of pancreatic CRBR editing. These results show that systematic delivery of the AAV8-CRBR-construct via intravenous injection can result in CRBR editing at the genome level in the liver and pancreas, as well as CRBR-mediated EGFP mRNA expression in pancreatic beta cells under the control of the Ins2 promoter.

We next tested whether providing both the sgRNA-CDS and Cas9 via AAV-DJ vectors could also elicit gene editing in wild-type mice (lacking endogenous Cas9). CRBR-mediated gene editing was achieved in the liver (Figure 5E) but not as efficiently as seen in the previous experiment where Cas9 was endogenously expressed (Figure 5D). This result suggests that CRBR-mediated gene editing is feasible in vivo via dual AAV delivery once both viral vectors are successfully transduced in the host cell. For human therapy purposes, a more direct intra-organ injection route may improve AAV delivery to the pancreas or other tissues that are challenging to target by intravenous injection. 
bioRxiv preprint doi: https://doi.org/10.1101/2020.12.17.423314; this version posted December 19, 2020. The copyright holder for this preprint (which was not certified by peer review) is the author/funder, who has granted bioRxiv a license to display the preprint in perpetuity. It is made available under aCC-BY-NC-ND 4.0 International license.

A

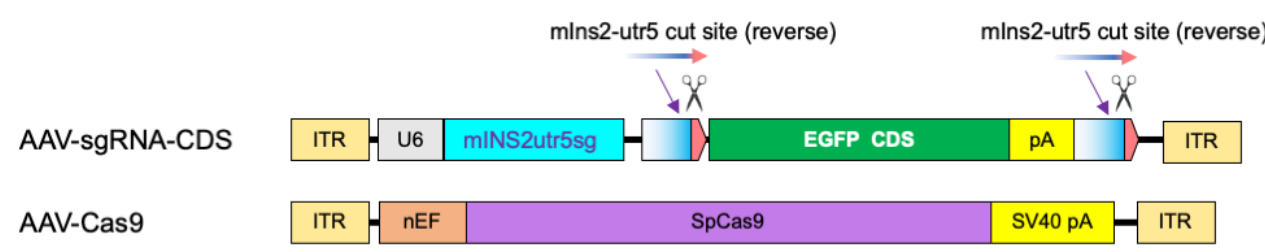

B
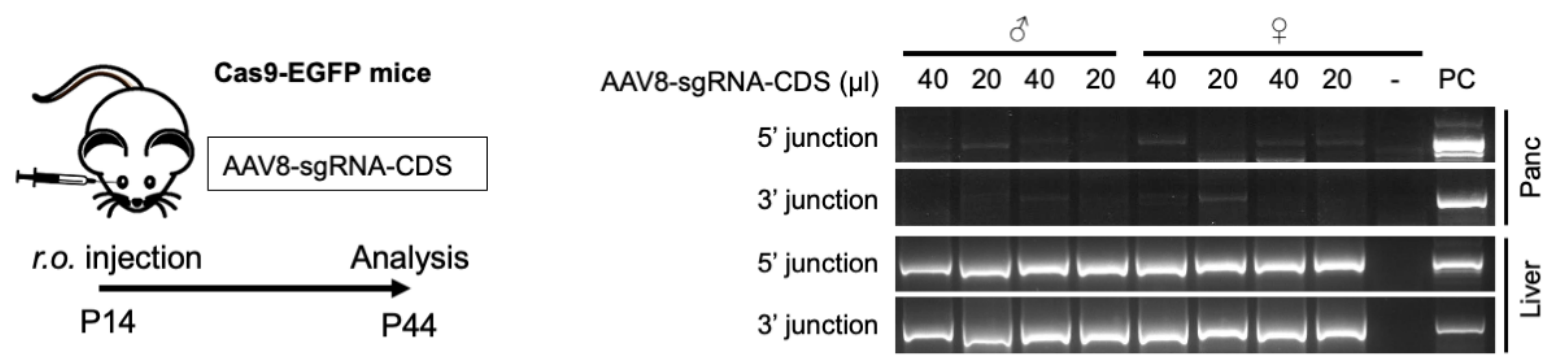

C
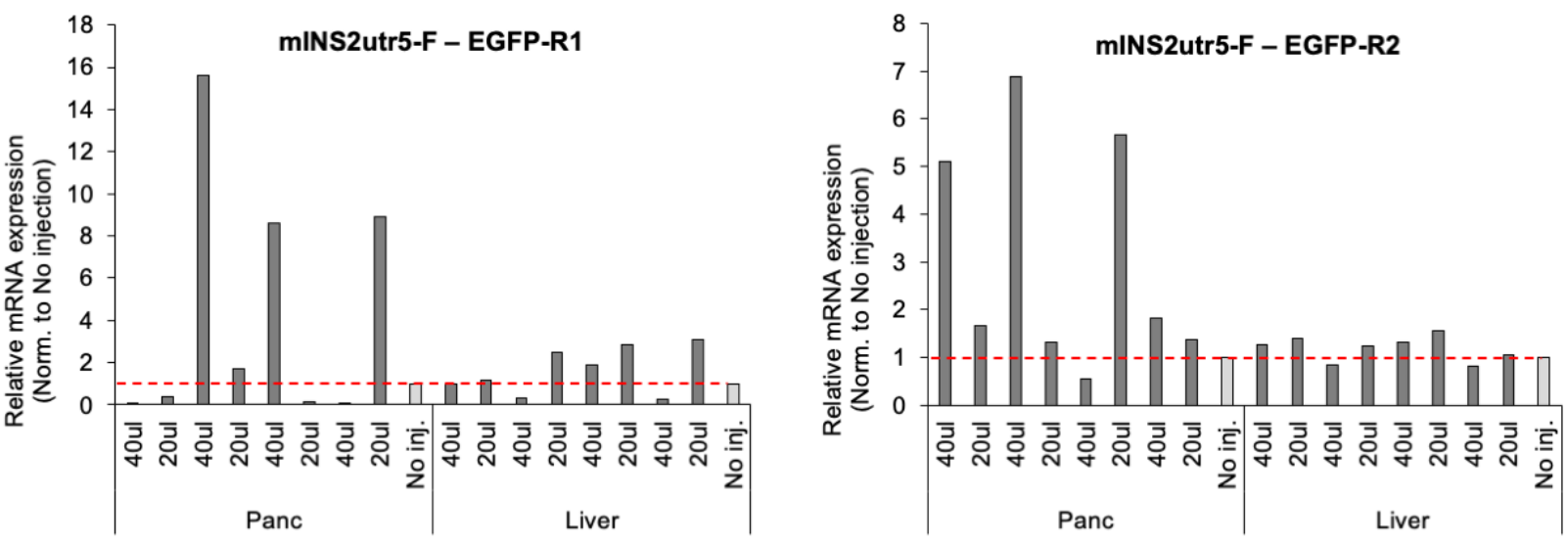

D

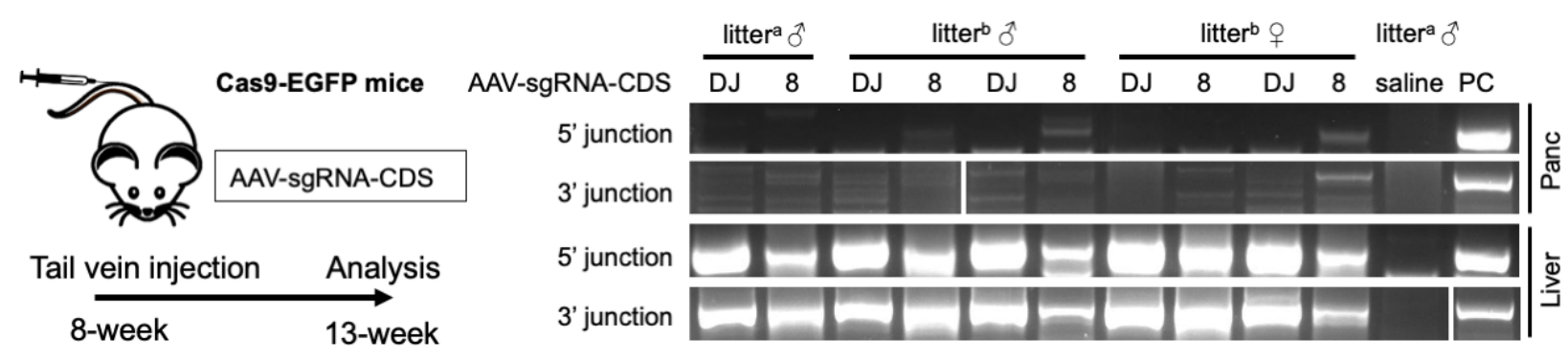

E

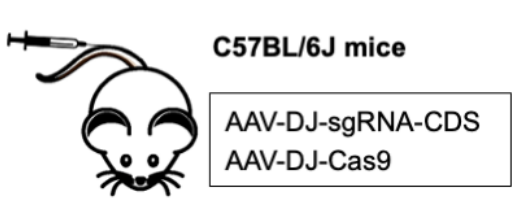

Tail vein injection Analysis

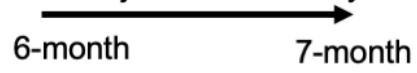

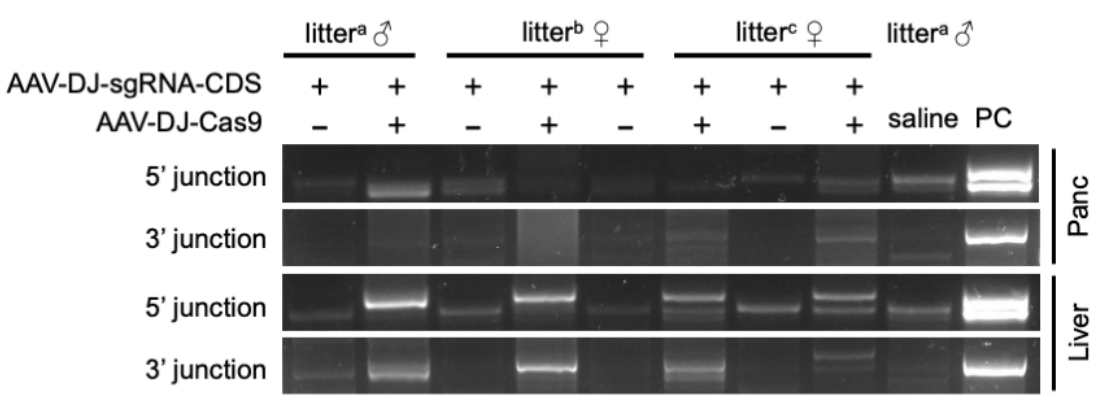

Figure 5. CRBR-mediated in vivo EGFP CDS integration in mouse Ins2 gene. 
A. Schematic of CRBR AAV vectors used in AAV delivery to Cas9-EGFP mice or wild-type mice. AAV vector provides the same EGFP CRBR cassette as in the EGFP-2cut donor plasmid but also includes a U6-driven mIns2utr5-sgRNA. Cas9 expression was considered to be introduced in all tissues under the universal promoter CAG in the Cas9-EGFP mice.

$B$ and C. P14 Cas9-EGFP mice from one litter (four males and five females) were administered with $40 \mu \mathrm{l}, 20 \mu \mathrm{l}$ or no injection of AAV8-U6-mINS2utr5sg-EGFP-2cut via r.o. injection. DNA and RNA from pancreas and liver were harvested 30d post injection. Genomic DNA (B) was tested for 5' junction PCR and 3' junction PCR analysis. EGFP mRNA expression levels (C) from the CRBR-edited $m / n s 2$ gene were measured by using a forward primer targeting mIns2 5'UTR and a reverse primer (R1 or R2) targeting EGFP to avoid picking up signals from the endogenous EGFP of the Cas9-EGFP mouse strain. The relative fold changes were quantified by normalizing to mActin first and calculated relative to the no injection control.

D. Eight-week old Cas9-EGFP mice from two litters (litter ${ }^{\mathrm{a}}$ or ${ }^{\mathrm{b}}$, gender is indicated in the figure) were administered with $50 \mu$ l of AAV-U6-mINS2utr5sg-EGFP-2cut in serotype DJ or 8, or a saline control via tail vein injection. Genomic DNA from pancreas and liver was harvested 35d post injection. CRBR editing at genome level was tested by 5 ' junction PCR and 3' junction PCR analysis.

E. Six-month old C57BL/6J mice from three litters (litter ${ }^{a, b}$ or c , gender is indicated in the figure) were administered with $50 \mu \mathrm{l}$ of AAV-U6-mINS2utr5sg-EGFP-2cut with or without $50 \mu \mathrm{l}$ of AAV-nEF-Cas9 in serotype DJ, or saline via tail vein injection. Genomic DNA from pancreas and liver was harvested 35d post injection. CRBR editing at genome level was tested by 5' junction PCR and 3' junction PCR analysis.

For B, D and E, all primers were designed to flank the junction sites. PC, positive control, was genomic DNA from MIN6 cells co-transfected with EGFP-2cut donor and pX459-mINS2utr5sg.

\section{CRBR-mediated ex vivo gene editing in human islets}

To further validate the CRBR strategy as a potential human gene therapeutic, we similarly targeted GFP to the insulin (INS) gene in isolated human islets. Primary human cadaveric islets were transfected or AAV infected with CRBR constructs containing CopGFP (alternative GFP reporter) CDS and targeting the INS gene. The CopGFP CRBR cassette was designed to insert into intron 1 between the two exons containing the 5'UTR and upstream of the insulin start codon (Figure 6A). The CRBR cassette contains the 3' half of homologous intronic sequences and the 5'UTR of exon 2 to allow splicing of the endogenous 5'UTR in exon 1 and exogenous 5'UTR in exon 2 from the CRBR cassette. Any unforeseen indels generated during integration/repair will be removed as intronic sequence from the resultant mRNA. We designed and tested both one-cut and two-cut donors to determine which strategy would be more efficacious (Figure 6A-B). The one-cut strategy generates only one insert linearized from the 1-cut donor, with one correct integrant out of two possible 
outcomes; whereas the two-cut strategy generates four possible inserts that may be integrated in two orientations, with two correct integrants out of eight possible outcomes (Figure S3). The one-cut strategy requires the integration of a much larger fragment $(4.2 \mathrm{~kb})$ in contrast to the two-cut strategy (0.9kb CRBR cassette), as it includes the extraneous vector sequences. However, these sequences should not interfere with gene expression because they are downstream of the transcription/translation terminators in the CRBR cassette.

This CRBR-CopGFP strategy was first tested in an easily transfected human cell line, AD293, to determine the optimal sgRNA within intron 1 and to optimize the donor design before testing on human islets (Figure S4A). The CopGFP 1-cut (or 2-cut) donor plasmids were engineered with the U6-hINSin1sg cassette that express the optimal sgRNA. The plasmid expressing SpCas9 and the 1cut (or 2-cut) donor were co-transfected into human islets. Six days post transfection, many CopGFPpositive cells were observed, which are pancreatic beta cells that possess an active insulin promoter and comprise $45-70 \%$ of the total cadaver islet cell population (Figure 6C and Table S1). Typically, about $60 \%$ of the cells in a human islet are insulin-secreting beta cells, whereas the remaining $40 \%$ secrete other metabolically important peptide hormones ${ }^{35}$. While these cells would be edited with equal frequency compared to beta cells, their insulin promoter is inactive, and we would therefore not expect those cells to express the CopGFP CRBR cassette. The 5' and 3' junction analyses confirmed CRBR editing of the human INS locus at the genome level (Figure 6D), and transcription of CopGFP from the human INS promoter was also detected (Figure 6E). Furthermore, we observed a modest reduction of human INS mRNA expression (Figure 6F), as expected. No biological replicates from the same batch of human islets were analyzed since the samples produce only enough genomic DNA or total RNA for one replicate per treatment. However, CopGFP integration at the genome level, CopGFP transcription, and reduction of human INS mRNA expression were seen in all human islet experiments using independent batches of islets (Figure S4B-E). Collectively, these results demonstrate that CRBR-mediate gene correction via plasmid transfection is feasible in human islets if a wild-type coding sequence is targeted downstream of a mutant gene's promoter. 
bioRxiv preprint doi: https://doi.org/10.1101/2020.12.17.423314; this version posted December 19, 2020. The copyright holder for this preprint (which was not certified by peer review) is the author/funder, who has granted bioRxiv a license to display the preprint in perpetuity. It is made available under aCC-BY-NC-ND 4.0 International license.

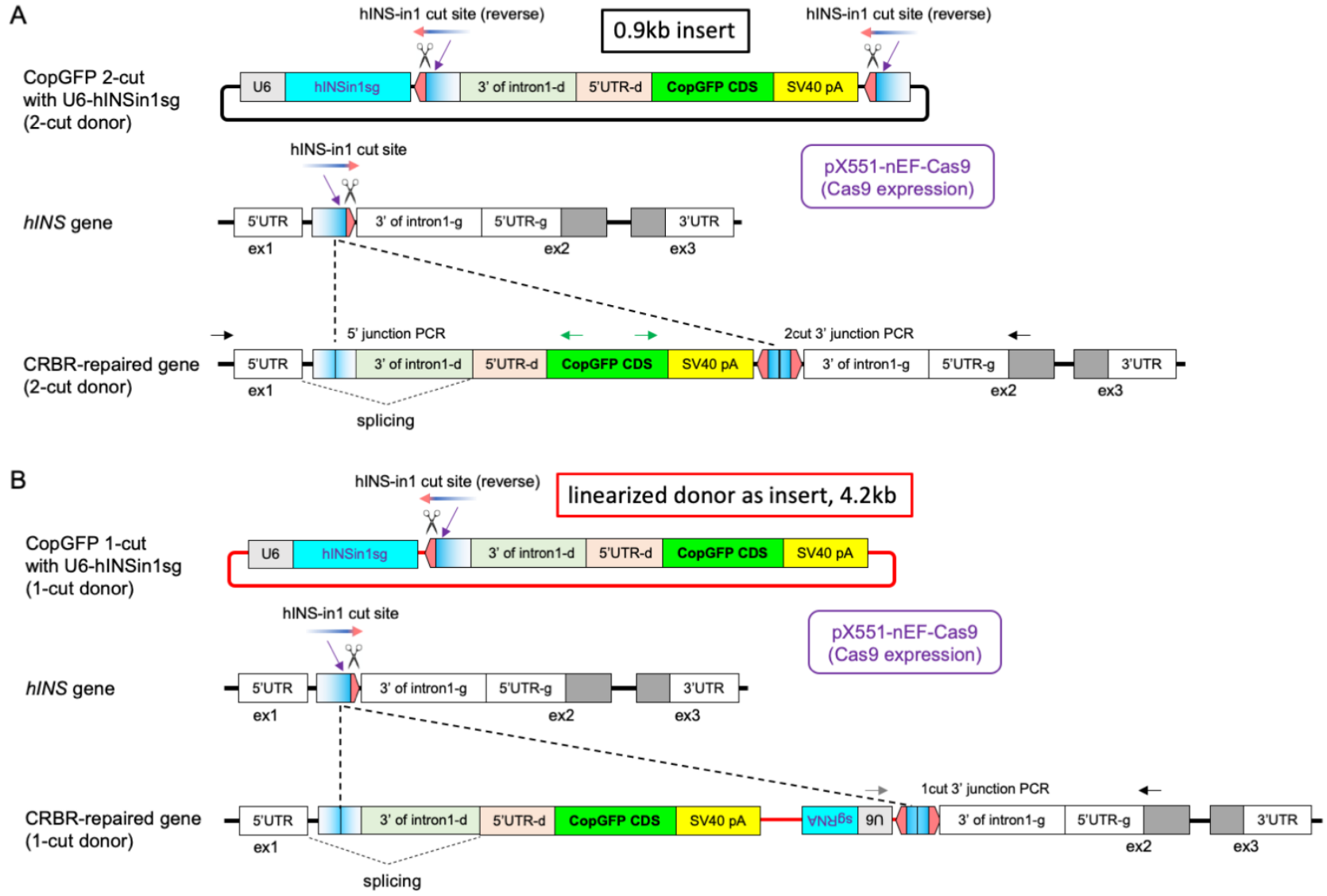

C
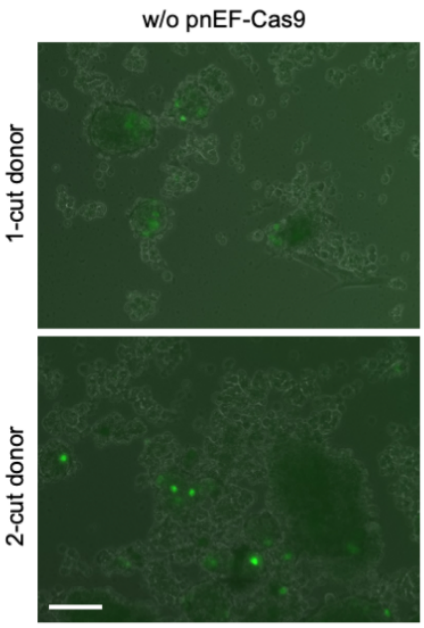

E
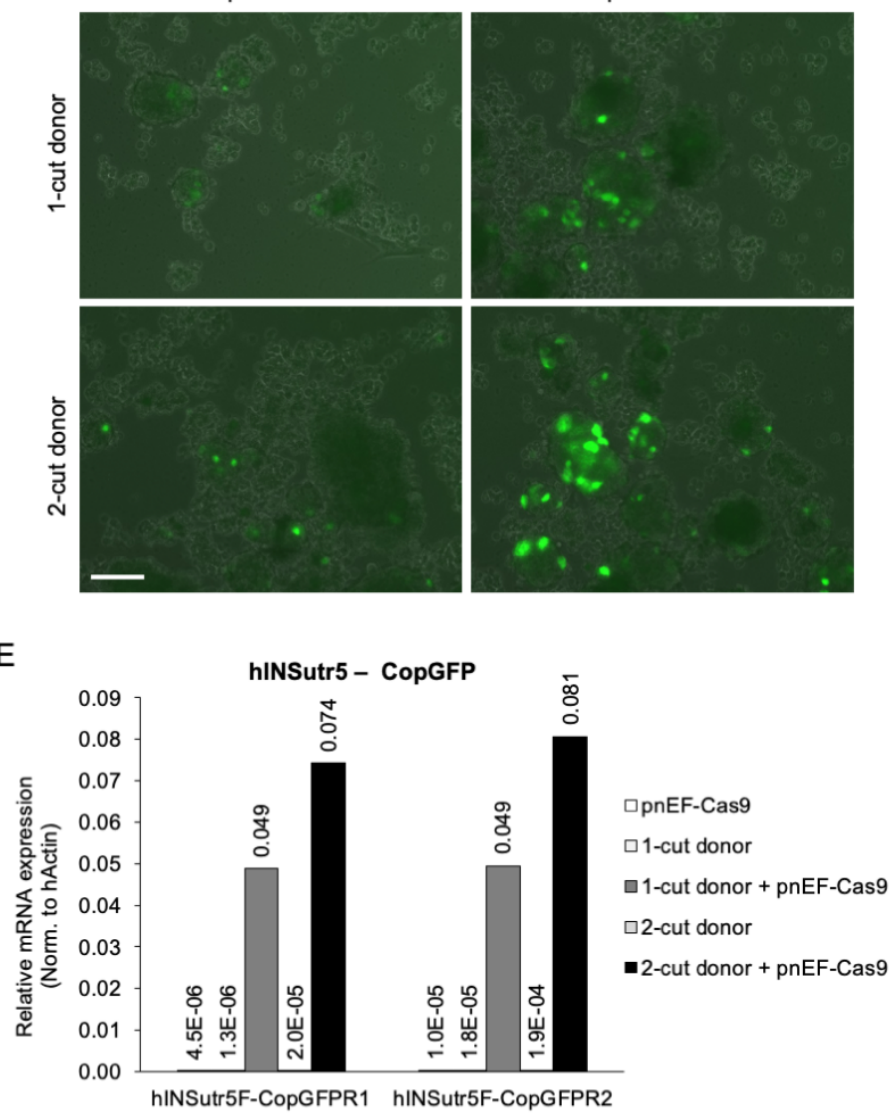

D

$\mathrm{F}$

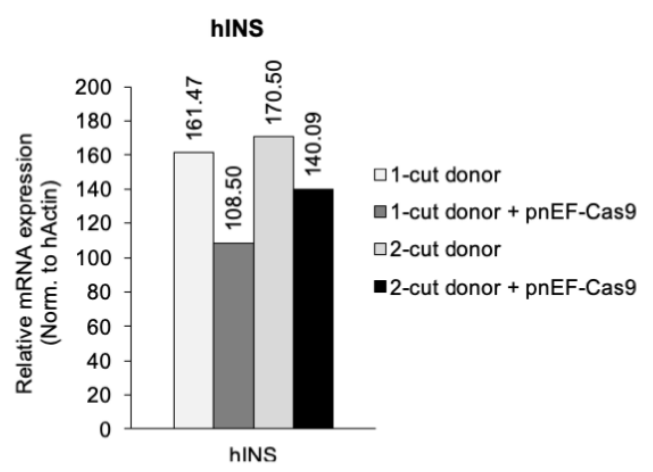




\section{Figure 6. CRBR-mediated ex vivo CopGFP CDS integration in human INS gene via plasmid transfection.}

A. Schematic of CRBR-CopGFP-2cut strategy for wild-type hINS genome. Donor plasmid provides a 3'intron1-utr5(in exon2)-CopGFP-SV40pA cassette that is flanked by Cas9/gRNA target sites in reverse orientation (5' CCN-20nt 3') as identified within the hINS intron 1 (5' 20nt-NGG 3'), and a U6driven hINSin1-sgRNA. Expression of Cas9 from pnEF-Cas9 and hINSin1-sgRNA from the donor leads to the cleavage of the hINS-in1 cut sites that are engineered in the donor to generate the CRBR cassette, and also a targeted DSB at genomic hINS intron 1 between exon 1 and 5'UTR in exon 2. B. Schematic of CRBR-CopGFP-1cut strategy for wild-type hINS genome. The 1-cut donor plasmid is the same as the 2-cut donor except for removing the 3' cut site. Expression of Cas9 and hINSin1sgRNA leads to the cleavage of the hINS-in1 cut site that is engineered in the donor, linearizing the donor, as well as a targeted DSB at genomic hINS intron 1. The 1-cut insert is $4.2 \mathrm{~kb}$, much larger than the 2-cut insert which is only $0.9 \mathrm{~kb}$. In both 1-cut and 2-cut strategies, correct integration of the CRBR cassette will be retained while incorrect integrant is prone to excision; the 5' junction in the CRBR-edited hINS intron 1 should be spliced out and results in a wild-type 5'UTR for normal translation initiation of CopGFP.

C-F. Human cadaveric islets (500 IEQs) were electroporated with $1 \mu \mathrm{g}$ of pnEF-Cas9, $1 \mu \mathrm{g}$ of pU6hINSin1sg-CopGFP-1cut, $1 \mu \mathrm{g}$ of pU6-hINSin1sg-CopGFP-2cut, or either donor in combination with pnEF-Cas9 using Neon transfection system. Six days post transfection, human islets were imaged (C) as live cultures at $10 \times$ objective, scale bar, $100 \mu \mathrm{m}$. Genomic DNA (D) was harvested for 5' junction PCR, 2cut 3' junction PCR, and 1cut 3' junction PCR analysis. Primers were designed to flank the junction sites. CopGFP mRNA expression levels from the CRBR-edited hINS gene (using a forward primer targeting hINS 5'UTR and a reverse primer [R1 or R2] targeting CopGFP) (E) and hINS mRNA expression levels $(F)$ were quantified by normalizing to hActin. Donor RRID: SAMN14255441.

Previous reports of AAV transduction of human islets has shown limited success ${ }^{36,37}$. However, our previous success in using AAV to edit the insulin gene in the mouse pancreas (Figure 5B-D) motivated us to evaluate various serotypes of AAV for their ability to deliver CRBR components into human islets and edit the human insulin gene. We tested GFP overexpressing AAV serotypes 2, 5, 6, $8,9, E B$, and DJ for their ability to transduce human islets, and found that AAV-DJ infection led to the most GFP-positive cells (Figure S5A). To test the ability of CRBR-mediated gene editing in human islets ex vivo via AAV-DJ transduction, human islets were co-incubated with AAV-DJ-sgRNA-CDS1cut (or 2cut) (Figure 7A) along with AAV-DJ-Cas9. CopGFP-positive cells were observed at 6-day post infection (Figure 7B). By 10- and 16-day post infection, these cells dramatically increased in both number and fluorescence intensity (Figure 7B and S5B). This indicates that living and functional human beta cells can maintain insulin expression for up to 16-day post infection and that CRBRediting via AAV transduction did not affect beta cell proliferation ex vivo. When CRBR integration was 
analyzed at the genome level, the expected 5' junction PCR was observed, however a few larger fragments were also amplified (Figure 7C). DNA sequence analysis revealed that the larger fragments contained the left ITR and U6-driven hINS-in1 sgRNA cassette, which could still be spliced out, resulting in a wild-type 5'UTR for normal translation initiation. The transcription of CopGFP from the human INS locus was measured at 18-day post infection (Figure 7D), with that of the one-cut strategy slightly exceeding that of the two-cut strategy. The 1-cut AAV integration size $(1.1 \mathrm{~kb})$ is not much bigger than the insert from the 2-cut AAV strategy $(0.9 \mathrm{~kb})$. Therefore, AAV transduction using 1-cut CRBR donor appears to be more efficient. In conclusion, these results indicate CRBR-mediated gene editing via AAV transduction works effectively with human host DNA repair machinery and that AAV serotype DJ is a promising candidate vector for gene therapy in human pancreatic beta cells. 
bioRxiv preprint doi: https://doi.org/10.1101/2020.12.17.423314; this version posted December 19, 2020. The copyright holder for this preprint (which was not certified by peer review) is the author/funder, who has granted bioRxiv a license to display the preprint in perpetuity. It is made available under aCC-BY-NC-ND 4.0 International license.

A

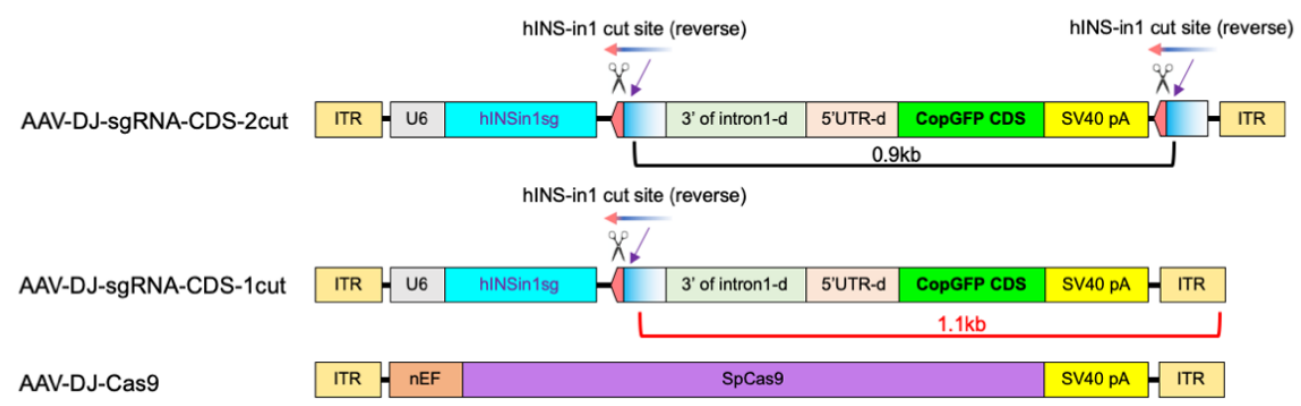

B
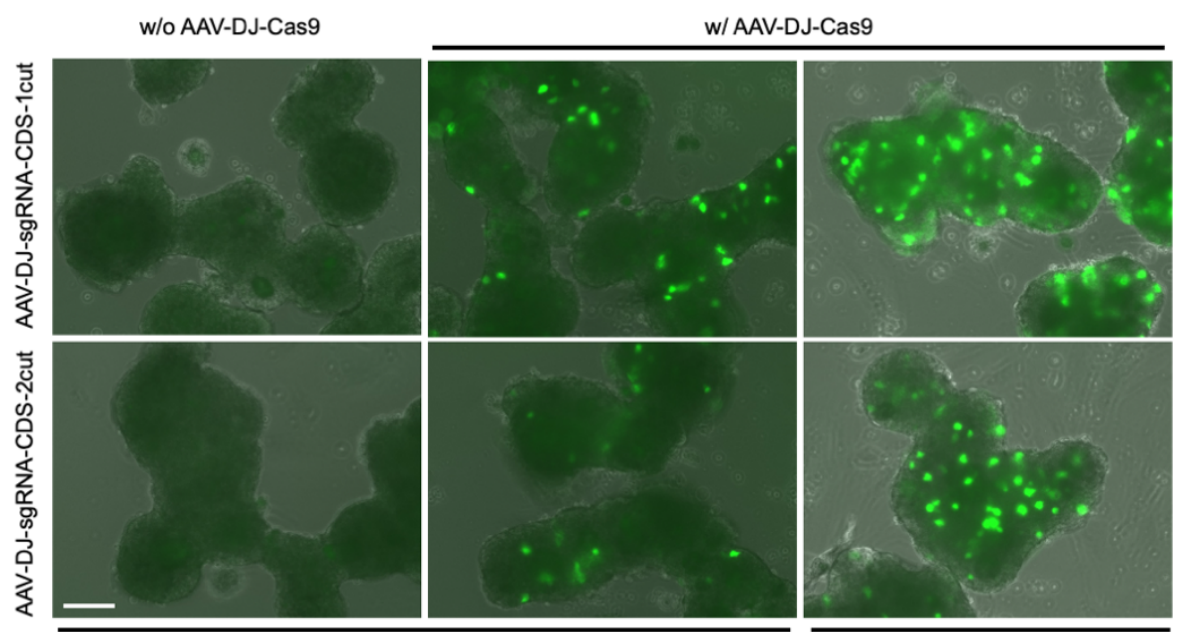

6d post infection

10d post infection

C

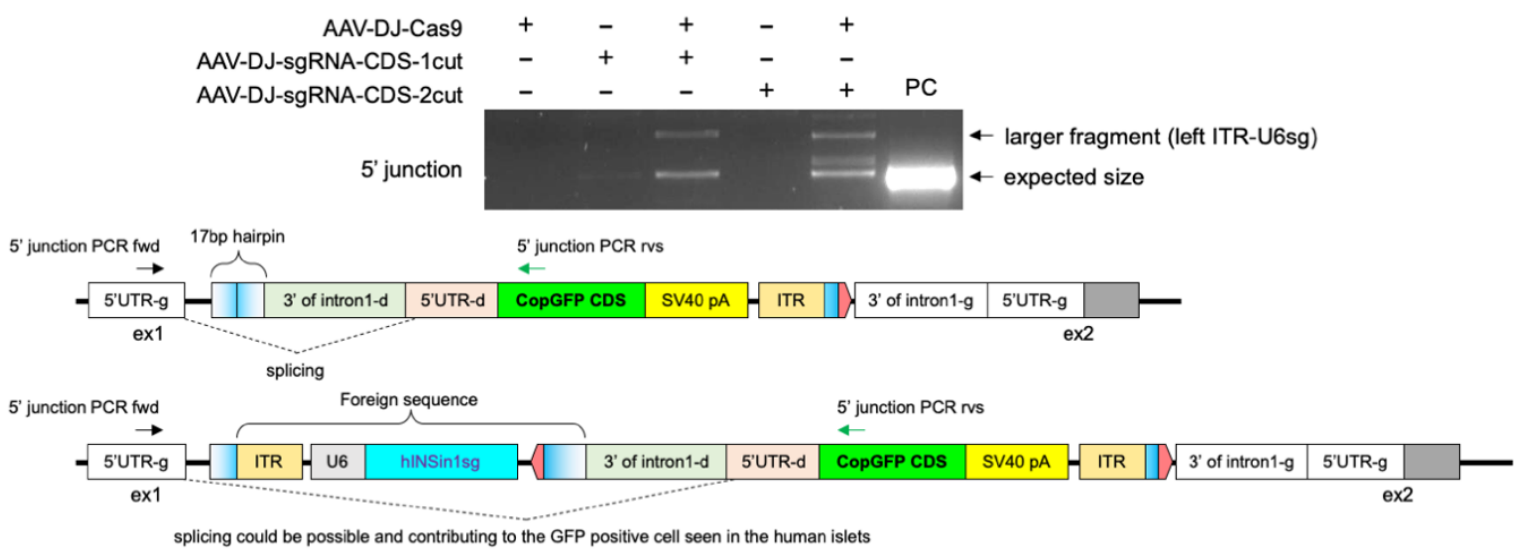

D

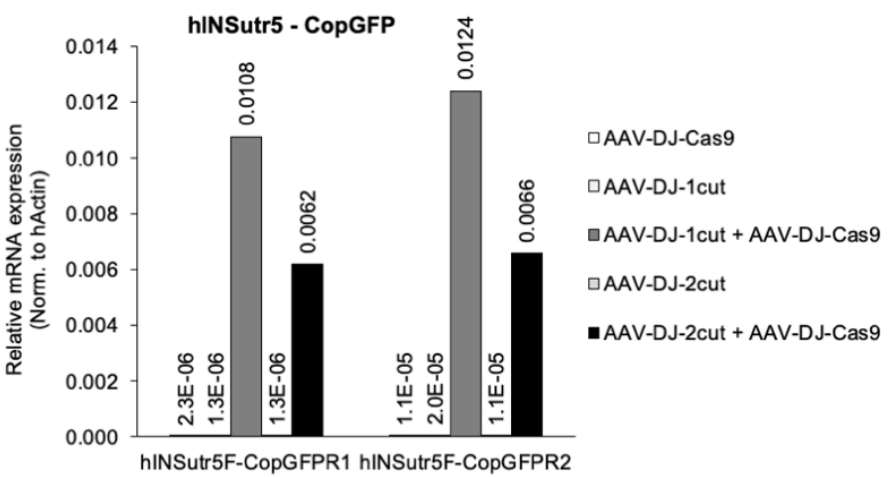

Figure 7. CRBR-mediated ex vivo CopGFP CDS integration in human INS gene via AAV-DJ transduction. 
A. Schematic of CRBR AAV vectors used in the CopGFP-2cut and CopGFP-1cut strategies for wildtype hINS genome targeting.

$B$ and C. Human cadaveric islets (300 IEQs) were incubated with AAV-DJ-nEF-Cas9, AAV-DJ-U6hINSin1sg-CopGFP-1cut, AAV-DJ-U6-hINSin1sg-CopGFP-2cut, or either donor AAV vector in combination with AAV-DJ-nEF-Cas9 at $60000 \mathrm{MOI}$. Human islets were imaged (B) 6d and 10d post

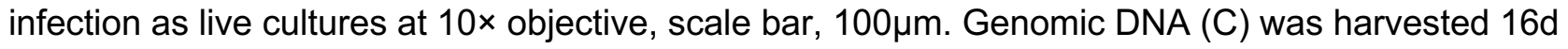
post infection for 5' junction PCR. Primers were designed to flank the 5' junction site. PC, positive control, was genomic DNA from AD293 cells co-transfected with CopGFP-2cut donor and pX459hINSin1sg. Donor RRID: SAMN15518672. Resultant genome diagrams show two possible AAV-1cut integrations: expected 5' junction generates a nascent mRNA with a 17bp hairpin which will be spliced out; in the case of Cas9/sgRNA cleavage failure, the whole AAV vector integrant will generate a nascent mRNA with the left ITR-U6sg in the intronic region, which could also be spliced out. $D$. A different batch of human cadaveric islets were treated the same as B and C, and RNA was harvested 18d post infection. CopGFP mRNA expression levels from the CRBR-edited hINS gene were quantified by normalizing to hActin. Donor RRID: SAMN15314807.

\section{Discussion}

Overexpression of a deficient gene via systemic injection of a recombinant adeno-associated virus (rAAV) derived vector was previously shown to provide a safe and efficient approach for gene therapy ${ }^{38,39}$. Delivering CRISPR-based therapeutics using AAV vectors ${ }^{40}$ has been the favored approach for targeted gene correction in vivo in mitotically active tissues. Studies ${ }^{41,42}$ aimed at improving efficiency of HDR in post-mitotic cells offer one solution, however the NHEJ-based repair pathway has provided an alternative strategy that is feasible in both mitotic and post-mitotic cells.

Three groups independently ${ }^{43-45}$ employed a NHEJ-based strategy to excise an exon of the Duchenne muscular dystrophy gene $(D m d)$ containing a deleterious mutation, which reversed muscular dystrophy in mice. However, the Dmd gene is atypical in its tolerance for exon loss, therefore, this strategy cannot be generalized to most other mutations. Consequently, a gene editing strategy that can repair a spectrum of mutations without requiring the design and testing of a specific repair template for each mutation is highly desirable.

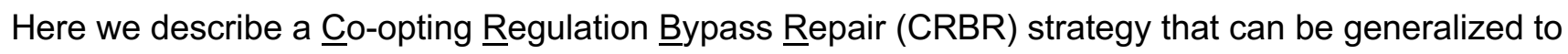
different kinds of monogenic diseases where traditional treatments or current gene therapy are not feasible or practical. The complete wild-type CDS used in CRBR strategy targets a non-coding region 
between the promoter and the downstream mutated region, thereby bypassing any mutation that may exist in the coding sequence. Once validated, the CRBR repair cassette should be able to rescue any deleterious or loss-of-function mutation that might exist in that gene. Currently, the efficiency of CRBR may be too low to directly repair genetic diseases systemically in humans where a large fraction of an organ or tissue may require repair to restore normal function. However, CRBR should be a highly effective method to repair mutations in autologous cells and tissues for transplantation back into the patient from which they were derived. Mutations in Perk, which result in severe and permanent neonatal diabetes, present a particularly difficult challenge because very few beta cells exist due to a severe postnatal cell proliferation defect ${ }^{27}$ and a block in proinsulin trafficking and processing ${ }^{46}$. Consequently, there may not be enough beta cells present in a WRS patient's islets to repair. A more promising route would be to derive patient specific induced pluripotent stems cells (PS-iPSCs) from a WRS patient, perform CRBR gene repair, screen for CRBR corrected PS-iPSCs, and differentiate them into functional beta cells using the Maxwell protocol ${ }^{47}$. These beta cells could then be transplanted back into the original patient. Repairing a defective gene in a patient's own cells would avoid transplantation rejection and the use of immunosuppressive drugs. Overall, CRBR gene repair combined with autologous cell replacement therapy should be generally applicable to a wide range of human genetic diseases.

While CRBR gene repair offers significant advantages, there are potential pitfalls that must be considered in the design and execution. Because CRBR relies upon the error-prone NHEJ repair pathway, small indels at the integration site of the CRBR cassette are common. It is thus important to restrict the integration site to non-coding and non-regulatory sequences. Ideally, the integration site should be either in the 5'UTR or within an intron upstream of the coding sequence of the subject gene. The introduction of translational start codons or strong secondary mRNA structure (Figure S6) in the 5' UTR and alternative splice sites in an intron must also be avoided. However, because the nature of the indels at the integration site cannot be predetermined, mutations may be generated that result in alternative translational and splicing regulatory sequences that interfere with normal gene expression. We and others have found that a small set of specific indels will be generated for any 
given CRISPR-Cas9 experiment (data not shown). Therefore, testing the design in cell culture first can help identify the specific array and frequency of indels that are likely to occur. If necessary, the design may be modified to avoid mutations that interfere with gene expression and regulation. Alternatively, if a gene repair autologous cell replacement (GR-ACR) strategy is used, a specific cell line can be clonally isolated that is devoid of interfering mutations.

Although other delivery methods ${ }^{48,49}$ can be used, rAAV vectors are currently the safest delivery vectors for in vivo genome editing. However, AAV vectors have a limited packaging capacity of $4 \mathrm{~kb}$. The CRBR strategy, which necessitates delivery of a large multi-element cassette (5'UTR/intronic sequences, CDS with stop codon, and heterologous polyA signal/ transcriptional terminator), will be constrained by this size limitation for viral packaging as well as genomic integration efficiency. Fortunately, about $95 \%$ of human proteins are encoded by genes that are less than $4 \mathrm{~kb}$. For genes that exceed 4kb, a partial CRBR CDS can be designed for integration into introns upstream of the defective coding exons. Whether or not the integration of a partial CDS cassette will provide a general solution for repairing a spectrum of mutations that exist among patients with a genetic disease depends upon the distribution of the mutations across the coding sequence.

To reduce the size of the CRBR repair cassette, the intronic sequences separating the CDS exons are excluded. However, this approach could be problematic for rare cases where alternative spliced transcripts are essential for normal gene function. In addition, important transcriptional regulatory elements such as enhancers may exist within intronic sequences and would be absent in the CRBR CDS-terminator cassette. In most cases this should not pose a problem since these cis-acting regulatory elements would still exist downstream in the endogenous mutant gene and could still potentially serve to regulate gene transcription. As with all gene therapy strategies, thoroughly testing repair efficacy in cell culture and/or model organisms is essential. A distinct advantage of CRBR gene repair is that, testing and validation need only be performed for a single design which can then be used to repair a spectrum of mutations among a population of human patients thus substantially reducing the cost of treatment. 


\section{Materials and Methods}

\section{Transgenic mice - Perk KO (c.1584C>A; p.Cys528X)}

SpCas9 mRNA (5meC, $\Psi$ ) was purchased from TriLink (San Diego, CA). In vitro transcription and purification of mPERKex9-sgRNA (sequence see Construction of plasmids) was as previously described $^{50}$. Repair template (200nt ssODN, 4 nmole Ultramer DNA Oligo) was purchase from Integrated DNA Technologies (IDT, Coralville, IA)

(cagccccactacagcaagaacatccgcaagaaggaccctatcctcctgctgcactggtggaaggagatattcgggacgatcctgcttgA atcgtGgccacAacGttTatcgtgcgcaggcttttccatcctcagccceacagggtaagatgctctgtcaacctaatgtgcttccaagtggttgc tgtgtaggaaacct).

A nonsense mutation was introduced by a $\mathrm{C}$ to $\mathrm{A}$ mutation on the ssODN template via HDR, $14 \mathrm{bp}$ from the Cas9/sgRNA cleavage. Three synonymous mutations were designed $2 \mathrm{bp}, 5 \mathrm{bp}$ and $8 \mathrm{bp}$ from PAM site to prevent re-excision of the HDR repaired genome. SpCas9 mRNA, sgRNA and ssODN were sent to the Harvard Genome Modification Facility for microinjection into C57BL/6J zygotes and implantation into pseudo pregnant females. Fifty-seven individuals survived to weaning age from one injection experiment; thirteen individuals carried the Perk KO allele (C528X).

\section{Transgenic mice - rPerk-CRBR (rPERKmyc integration at 5'UTR of $\boldsymbol{m P e r k}$ )}

SpCas9 protein was purchased from IDT. A synthetic mPERKutr5-sgRNA (target sequence, see Construction of plasmids) was purchased from Synthego (Redwood City, CA). A rPERK CDS with Myc tag at the C-terminus was designed to be integrated into mouse Perk 5'UTR region using the CRBR strategy as described in Results. The SpCas9 protein, sgRNA and rPERKmyc-2cut donor plasmid were sent to Harvard Genome Modification Facility for microinjection into C57BL/6J zygotes and implantation into pseudo pregnant females. Twenty-one individuals survived to weaning age from two injection experiments; one individual carried the CRBR-edited allele (rPERK-CRBR).

\section{Genetic strains}

B6J.129(Cg)-Gt(ROSA) 26Sortm1.1(CAG-cas9*,-EGFP)Fezh/J (Cas9-EGFP), C57BL/6J (wild-type) and 129S1/SvImJ (wild-type) mice were purchased from the Jackson Laboratory. Perk KO allele ( $\Delta$ ex7-9) were generated as previously described ${ }^{26}$. Perk ${ }^{\Delta e x 7-9 /+}$ strain (used to cross with Perk ${ }^{\text {rPERK-CRBR/+ }}{ }^{\text {) was }}$ congenic for C57BL/6J. Perk ${ }^{\mathrm{C528X/+}}$, Perk ${ }^{\text {rPERK-CRBR/+ }}$ and offspring (Figure 3) were of mixed C57BL/6J and 129S1/SvlmJ background. The Cas9-EGFP strain (Figure 5) was of mixed C57BL/6J and 129S1/SvImJ background. Blood glucose was measured from tail blood using OneTouch UltraMIni glucometer (LifeScan, Malvern, PA). Mice were sacrificed by $\mathrm{CO}_{2}$ euthanization. All animal studies 
were reviewed and approved by the Institutional Animal Care and Use Committee (IACUC) of the Pennsylvania State University.

\section{Construction of plasmids}

The vectors expressing SpCas9 and sgRNAs targeting $m P E R K$, mIns2 and hINS genes were cloned into the pX459 plasmid (pSpCas9(BB)-2A-Puro V2.0, (Addgene, Watertown, MA, plasmid \#62988, deposited by Feng Zhang) as previously described ${ }^{51}$. Oligonucleotides for Bbsl site cloning see Table S2. The Cas9/sgRNA genomic target sequences (20nt + $\underline{\text { PAM})}$ ) on sense $(+)$ or antisense strand (-) used in this study include: mPerk-ex9, CCTGCGCACGATGAAGGTCGTGG (-);

mPerk-in6, TAGTTCGGGATCGCCACATGAGG (-);

mPerk-utr5, AGACATCGCCCATTGAGCGAGGG (-);

mlns2-utr5, TGTAGCGGATCACTTAGGGCTGG (-);

hINS-in1 (or hINS-in1-Reverse in Figure S4), GCCCCAGCTCTGCAGCAGGGAGG (+);

hINS-in1-Same (Figure S4), TGGGCTCGTGAAGCATGTGGGGG (+).

Each of these target sequences were determined from 2-3 possible choices (top scored from crispr.mit.edu or benchling.com/crispr/) by Surveyor Assay (IDT) or T7 Endonuclease I (T7E1) Assay (New England Biolabs, Ipswich, MA). To construct rPERKex7-17-2cut (Figure S7), rPERKex717CDS-bGHpA were amplified by mega primer adding 3' cut site to the amplicon from pcDNA-rPERK (in house) and TA-cloned into pCR2.1 (Invitrogen, Carlsbad, CA), followed by subcloning of the 3' part of mPerk intron 6 and a 5' cut site by PCR amplification into the pCR2.1-rPERKex7-17CDS-bGHpA3pCUT. A rPERK-2cut was first generated by cloning ITR-mPERKutr5-rPERK-CDS-bGHpA3x3pCUT-ITR into pBluescript II KS (+) through Pcil and Sall (synthesized by GenScript, Piscataway, NJ). The rPERKmyc-2cut (Figure S8), was then generated by cloning mPERK(450bp)-myc from pcDNA-mPERK-9E10 (in house) into rPERK-2cut through Sapl and Xhol to replace rPERK(450bp). The 150aa C-terminus is conserved between mPERK and rPERK. The EGFP-2cut (Figure S10) for mIns2 targeting was generated by cloning ITR-U6-mINS2utr5sg-5pCUT-EGFP-CDS-pA-3pCUT-ITR into pUC57-Kan through EcoRV (synthesized by GenScript). A short (49bp) polyadenylation signal was used as previous described ${ }^{24}$. AAV-U6-mINS2utr5sg-EGFP-2cut in serotype 8 or DJ was packaged using EGFP-2cut. CopGFP-CDS-SV40pA sequence were obtained from Lonza of its pmaxGFP plasmid. The CopGFP-2cut (Figure S11) for hINS targeting was generated by cloning ITRU6-Bbsl-scaffold-hINSin1(flipped cut site for sg-Reverse)-CopGFP-CDS-SV40pA-3×3pCUT-ITR into pUC57-Kan through EcoRV (synthesized by GenScript). The CopGFP-1cut was generated by Mfel double digestion to remove the $3 \times 3$ pCUT from the CopGFP-2cut (Figure S11). The CopGFP-1cut (or 2cut) with U6-hINSin1sg (Figure S12 and S13) was constructed by cloning the hINSin1sg-Reverse 
into $\mathrm{Bbsl}$ site and was then used either in plasmid experiment or to package AAV-DJ-U6-hINSin1sgCopGFP-1cut (or 2cut). pAAV-nEF-Cas9 was purchased from Addgene (plasmid \#87115, deposited by Juan Belmonte) and was used either in plasmid experiment or AAV-nEF-Cas9 packaging in serotype DJ.

\section{Cell culture}

Mouse embryonic fibroblasts (MEF) cells were immortalized from Perk ${ }^{\Delta \mathrm{ex7}-9 / \Delta e x 7-9} 52$ and Perk ${ }^{\mathrm{C528X} / \mathrm{C} 528 \mathrm{X}}$ mice using a plasmid carrying the SV40 large T antigen (SV40 1: pBSSVD2005, Addgene, plasmid \#21826, deposited by David Ron). Following immortalization, MEF cells were maintained in Dulbecco's Modified Eagle Medium, DMEM (Gibco, Gaithersburg, MD) supplemented with 10\% fetal bovine serum, FBS (Gemini, West Sacramento, CA) and 1× Penicillin-Streptomycin (Pen-Strep) at $100 \mathrm{U} / \mathrm{ml}-100 \mu \mathrm{g} / \mathrm{ml}$ (Gibco). Mouse MIN6 (Dr. Jun-Ichi Miyazaki, Osaka University, Japan) beta cells and human AD293 cells (Agilent, Santa Clara, CA) were cultured under the same conditions as MEF cells. Primary human cadaveric islets were obtained from Prodo Labs of Integrated Islet Distribution Program (IIDP). Upon receipt, islets were transferred from shipping media to CMRL 1066 (Connaught Medical Research Laboratories, Toronto, Canada; purchased from Gibco) supplemented with 10\% FBS, $1 \times$ Pen-Strep and 2mM L-Glutamine (Gibco) at a concentration of 800-1000 islet equivalents (IEQ) per milliliter in a non-tissue culture treated $6 \mathrm{~cm}$ dish and cultured overnight. All cells were cultured in a humidified, $5 \% \mathrm{CO}_{2}$ incubator at $37^{\circ} \mathrm{C}$.

\section{Plasmid transfection via electroporation}

Perk ${ }^{\text {ex7-9/ } / \mathrm{ex7-9}}$ MEF cells were transfected with CRISPR/Cas9 and CRBR donor constructs by electroporation using the MEF 2 Nucleofector Kit (Lonza, Basel, Switzerland), program T-20 in Nucleofector $^{\mathrm{TM}} 2 \mathrm{~b}$ Device (Lonza) according to the manufacturer's protocol. MIN6 cells were similarly electroporated using Nucleofector Kit V (Lonza), program G-16. The pmaxGFP plasmid provided in the Nucleofector Kit was used as transfection positive control in all plasmid electroporation experiments. To achieve higher electroporation efficiency, the Neon Transfection system (Invitrogen) was used for the following cells in a $10 \mu$ lectroporation system (Invitrogen) with no more than $1 \mu \mathrm{g}$ plasmid DNA per $10 \mu$ treatment: Perk ${ }^{\text {C528X/C528X }}$ MEF cells, $1 \times 10^{7}$ cells $/ \mathrm{ml}, 1650 \mathrm{~V}, 20 \mathrm{~ms}, 1$ pulse; AD293 cells, $5 \times 10^{6}$ cells $/ \mathrm{ml}, 1245 \mathrm{~V}, 10 \mathrm{~ms}, 3$ pulses; human islets, $500 \mathrm{IEQs} / 10 \mathrm{ul}, 1050 \mathrm{~V}, 40 \mathrm{~ms}, 1$ pulse. The Neon procedure for electroporation of human islets was adapted from previously described protocols $^{53,54}$. Briefly, about 1000 IEQs for two replicates of one treatment was transferred to a $1.5 \mathrm{ml}$ tube and centrifuged for $1 \mathrm{~min}$ at $100 \mathrm{~g}$ and washed with PBS and re-centrifuged. The islets were then incubated with Accutase (Gibco) for $2 \mathrm{~min}$ at $37^{\circ} \mathrm{C}$ to partially dissociate them, and then washed with PBS and resuspended in $20 \mu \mathrm{l}$ buffer with $2 \mu \mathrm{g}$ of each plasmid DNA needed for the treatment. 
About 500 IEQs in $10 \mu \mathrm{l}$ with $1 \mu \mathrm{g}$ plasmid DNA were electroporated with 1 pulse at $1050 \mathrm{~V}$ for $40 \mathrm{~ms}$ and then cultured individually in a non-tissue culture treated 24-well plate.

\section{AAV production and titration}

AAVs carrying hGFAP::Cre and CAG::FLEx-GFP for serotype testing in human islets were as previously described ${ }^{55}$. AAV8-U6-mINS2utr5sg-EGFP-2cut $\left(6.15 \times 10^{13} \mathrm{GC} / \mathrm{ml}\right)$ was produced and purified by Penn Vector Core. AAV-DJ-U6-mINS2utr5sg-EGFP-2cut (2.92×1012 GC/ml), AAV-DJ-U6hINSin1sg-CopGFP-2cut $\left(1.83 \times 10^{13} \mathrm{GC} / \mathrm{ml}\right)$, AAV-DJ-U6-hINSin1sg-CopGFP-1cut $\left(6.02 \times 10^{12} \mathrm{GC} / \mathrm{ml}\right)$, and AAV-DJ-nEF-Cas $9\left(3.83 \times 10^{12} \mathrm{GC} / \mathrm{ml}\right)$ were produced and purified as described below. Briefly, recombinant AAVs were produced in 293AAV cells (Cell Biolabs, San Diego, CA). Polyethylenimine (PEI, linear, MW 25,000) was used for transfection of triple plasmids: the pAAV vector constructs, pAAV2/8-RC (Penn Vector Core) or pAAV-DJ (Cell Biolabs) and pHelper (Cell Biolabs). Cells were scrapped in their medium and centrifuged, frozen, and thawed four times by placing it alternately in dry ice-ethanol and $37^{\circ} \mathrm{C}$ water bath, $72 \mathrm{hrs}$ post transfection. AAV crude lysate was purified by centrifugation at 54,000 rpm for $1 \mathrm{hr}$ in discontinuous iodixanol gradients with a Beckman SW55Ti rotor. The virus-containing layer was extracted, and viruses were concentrated by Millipore Amicon Ultra Centrifugal Filters (Millipore-Sigma, Bedford MA). Virus titers were determined by qPCR according to Addgene protocol.

\section{AAV transduction of human islets}

AAV-DJ-U6-hINSin1sg-CopGFP-2cut, AAV-DJ-U6-hINSin1sg-CopGFP-1cut and AAV-DJ-nEF-Cas9

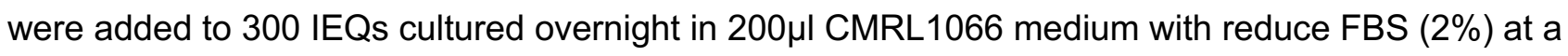
final titer of $9.0 \times 10^{10} \mathrm{GC} / \mathrm{ml}$. If $1 \mathrm{IEQ}$ is considered to be 1000 cells, the AAV incubation of human islets was at 60,000 MOI. CMRL1066 medium with 10\% FBS was added to the sample at 1d post infection.

\section{AAV administration via intravenous injection}

P14 Cas9-EGFP mice were injected with $20 \mu \mathrm{l}$ or $40 \mu$ l of AAV8-U6-mINS2utr5sg-EGFP-2cut, via retro-

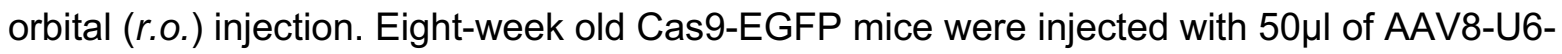
mINS2utr5sg-EGFP-2cut or AAV-DJ-U6-mINS2utr5sg-EGFP-2cut, or 50 $\mu$ l saline solution via tail vein

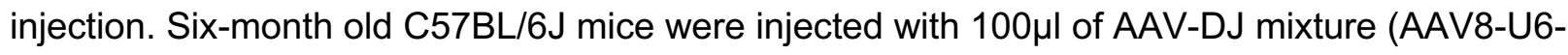
mINS2utr5sg-EGFP-2cut, with or without AAV-DJ-nEF-Cas9), or $100 \mu$ saline solution via tail vein injection.

\section{Single cell sorting}


MEF cells and MIN6 cells were single cell sorted according to size configuration or GFP signal using Beckman Coulter MoFlo Astrios (Beckman-Coulter, Brea, CA) performed by Flow Cytometry Facility at the Huck Institutes of the Life Sciences at Penn State University. Cells were dissociated using $0.25 \%$ Trypsin-EDTA solution for $5 \mathrm{~min}$ at $37^{\circ} \mathrm{C}$ and warm DMEM medium supplemented with $10 \%$ FBS was added to stop digestion. Cells were then transferred into a $15 \mathrm{ml}$ tube and centrifuged at $200 \mathrm{~g}$ for $1 \mathrm{~min}$ at room temperature. The cells were re-suspended thoroughly in DMEM medium with $1 \times$ Pen-Strep as single cells and were sorted into 96-well plate with full DMEM medium.

\section{Genomic DNA extraction and diagnostic PCR analysis}

Genomic DNA was extracted from cell culture or mouse tissue by digesting in lysis buffer (5mM EDTA, $0.2 \%$ SDS, $200 \mathrm{mM} \mathrm{NaCl}$, and $100 \mathrm{mM}$ Tris- $\mathrm{HCl}$, pH8.5) with $100 \mu \mathrm{g} / \mathrm{ml}$ proteinase $\mathrm{K}$ overnight at $50^{\circ} \mathrm{C}$ and then precipitated with 1 volume of isopropanol and dissolved in TE buffer (10mM Tris$\mathrm{HCl}, 1.0 \mathrm{mM}$ EDTA, pH8.0). Blood DNA was extracted using Monarch Genomic DNA Purification Kit (New England Biolabs). Diagnostic PCRs were performed using GoTaq Master Mix (Promega, Madison, WI). Five percent of DMSO was added to improve amplification of GC-rich sequences. PCR product purification was carried out using the QIAquick PCR Purification Kit (Qiagen, Hilden, Germany). Gel purification to recover PCR fragments after electrophoretic separation was performed using the Zymoclean Gel DNA Recovery Kit (Zymo, Irvine, CA). Sanger sequencing of the PCR products was performed by Genomics Core Facility at the Huck Institutes of the Life Sciences at Penn State University. DNA sequencing results were analyzed using the SnapGene software. See Table S3 for primer sequences.

\section{RNA isolation and quantitative PCR analysis}

Total RNA from cell lines and mouse tissues other than pancreas were extracted using the QuickRNA Miniprep Kit (Zymo). Pancreas RNA was extracted as previously described by Robert C. De Lisle (10.3998/panc.2014.9). Human islet RNA was extracted using AllPrep DNA/RNA/Protein Mini Kit (Qiagen). Reverse transcription was performed using qScript cDNA SuperMix (Quanta, Beverly, MA). Quantitative mRNA measurement was carried out using PerfeCTa SYBR Green SuperMix ROX (Quanta) with the StepOnePlus Real-time PCR system (Applied Biosystems, Foster City, CA). Gene expression levels were normalized to endogenous mouse Actin (Actb) or human Actin (ACTA1) levels of the same sample. The relative fold change in expression was calculated using the $\Delta \Delta \mathrm{Ct}$ method. See Table S4 for primer sequences.

\section{GFP imaging and histological analysis}

MIN6 cells and human islets were imaged as live cultures using the FITC and Transillumination channels of the ECHO Revolve microscope (Echo Labs, San Diego, CA). Fluorescence images were 
captured with the ECHO Revolve microscope. Whole pancreata were harvested as previously described ${ }^{56}$. Slides were dewaxed and Hematoxylin and Eosin stained by Leica Autostainer ST5010 $\mathrm{XL}$ (Wetzlar, Germany) and bright field images were captured with the ECHO Revolve microscope.

\section{Immunoblot analysis}

Total cell lysates were made from mouse pancreatic tissue using RIPA buffer (1\% Nonidet P40, 0.5\% sodium doxycholate, $0.1 \%$ SDS, $1 \times$ PBS, $\mathrm{pH} 8.0$ ) with $1 \times$ Protease Inhibitor cocktails and $1 \times$ Phosphatase Inhibitor cocktail 2 and 3 (Millipore-Sigma). Tissue lysates or MEF cells were denatured by boiling the lysates in 2x SDS sample buffer prior to electrophoresis on NuPAGE $8 \%$ Bis-Tris Midi gel (Invitrogen). The separated proteins were transferred to nitrocellulose membranes $(0.45 \mu \mathrm{m}$, Thermo Scientific, Waltham, MA) in carbonate transfer buffer using wet transfer conditions (Criterion Blotter, BioRad, Hercules, CA). Primary antibodies (diluted in 5\% BSA-TBST) used include: PhosphoPERK (Thr980) (\#3179, Cell signaling, Danvers, MA), PERK (\#3192, Cell Signaling), Phospho-elF2 $\alpha$ (Ser51) (\#9721, Cell signaling), elF2a (\#AHO1182, Invitrogen), Myc Tag (\#R950-25, Invitrogen) and Actin (\#A5060, Millipore-Sigma). Appropriate IRDye-conjugated secondary antibodies were used, and IR fluorescence was detected using the LI-COR Odyssey CLx Imaging System and quantified using the LI-COR Image Studio Software (LI-COR, Lincoln, NE).

\section{Statistical analysis}

Numerical data were represented as mean +/- SE. Statistical significance was determined using Student's $t$-test, where appropriate.

\section{$\underline{\text { Author Contributions }}$}

Conceptualization, J.H., R.A.B., B.C.M., D.R.C.; Methodology, J.H., R.A.B., D.R.C.; Validation, J.H., R.A.B., B.C.M., D.R.C.; Formal Analysis, J.H., A.L., R.A.B.; Investigation, J.H., R.A.B., A.L., ; Resources, Z.P.; Writing - Original Draft, J.H.; Writing - Review \& Editing, J.H., R.A.B., B.C.M., D.R.C.; Visualization - J.H.; Funding Acquisition, J.H., R.A.B., B.C.M., and D.R.C.

\section{Acknowledgments}

Human pancreatic islets were provided by the NIDDK-funded Integrated Islet Distribution Program (IIDP) (RRID:SCR_014387) at City of Hope, NIH Grant \# 2UC4DK098085. We thank the Harvard Genome Modification Facility for providing the mouse zygote microinjection service (Job 1772 for Perk $^{\text {C528X }}$ allele generation and Job 2182 for Perk ${ }^{\text {CRBR-rPERKmyc }}$ allele generation). We thank the Genomics Core Facility, Flow Cytometry Facility and Microscopy Core Facility at the Huck Institutes of 
the Life Sciences at Penn State University for providing the Sanger Sequencing service, Cell Sorting service, and Histology lab equipment for tissue processing. This work was supported by National Institutes of Health Grant R01 DK88140.

\section{$\underline{\text { References }}$}

1. Wilson, JM (2019). Cycling at the Frontiers of Gene Therapy. Human gene therapy Clinical development 30: 47-49.

2. Dunbar, CE, High, KA, Joung, JK, Kohn, DB, Ozawa, K, and Sadelain, M (2018). Gene therapy comes of age. Science (New York, NY) 359.

3. Lundstrom, K (2018). Viral Vectors in Gene Therapy. Diseases 6.

4. Jinek, M, Chylinski, K, Fonfara, I, Hauer, M, Doudna, JA, and Charpentier, E (2012). A programmable dual-RNA-guided DNA endonuclease in adaptive bacterial immunity. Science 337: 816-821.

5. Cong, L, Ran, FA, Cox, D, Lin, S, Barretto, R, Habib, N, et al. (2013). Multiplex genome engineering using CRISPR/Cas systems. Science 339: 819-823.

6. Mali, P, Yang, L, Esvelt, KM, Aach, J, Guell, M, DiCarlo, JE, et al. (2013). RNA-guided human genome engineering via Cas9. Science 339: 823-826.

7. Cho, SW, Kim, S, Kim, JM, and Kim, JS (2013). Targeted genome engineering in human cells with the Cas9 RNA-guided endonuclease. Nat Biotechnol 31: 230-232.

8. Yin, H, Xue, W, Chen, S, Bogorad, RL, Benedetti, E, Grompe, M, et al. (2014). Genome editing with Cas9 in adult mice corrects a disease mutation and phenotype. Nature biotechnology 32: 551-553.

9. Yin, H, Song, C-Q, Dorkin, JR, Zhu, LJ, Li, Y, Wu, Q et al. (2016). Therapeutic genome editing by combined viral and non-viral delivery of CRISPR system components in vivo. Nature biotechnology 34: 328-333.

10. Tran, NT, Graf, R, Wulf-Goldenberg, A, Stecklum, M, Strauß, G, Kühn, R, et al. (2020). CRISPRCas9-Mediated ELANE Mutation Correction in Hematopoietic Stem and Progenitor Cells to Treat Severe Congenital Neutropenia. Mol Ther.

11. Ohmori, T, Nagao, Y, Mizukami, H, Sakata, A, Muramatsu, SI, Ozawa, K, et al. (2017). CRISPR/Cas9-mediated genome editing via postnatal administration of AAV vector cures haemophilia B mice. Sci Rep 7: 4159.

12. Wang, L, Yang, Y, Breton, CA, White, J, Zhang, J, Che, Y, et al. (2019). CRISPR/Cas9-mediated in vivo gene targeting corrects hemostasis in newborn and adult factor IX-knockout mice. Blood 133: 2745-2752.

13. Vagni, P, Perlini, LE, Chenais, NAL, Marchetti, T, Parrini, M, Contestabile, A, et al. (2019). Gene Editing Preserves Visual Functions in a Mouse Model of Retinal Degeneration. Front Neurosci 13: 945.

14. Cai, Y, Cheng, T, Yao, Y, Li, X, Ma, Y, Li, L, et al. (2019). In vivo genome editing rescues photoreceptor degeneration via a Cas9/RecA-mediated homology-directed repair pathway. Sci Adv 5: eaav3335.

15. Cox, DB, Platt, RJ, and Zhang, F (2015). Therapeutic genome editing: prospects and challenges. Nat Med 21: 121-131. 
16. Panier, S, and Durocher, D (2013). Push back to respond better: regulatory inhibition of the DNA double-strand break response. Nat Rev Mol Cell Biol 14: 661-672.

17. Komor, AC, Kim, YB, Packer, MS, Zuris, JA, and Liu, DR (2016). Programmable editing of a target base in genomic DNA without double-stranded DNA cleavage. Nature 533: 420-424.

18. Gaudelli, NM, Komor, AC, Rees, HA, Packer, MS, Badran, AH, Bryson, DI, et al. (2017). Programmable base editing of $A \bullet T$ to $G \bullet C$ in genomic DNA without DNA cleavage. Nature 551: 464-471.

19. Yeh, WH, Chiang, H, Rees, HA, Edge, ASB, and Liu, DR (2018). In vivo base editing of post-mitotic sensory cells. Nat Commun 9: 2184.

20. Villiger, L, Grisch-Chan, HM, Lindsay, H, Ringnalda, F, Pogliano, CB, Allegri, G, et al. (2018). Treatment of a metabolic liver disease by in vivo genome base editing in adult mice. Nat Med 24: 1519-1525.

21. Bansal, V, Gassenhuber, J, Phillips, T, Oliveira, G, Harbaugh, R, Villarasa, N, et al. (2017). Spectrum of mutations in monogenic diabetes genes identified from high-throughput DNA sequencing of 6888 individuals. BMC Med 15: 213.

22. Rebbeck, TR, Friebel, TM, Friedman, E, Hamann, U, Huo, D, Kwong, A, et al. (2018). Mutational spectrum in a worldwide study of 29,700 families with BRCA1 or BRCA2 mutations. Hum Mutat 39: 593-620.

23. Julier, C, and Nicolino, M (2010). Wolcott-Rallison syndrome. Orphanet J Rare Dis 5: 29.

24. Suzuki, K, Tsunekawa, Y, Hernandez-Benitez, R, Wu, J, Zhu, J, Kim, EJ, et al. (2016). In vivo genome editing via CRISPR/Cas9 mediated homology-independent targeted integration. Nature 540: 144-149.

25. Harding, HP, Zeng, H, Zhang, Y, Jungries, R, Chung, P, Plesken, $H$, et al. (2001). Diabetes mellitus and exocrine pancreatic dysfunction in perk-/- mice reveals a role for translational control in secretory cell survival. Molecular cell 7: 1153-1163.

26. Zhang, P, McGrath, B, Li, Sa, Frank, A, Zambito, F, Reinert, J, et al. (2002). The PERK eukaryotic initiation factor 2 alpha kinase is required for the development of the skeletal system, postnatal growth, and the function and viability of the pancreas. Molecular and cellular biology 22: 38643874.

27. Zhang, W, Feng, D, Li, Y, lida, K, McGrath, B, and Cavener, DR (2006). PERK EIF2AK3 control of pancreatic beta cell differentiation and proliferation is required for postnatal glucose homeostasis. Cell metabolism 4: 491-497.

28. Li, Y, lida, K, O'Neil, J, Zhang, P, Li, Sa, Frank, A, et al. (2003). PERK elF2alpha kinase regulates neonatal growth by controlling the expression of circulating insulin-like growth factor-I derived from the liver. Endocrinology 144: 3505-3513.

29. lida, K, Li, Y, McGrath, BC, Frank, A, and Cavener, DR (2007). PERK elF2 alpha kinase is required to regulate the viability of the exocrine pancreas in mice. BMC cell biology 8: 38.

30. Hellen, CU, and Sarnow, P (2001). Internal ribosome entry sites in eukaryotic mRNA molecules. Genes Dev 15: 1593-1612.

31. Gunisova, S, Hronova, V, Mohammad, MP, Hinnebusch, AG, and Valasek, LS (2018). Please do not recycle! Translation reinitiation in microbes and higher eukaryotes. FEMS Microbiol Rev 42: 165-192.

32. Cheng, H, Wolfe, SH, Valencia, V, Qian, K, Shen, L, Phillips, MI, et al. (2007). Efficient and persistent transduction of exocrine and endocrine pancreas by adeno-associated virus type $8 . J$ Biomed Sci 14: 585-594. 
33. Rehman, KK, Trucco, M, Wang, Z, Xiao, X, and Robbins, PD (2008). AAV8-mediated gene transfer of interleukin-4 to endogenous beta-cells prevents the onset of diabetes in NOD mice. Mol Ther 16: 1409-1416.

34. Mulder, NL, Havinga, R, Kluiver, J, Groen, AK, and Kruit, JK (2019). AAV8-mediated gene transfer of microRNA-132 improves beta cell function in mice fed a high-fat diet. J Endocrinol 240: 123132.

35. Da Silva Xavier, G (2018). The Cells of the Islets of Langerhans. J Clin Med 7.

36. Rehman, KK, Wang, Z, Bottino, R, Balamurugan, AN, Trucco, M, Li, J, et al. (2005). Efficient gene delivery to human and rodent islets with double-stranded (ds) AAV-based vectors. Gene Ther 12: 1313-1323.

37. Craig, AT, Gavrilova, O, Dwyer, NK, Jou, W, Pack, S, Liu, E, et al. (2009). Transduction of rat pancreatic islets with pseudotyped adeno-associated virus vectors. Virol J 6: 61.

38. Park, K, Kim, WJ, Cho, YH, Lee, YI, Lee, H, Jeong, S, et al. (2008). Cancer gene therapy using adeno-associated virus vectors. Front Biosci 13: 2653-2659.

39. Kattenhorn, LM, Tipper, CH, Stoica, L, Geraghty, DS, Wright, TL, Clark, KR, et al. (2016). AdenoAssociated Virus Gene Therapy for Liver Disease. Human gene therapy 27: 947-961.

40. Wang, D, Zhang, F, and Gao, G (2020). CRISPR-Based Therapeutic Genome Editing: Strategies and In Vivo Delivery by AAV Vectors. Cell 181: 136-150.

41. Canny, MD, Moatti, N, Wan, LCK, Fradet-Turcotte, A, Krasner, D, Mateos-Gomez, PA, et al. (2018). Inhibition of 53BP1 favors homology-dependent DNA repair and increases CRISPR-Cas9 genome-editing efficiency. Nat Biotechnol 36: 95-102.

42. Nishiyama, J, Mikuni, T, and Yasuda, R (2017). Virus-Mediated Genome Editing via HomologyDirected Repair in Mitotic and Postmitotic Cells in Mammalian Brain. Neuron 96: 755-768.e755.

43. Long, C, Amoasii, L, Mireault, AA, McAnally, JR, Li, H, Sanchez-Ortiz, E, et al. (2016). Postnatal genome editing partially restores dystrophin expression in a mouse model of muscular dystrophy. Science (New York, NY) 351: 400-403.

44. Nelson, CE, Hakim, CH, Ousterout, DG, Thakore, PI, Moreb, EA, Castellanos Rivera, RM, et al. (2016). In vivo genome editing improves muscle function in a mouse model of Duchenne muscular dystrophy. Science (New York, NY) 351: 403-407.

45. Tabebordbar, M, Zhu, K, Cheng, JKW, Chew, WL, Widrick, JJ, Yan, WX, et al. (2016). In vivo gene editing in dystrophic mouse muscle and muscle stem cells. Science (New York, NY) 351: 407411.

46. Sowers, CR, Wang, R, Bourne, RA, McGrath, BC, Hu, J, Bevilacqua, SC, et al. (2018). The protein kinase PERK/EIF2AK3 regulates proinsulin processing not via protein synthesis but by controlling endoplasmic reticulum chaperones. The Journal of biological chemistry 293: 5134-5149.

47. Maxwell, KG, Augsornworawat, P, Velazco-Cruz, L, Kim, MH, Asada, R, Hogrebe, NJ, et al. (2020). Gene-edited human stem cell-derived $\beta$ cells from a patient with monogenic diabetes reverse preexisting diabetes in mice. Sci Transl Med 12.

48. Wilbie, D, Walther, J, and Mastrobattista, E (2019). Delivery Aspects of CRISPR/Cas for in Vivo Genome Editing. Acc Chem Res 52: 1555-1564.

49. Yin, H, Song, CQ, Suresh, S, Wu, Q, Walsh, S, Rhym, LH, et al. (2017). Structure-guided chemical modification of guide RNA enables potent non-viral in vivo genome editing. Nat Biotechnol 35: 1179-1187.

50. Yang, H, Wang, H, and Jaenisch, R (2014). Generating genetically modified mice using CRISPR/Cas-mediated genome engineering. Nat Protoc 9: 1956-1968. 
51. Ran, FA, Hsu, PD, Wright, J, Agarwala, V, Scott, DA, and Zhang, F (2013). Genome engineering using the CRISPR-Cas9 system. Nature protocols 8: 2281-2308.

52. Jiang, HY, Wek, SA, McGrath, BC, Scheuner, D, Kaufman, RJ, Cavener, DR, et al. (2003). Phosphorylation of the alpha subunit of eukaryotic initiation factor 2 is required for activation of NF-kappaB in response to diverse cellular stresses. Mol Cell Biol 23: 5651-5663.

53. Tamaki, S, Nye, C, Slorach, E, Scharp, D, Blau, HM, Whiteley, PE, et al. (2014). Simultaneous silencing of multiple RB and p53 pathway members induces cell cycle reentry in intact human pancreatic islets. BMC Biotechnol 14: 86.

54. Lefebvre, B, Vandewalle, B, Longue, J, Moerman, E, Lukowiak, B, Gmyr, V, et al. (2010). Efficient gene delivery and silencing of mouse and human pancreatic islets. BMC Biotechnol 10: 28.

55. Chen, YC, Ma, NX, Pei, ZF, Wu, Z, Do-Monte, FH, Keefe, S, et al. (2020). A NeuroD1 AAV-Based Gene Therapy for Functional Brain Repair after Ischemic Injury through In Vivo Astrocyte-toNeuron Conversion. Mol Ther 28: 217-234.

56. Gupta, S, McGrath, B, and Cavener, DR (2010). PERK (EIF2AK3) regulates proinsulin trafficking and quality control in the secretory pathway. Diabetes 59: 1937-1947. 
bioRxiv preprint doi: https://doi.org/10.1101/2020.12.17.423314; this version posted December 19, 2020. The copyright holder for this preprint (which was not certified by peer review) is the author/funder, who has granted bioRxiv a license to display the preprint in perpetuity. It is made available under aCC-BY-NC-ND 4.0 International license.

A

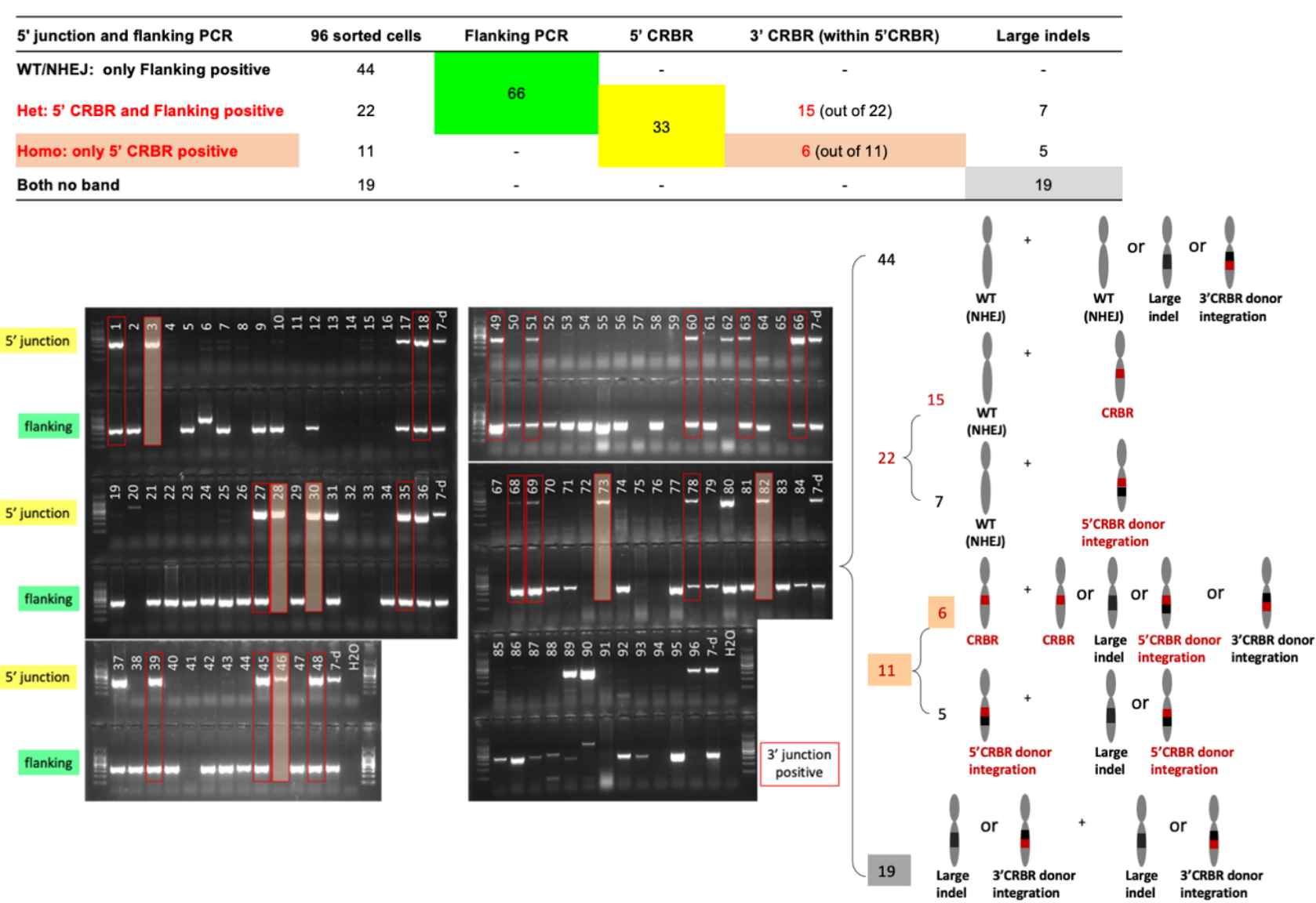

B

\begin{tabular}{|c|c|c|c|c|}
\hline Cell ID & Mouse $F$ & 5' junction PCR & 3' junction PCR & Flanking PCR (WT/small NHEJ) \\
\hline 1 & CRBR/small NHEJ indel & clean joint & 4bp deletion (-4 to -1$)$ & 2 bp deletion ( $G T$ at +1 to +2 ) \\
\hline 3 & CRBR/backbone integration & $11 \mathrm{bp}$ deletion $(-1$ to +10$)$ & clean joint ( $3^{\prime}$ seq mixture) & no band \\
\hline 28 & CRBR/large indel & $2 \mathrm{bp}$ insertion ( $\mathrm{TG}$ at +1 ) & clean joint & no band \\
\hline 35 & CRBR/small NHEJ indel & 1 bp mutation ( $T$ to $C$ mutation at -1 ) & clean joint & $2 \mathrm{bp}$ deletion ( $\mathrm{GT}$ at +1 to +2 ) \\
\hline 46 & CRBR/large integration & 1bp insertion ( $C$ at +1$)$ & clean joint & no band \\
\hline 66 & CRBR/small NHEJ indel & clean joint & 4bp deletion $(-4$ to -1$)$ & $2 \mathrm{bp}$ deletion ( $\mathrm{GT}$ at +1 to +2 ) \\
\hline 73 & CRBR/large indel & $2 \mathrm{bp}$ insertion ( $\mathrm{TG}$ at +1 ) & clean joint & no band \\
\hline 82 & CRBR/backbone integration & 2 bp insertion ( $T G$ at +1 ) & clean joint (5' seq mixture) & no band \\
\hline
\end{tabular}

Sorted single cell line \#3

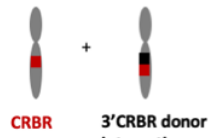

integration

C

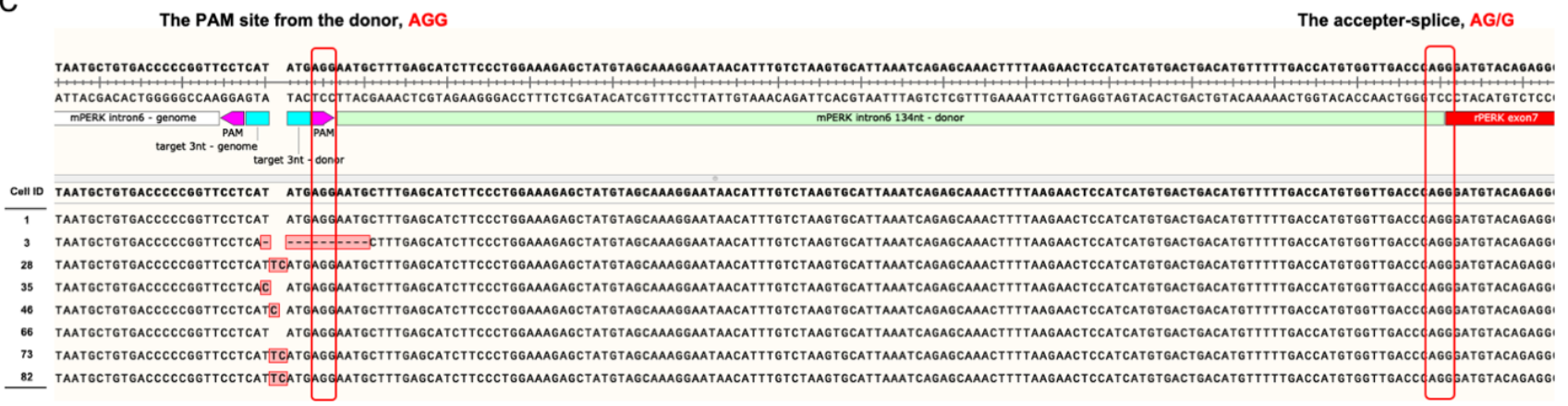

\section{Figure S1. Allele analysis of single sorted Perk ${ }^{\Delta e x 7-9 / \Delta e x 7-9}$ MEF cell lines with CRBR editing.}

A. Possible composition of the two alleles in the single sorted Perk ${ }^{\Delta \mathrm{ex} 7-9 / \Delta \mathrm{ex} 7-9} \mathrm{MEF}$ cell lines according to the PCR analysis. Positive 5' junction PCR in total 96 cell lines showed 33 sorted cells have CRBR editing in at least one allele. Positive flanking PCR showed 22 out of the 33 have the other allele cleanly rejointed or with small NHEJ indels at the DSB in the genome. Positive 3 ' junction PCR found 
in the 33 cell lines (that were 5' junction positive) are highlighted with red rectangle on the DNA gel. 7d, positive control, was genomic DNA of Perk ${ }^{\Delta e x 7-9 / \Delta e x 7-9}$ MEF cells co-transfected with $p X 459-$ mPERKin6sg and rPERKex7-17-2cut.

B. Eight cell lines (positive for 5' junction PCR) were subjected to sequence analysis for 5' junction PCR, 3' junction PCR and flanking PCR. Sequencing of PCR product that contained mixed signals on either side of the junction suggests the unknown large indel on the second allele could be a whole donor integration.

C. Alignment of the sequencing of the 5' junction PCR of 8 cell lines to the CRBR edited genome. Except \#3 cell line, all other 7 cell lines retained the AG/G from the donor cut site residues, which may be recognized as a splice-acceptor 135bp upstream of the intended slicing site between the 3' of mPerk intron 6 and $r$ Perk exon 7. The extra 135bp intronic sequence encodes a stop codon in the 7 cell lines that would cause a nonsense-mediated mRNA decay of the chimeric mouse-rat Perk transcript. 
A
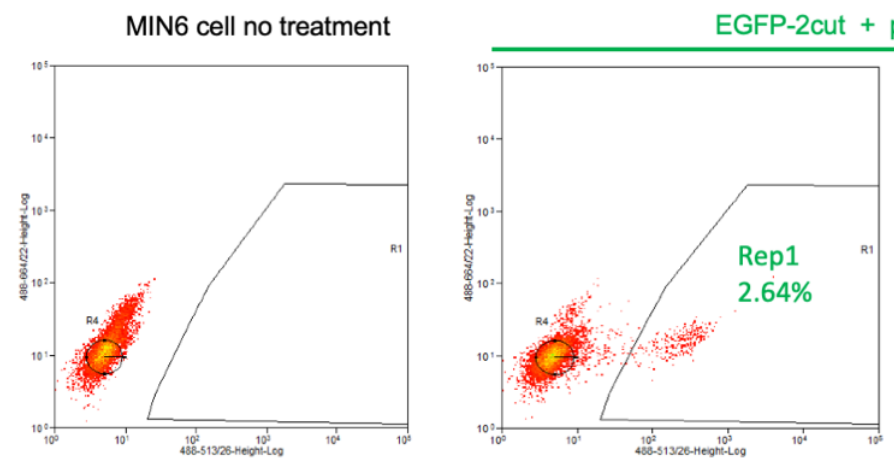

EGFP-2cut + pX459-mINS2utr5sg

B

\#8

\#10

$\# 13$
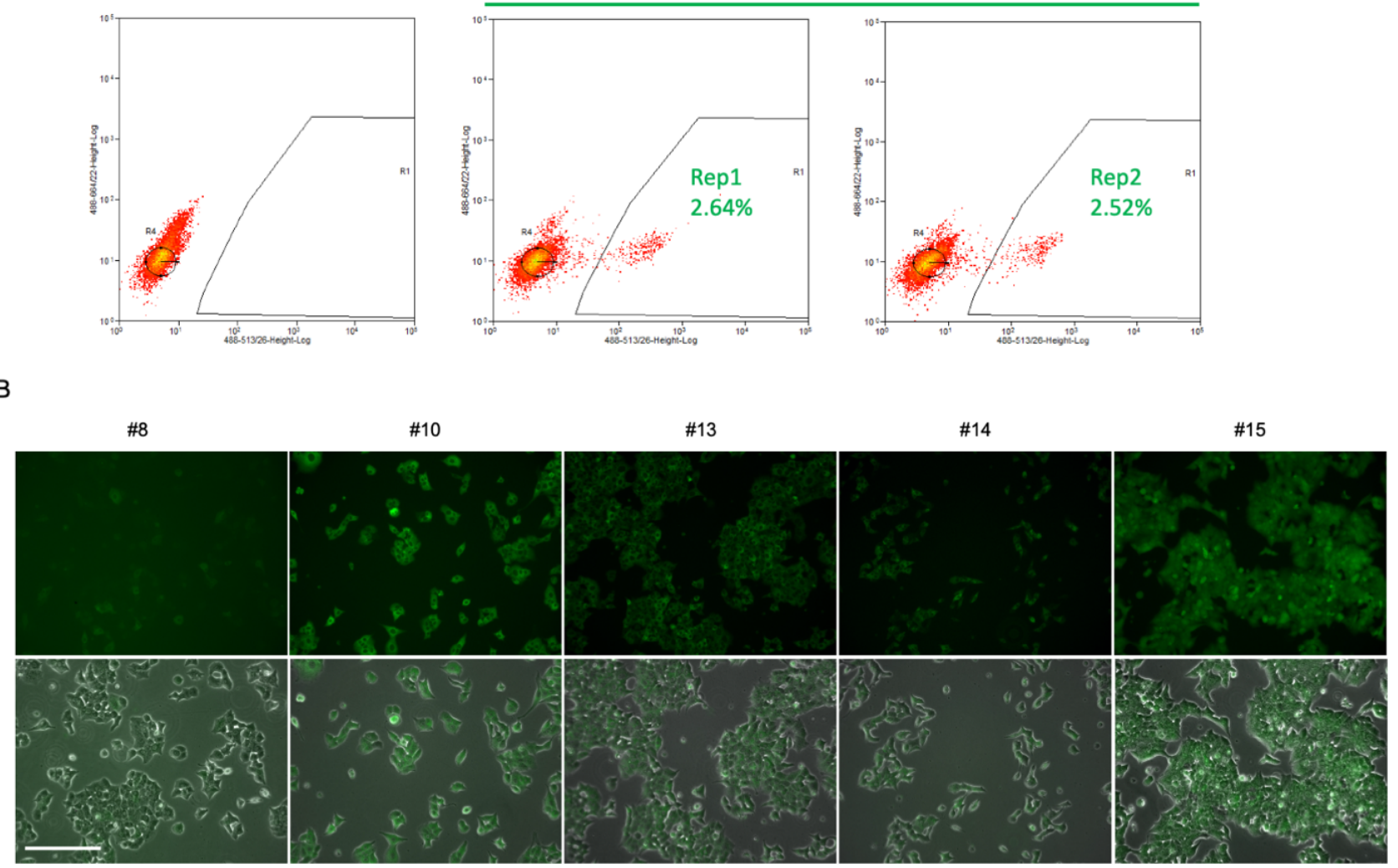

C

\begin{tabular}{|c|c|c|c|c|c|c|}
\hline Cell ID & Mouse Ins2 5'UTR at Ch7 & 5 ' junction PCR & 3' junction PCR & Flanking PCR (WT/small NHEJ) & Whole plasmid integration & Visible GFP \\
\hline 8 & CRBR/small NHEJ indel & clean joint & 102bp insertion (btw -1 and +1) & $2 \mathrm{bp}$ deletion $(+1$ to +2$)$ & no band & mixed; $\sim 5 \%$ \\
\hline 10 & CRBR/small NHEJ indel & clean joint & clean joint & $2 \mathrm{bp} \mathrm{del}+1 \mathrm{bp}$ ins (btw -1 and +1 ) & no band & all cells; high \\
\hline 13 & CRBR/small NHEJ indel & clean joint & 4 bp deletion $(-1$ to +3$)$ & $4 \mathrm{bp}$ deletion $(+1$ to +2$)$ & no band & all cells; high \\
\hline 14 & CRBR/small NHEJ indel & 1bp insertion (btw -1 and +1) & clean joint & $2 \mathrm{bp}$ deletion $(+1$ to +2$)$ & no band & all cells; medium \\
\hline 15 & CRBR/backbone integration & clean joint & clean joint & no band & $10 \mathrm{bp}$ del $+275 \mathrm{bp}$ ins at $3^{\prime}$ junction & all cells; high \\
\hline
\end{tabular}

\section{Figure S2. Single cell sorting of CRBR-edited GFP-positive MIN6 cells.}

A. Single cell sorting revealed about $2.5 \%$ of MIN6 cells in the mixed cell population at $21 \mathrm{~d}$ post cotransfection of EGFP-2cut plasmid and Cas9/sgRNA plasmid had EGFP CRBR cassette integration and GFP protein expression.

B and C. Five single sorted GFP-positive MIN6 cell lines (\#8, 10, 13, 14, and 15) were (B) imaged as live cultures at $20 \times$ objective, scale bar, $100 \mu \mathrm{m}$. Same exposure time and light intensity was applied. Sequence analysis (C) for 5' junction PCR, 3' junction PCR, flanking PCR and whole plasmid integration PCR of the same sorted cell lines are described in the table. 


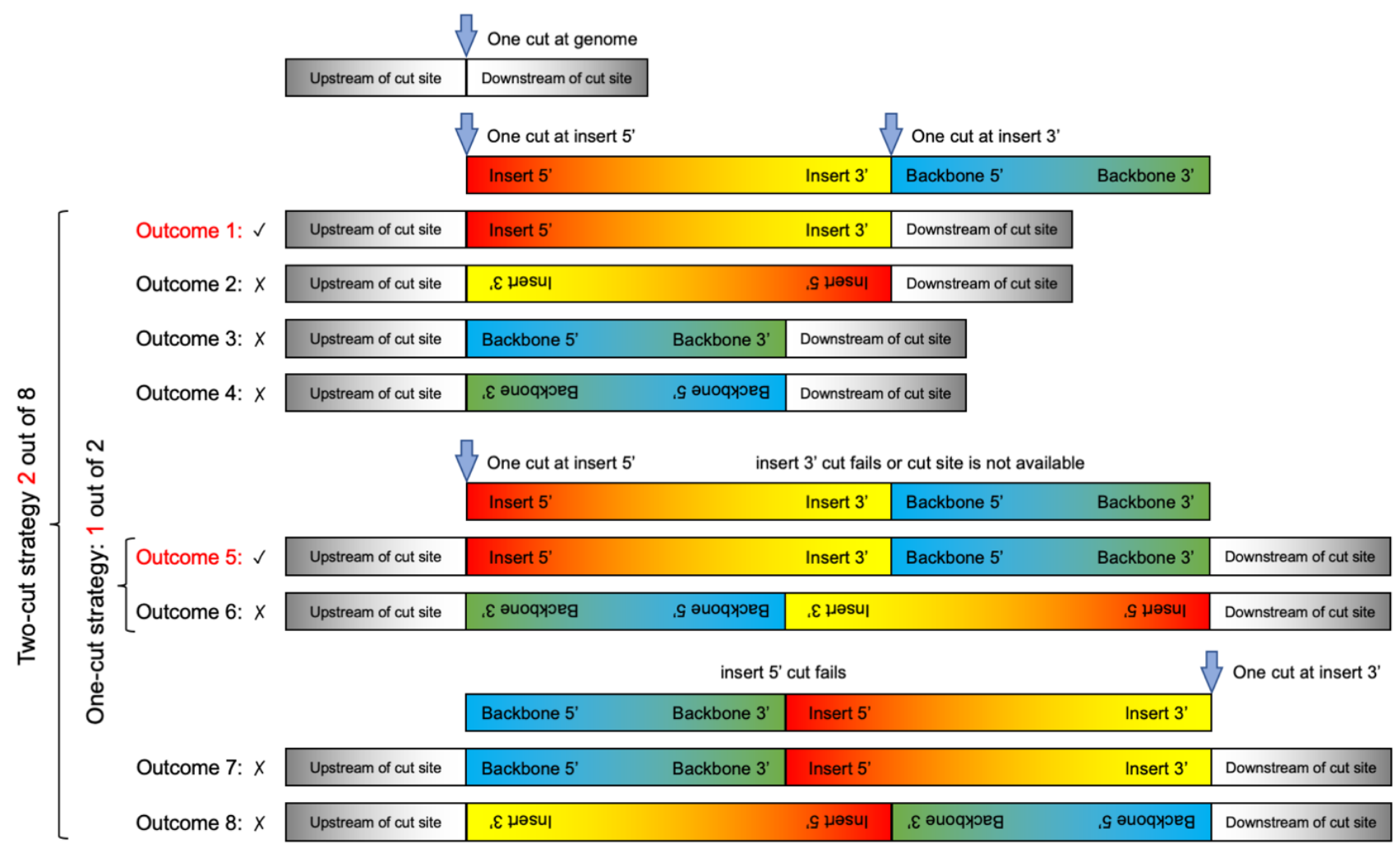

Figure S3. Schematic of possible integrants from CRBR 2-cut strategy and CRBR 1-cut strategy.

Plasmid donor with two Cas9/sgRNA target sites (2-cut donor) can generate insert fragment and backbone fragment when both cuts take place, and four integrants (outcome 1 4) could be generated randomly if not considering the engineered reverse-orientated cut site effect. When either cleavage fails, the 2-cut donor could be linearized in two ways and integrated into genome in two orientations (outcome 5 8). Only outcome 1 and 5 would express the CRBR cassette correctly. Plasmid donor with one Cas9/sgRNA target site (1-cut donor) at the 5 ' of the insert could be integrated as a linearized donor in two orientations, so 1 out of 2 outcomes is the correct integrant for CRBR editing. 
A

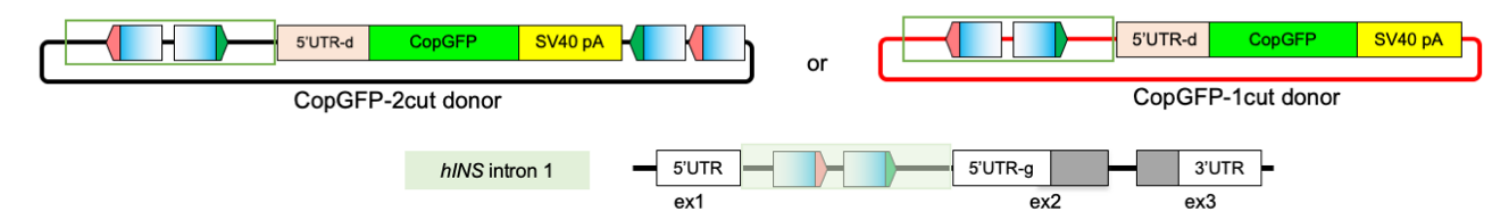

5 ' junction upstream of

pX459-hINSin1sg-Same CopGFP CDS

pX459-hINSin1sg-Reverse

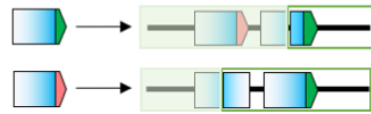

preserved but prone to re-excision

no re-excision,
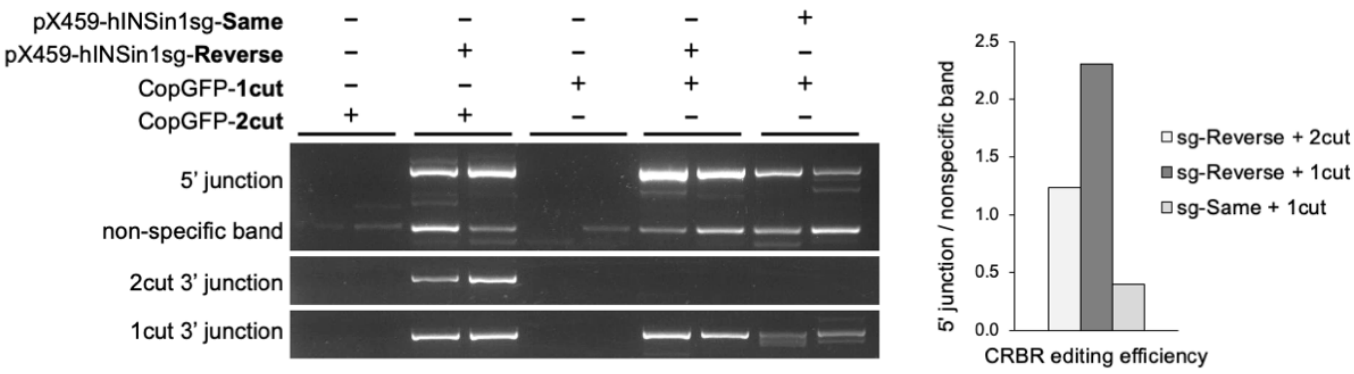

B

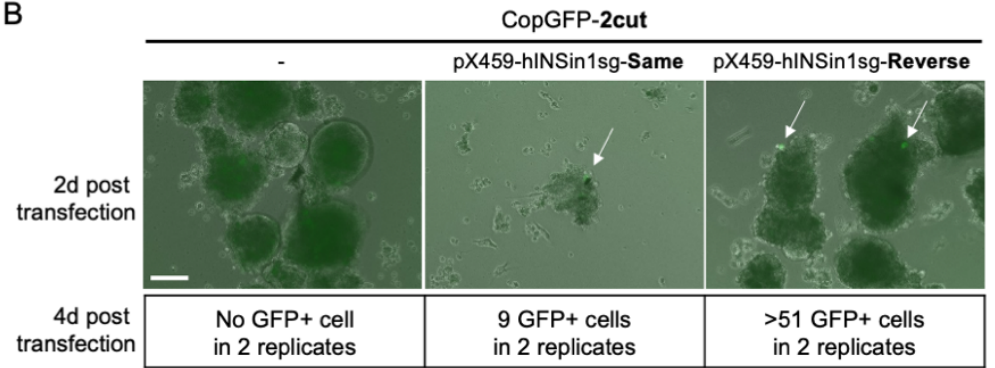

C

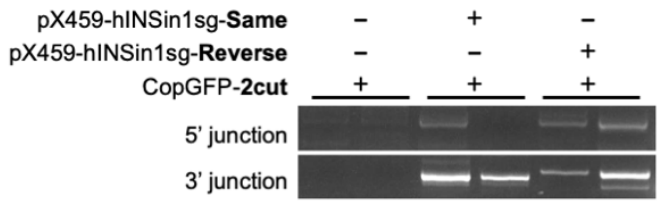

$\mathrm{D}$

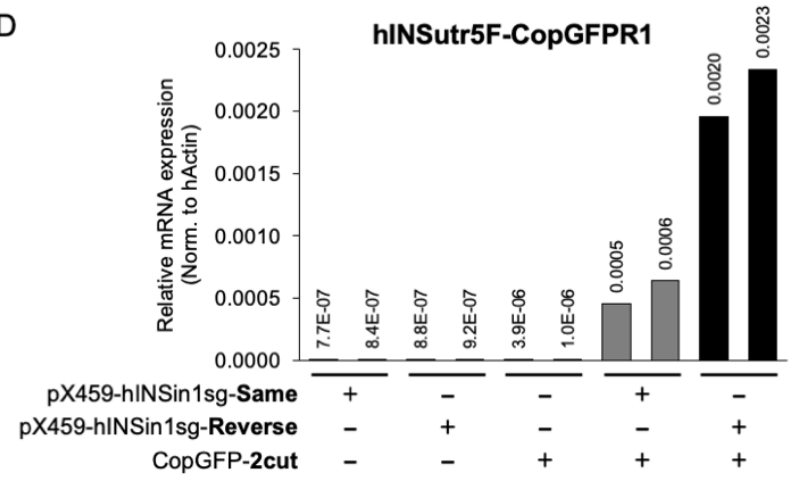

E

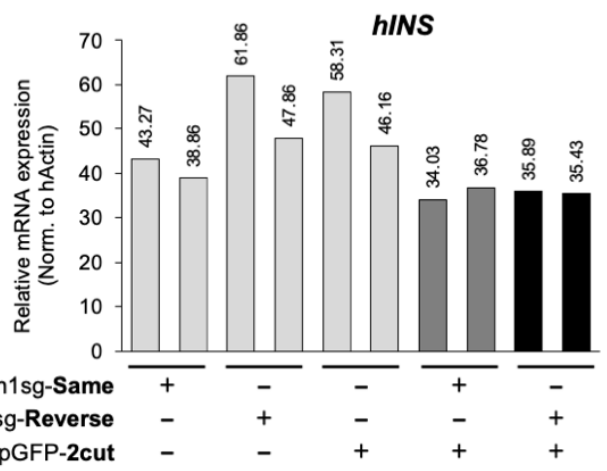

Figure S4. Reverse-orientated vs same-orientated target sites comparison; 2-cut donor vs 1cut donor comparison.

A. Two Cas9/sgRNA targeted sites in hINS intron 1 were identified, both of which have NGG on the sense strand (5' 20nt-NGG 3'). The upstream targeted site (red PAM) was engineered in the reverse orientation in the donor (termed as hINSin1sg-Reverse) and the downstream targeted site (green PAM) was engineered in the same orientation in the donor (termed as hINSin1sg-Same). This design allowed the 3 ' intron 1 downstream of the cut site to be wild-type to the genome, no matter which 
sgRNA was finally determined to be used in later study. AD293 cells were electroporated with $1 \mu \mathrm{g}$ of CopGFP-1cut donor in combination with $1 \mu \mathrm{g}$ of pX459-hINSin1sg-Same or pX459-hINSin1sgReverse; or pX459-hINSin1sg-Reverse in combination with CopGFP-2cut donor or CopGFP-1cut donor. Genomic DNA was harvested 3d post transfection for 5' junction PCR, 2cut 3' junction PCR and 1cut 3' junction PCR analysis. 5' junction PCR band intensity was calculated relative to the nonspecific band.

B-E. Human cadaveric islets (500 IEQs) were electroporated with $1 \mu \mathrm{g}$ of CopGFP-2cut donor with $1 \mu \mathrm{g}$ of pX459-hINSin1sg-Same or pX459-hINSin1sg-Reverse using 10ul Neon transfection system with two replicates. Two- or four-day post transfection, human islets were imaged (B) as live cultures at $10 \times$ objective, scale bar, $100 \mu \mathrm{m}$. White arrows, GFP positive cells. Five-day post transfection, genomic DNA (C) was harvested for 5' junction PCR and 3' junction PCR analysis. CopGFP mRNA expression levels from the CRBR-edited hINS gene (D) and hINS mRNA expression levels (E) were quantified by normalizing to hActin. Donor RRID: SAMN13254972. 


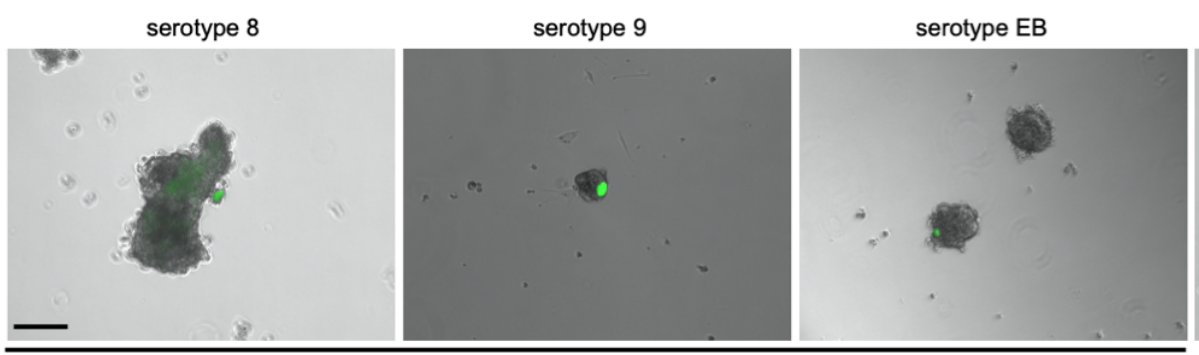

$<3$ islets have GFP+ cell

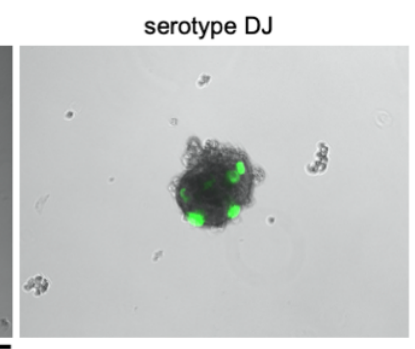

$>20$ islets have GFP+ cell

B
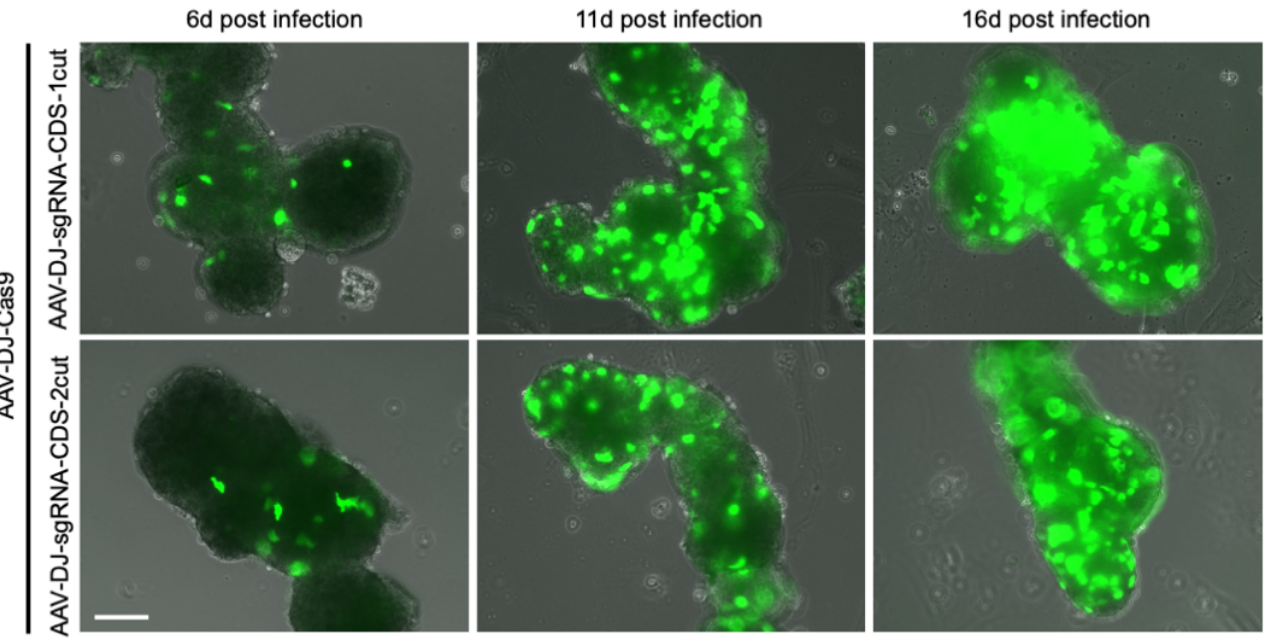

Figure S5. AAV serotype testing in human islets and long time GFP expression via CRBRmediated AAV-DJ based gene targeting and expression.

A. Human cadaveric islets (about 30 IEQs) were co-incubated with AAV-GFAP::Cre and AAVCAG::FLEx-GFP in serotype 2, 5, 6, 8, 9, EB, and DJ, MOI>60000. Human islets were imaged 6d

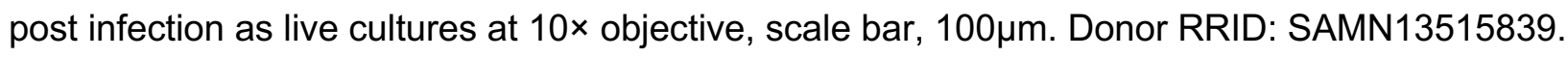

B. Human cadaveric islets (about 30 IEQs) were co-incubated with AAV-DJ-nEF-Cas9 and AAV-DJU6-hINSin1sg-CopGFP-1cut or AAV-DJ-U6-hINSin1sg-CopGFP-2cut, MOI>60000. Human islets were imaged $6 \mathrm{~d}, 11 \mathrm{~d}$, and $16 \mathrm{~d}$ post infection as live cultures at $10 \times$ objective, scale bar, $100 \mu \mathrm{m}$. Same exposure time and light intensity was applied. Donor RRID: SAMN14255441. 


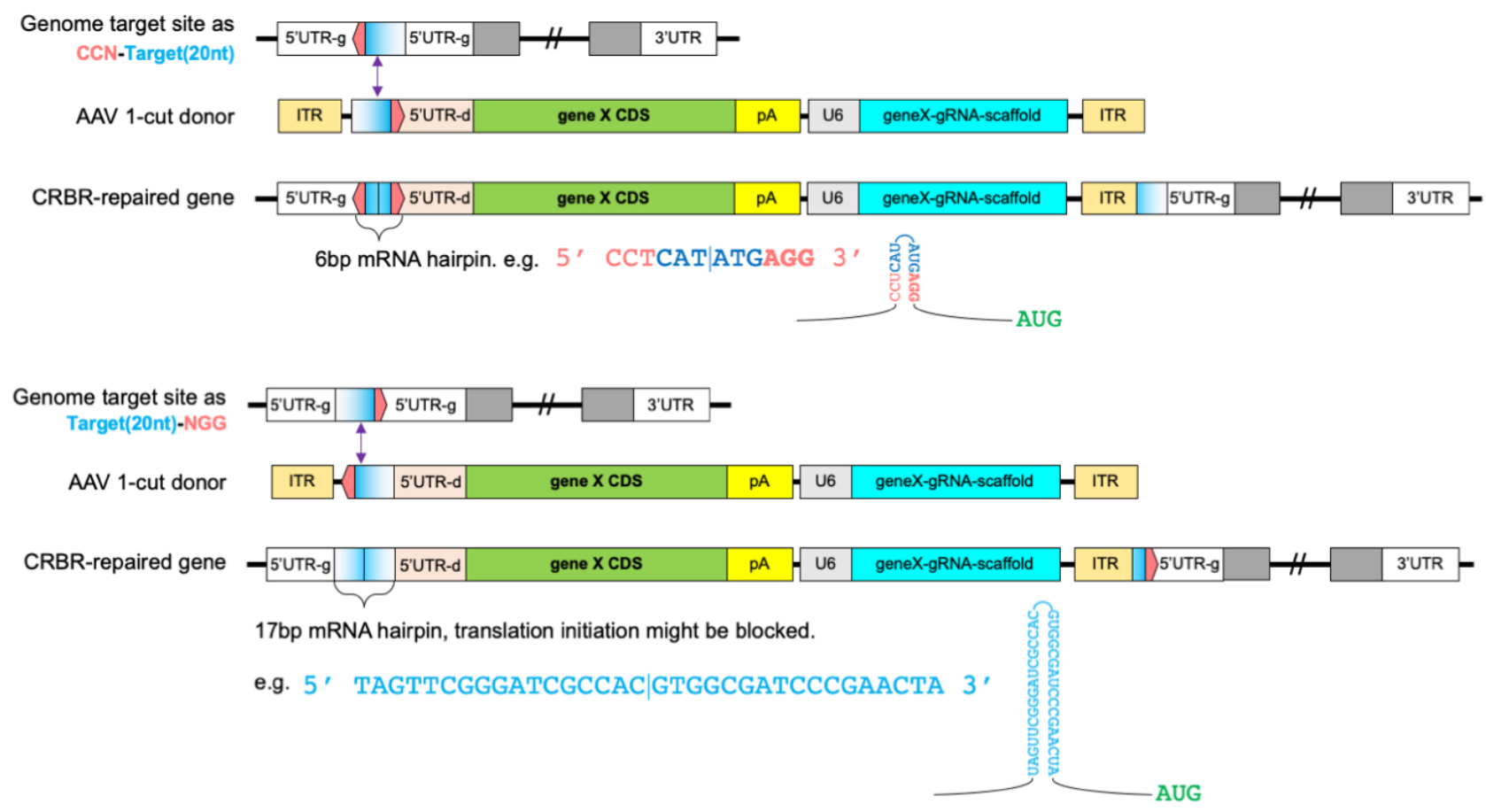

Figure S6. Two scenarios of genome target site and corresponding result genome using reverse-orientated target site in the donor.

Top scenario, when the PAM site (NGG) of the genome target site is located on the antisense strand (5' CCN-20nt 3'), the result genome will have a 6bp mRNA hairpin and probably will not block translation initiation; Bottom scenario, when the PAM site (NGG) of the genome target site is located on the sense strand (5'20nt-NGG 3'), the result genome will have a 17bp mRNA hairpin which may block the translation initiation. In a EGFP targeting human INS gene experiment (data not shown), translation of an EGFP cassette was not observe in the human islets, even though CRBR editing at both genome level and transcription level were confirmed, whereas a similar CRBR strategy was successful in EGFP targeting mouse Ins2 gene. It is believed that the $17 \mathrm{bp}$ hairpin might be blocking the translation, because the only difference between the CRBR targeting of $h I N S$ and $m / n s 2$ is that the hINS strategy generated a 17bp hairpin and mIns2 generated a $6 \mathrm{bp}$ hairpin in the mRNA transcript very close to the start codon. 
bioRxiv preprint doi: https://doi.org/10.1101/2020.12.17.423314; this version posted December 19, 2020. The copyright holder for this preprint (which was not certified by peer review) is the author/funder, who has granted bioRxiv a license to display the preprint in perpetuity. It is made available under aCC-BY-NC-ND 4.0 International license.
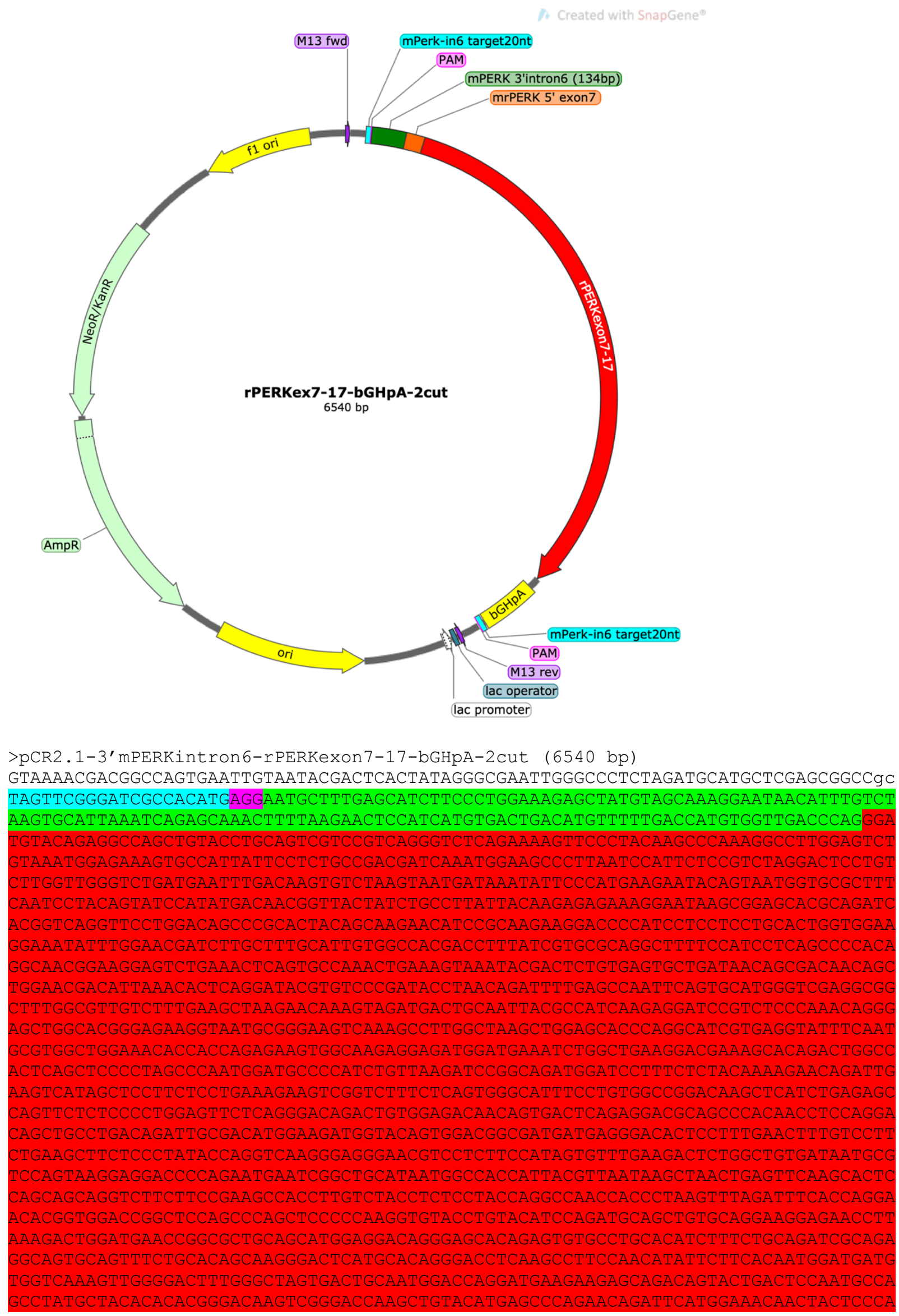

46 
bioRxiv preprint doi: https://doi.org/10.1101/2020.12.17.423314; this version posted December 19, 2020. The copyright holder for this preprint (which was not certified by peer review) is the author/funder, who has granted bioRxiv a license to display the preprint in perpetuity. It is made available under aCC-BY-NC-ND 4.0 International license.

TAAAGTGGACATCTTCTCTTTAGGCTTGATTCTGTTTGAACTCCTTTACCCATTCAGCACTCAGATGGAACGAGTTAGGA
CTTTAACTGATGTAAGAAATCTCAAGTTTCCACCACTGTTCACTCAGAAATATCCCCAAGAGCATATGATGGTTCAAGAC
ATGCTTTCTCCATCCCCCATGGAGCGGCCTGAAGCCACAGACATCATTGAAAATGCTGTGTTTGAGAACTTGGAGTTCC
TGGGAAAACGGTTCTGAGACAGCGGTCCCGCTCCTTGAGTTCATCCGGAACTAAACATTCCAGACAGCCCAGCAGCACAT
TCAGCCCACTGCCTGGCAACTAGTCTCGAGTCTAGAGGGCCCGTTAAACCCGCTGATCAGCCTCGACTGTGCCTTCTAG TTGCCAGCCATCTGTTGTTTGCCCCTCCCCCGTGCCTTCCTTGACCCTGGAAGGTGCCACTCCCACTGTCCTTTCCTAAT AAAATGAGGAAATTGCATCGCATTGTCTGAGTAGGTGTCATTCTATTCTGGGGGGTGGGGTGGGGCAGGACAGCAAGGGG GAGGATTGGGAAGACAATAGCAGGCATGCTGGGGATGCGGTGGGCTCTATGGCAATTGTAGTTCGGGATCGCCACATGAG

GTAAGCCGAATTCCAGCACACTGGCGGCCGTTACTAGTGGATCCGAGCTCGGTACCAAGCTTGGCGTAATCATGGTCATA GCTGTTTCCTGTGTGAAATTGTTATCCGCTCACAATTCCACACAACATACGAGCCGGAAGCATAAAGTGTAAAGCCTGGG GTGCCTAATGAGTGAGCTAACTCACATTAATTGCGTTGCGCTCACTGCCCGCTTTCCAGTCGGGAAACCTGTCGTGCCAG CTGCATTAATGAATCGGCCAACGCGCGGGGAGAGGCGGTTTGCGTATTGGGCGCTCTTCCGCTTCCTCGCTCACTGACTC GCTGCGCTCGGTCGTTCGGCTGCGGCGAGCGGTATCAGCTCACTCAAAGGCGGTAATACGGTTATCCACAGAATCAGGGG ATAACGCAGGAAAGAACATGTGAGCAAAAGGCCAGCAAAAGGCCAGGAACCGTAAAAAGGCCGCGTTGCTGGCGTTTTTC CATAGGCTCCGCCCCCCTGACGAGCATCACAAAAATCGACGCTCAAGTCAGAGGTGGCGAAACCCGACAGGACTATAAAG ATACCAGGCGTTTCCCCCTGGAAGCTCCCTCGTGCGCTCTCCTGTTCCGACCCTGCCGCTTACCGGATACCTGTCCGCCT TTCTCCCTTCGGGAAGCGTGGCGCTTTCTCATAGCTCACGCTGTAGGTATCTCAGTTCGGTGTAGGTCGTTCGCTCCAAG CTGGGCTGTGTGCACGAACCCCCCGTTCAGCCCGACCGCTGCGCCTTATCCGGTAACTATCGTCTTGAGTCCAACCCGGT AAGACACGACTTATCGCCACTGGCAGCAGCCACTGGTAACAGGATTAGCAGAGCGAGGTATGTAGGCGGTGCTACAGAGT TCTTGAAGTGGTGGCCTAACTACGGCTACACTAGAAGAACAGTATTTGGTATCTGCGCTCTGCTGAAGCCAGTTACCTTC GGAAAAAGAGTTGGTAGCTCTTGATCCGGCAAACAAACCACCGCTGGTAGCGGTGGTTTTTTTGTTTGCAAGCAGCAGAT TACGCGCAGAAAAAAAGGATCTCAAGAAGATCCTTTGATCTTTTCTACGGGGTCTGACGCTCAGTGGAACGAAAACTCAC GTTAAGGGATTTTGGTCATGAGATTATCAAAAAGGATCTTCACCTAGATCCTTTTAAATTAAAAATGAAGTTTTAAATCA ATCTAAAGTATATATGAGTAAACTTGGTCTGACAGTTACCAATGCTTAATCAGTGAGGCACCTATCTCAGCGATCTGTCT ATTTCGTTCATCCATAGTTGCCTGACTCCCCGTCGTGTAGATAACTACGATACGGGAGGGCTTACCATCTGGCCCCAGTG CTGCAATGATACCGCGAGACCCACGCTCACCGGCTCCAGATTTATCAGCAATAAACCAGCCAGCCGGAAGGGCCGAGCGC AGAAGTGGTCCTGCAACTTTATCCGCCTCCATCCAGTCTATTAATTGTTGCCGGGAAGCTAGAGTAAGTAGTTCGCCAGT TAATAGTTTGCGCAACGTTGTTGCCATTGCTACAGGCATCGTGGTGTCACGCTCGTCGTTTGGTATGGCTTCATTCAGCT CCGGTTCCCAACGATCAAGGCGAGTTACATGATCCCCCATGTTGTGCAAAAAAGCGGTTAGCTCCTTCGGTCCTCCGATC GTTGTCAGAAGTAAGTTGGCCGCAGTGTTATCACTCATGGTTATGGCAGCACTGCATAATTCTCTTACTGTCATGCCATC CGTAAGATGCTTTTCTGTGACTGGTGAGTACTCAACCAAGTCATTCTGAGAATAGTGTATGCGGCGACCGAGTTGCTCTT GCCCGGCGTCAATACGGGATAATACCGCGCCACATAGCAGAACTTTAAAAGTGCTCATCATTGGAAAACGTTCTTCGGGG CGAAAACTCTCAAGGATCTTACCGCTGTTGAGATCCAGTTCGATGTAACCCACTCGTGCACCCAACTGATCTTCAGCATC TTTTACTTTCACCAGCGTTTCTGGGTGAGCAAAAACAGGAAGGCAAAATGCCGCAAAAAAGGGAATAAGGGCGACACGGA AATGTTGAATACTCATACTCTTCCTTTTTCAATTCAGAAGAACTCGTCAAGAAGGCGATAGAAGGCGATGCGCTGCGAAT CGGGAGCGGCGATACCGTAAAGCACGAGGAAGCGGTCAGCCCATTCGCCGCCAAGCTCTTCAGCAATATCACGGGTAGCC AACGCTATGTCCTGATAGCGGTCCGCCACACCCAGCCGGCCACAGTCGATGAATCCAGAAAAGCGGCCATTTTCCACCAT GATATTCGGCAAGCAGGCATCGCCATGGGTCACGACGAGATCCTCGCCGTCGGGCATGCGCGCCTTGAGCCTGGCGAACA GTTCGGCTGGCGCGAGCCCCTGATGCTCTTCGTCCAGATCATCCTGATCGACAAGACCGGCTTCCATCCGAGTACGTGCT CGCTCGATGCGATGTTTCGCTTGGTGGTCGAATGGGCAGGTAGCCGGATCAAGCGTATGCAGCCGCCGCATTGCATCAGC CATGATGGATACTTTCTCGGCAGGAGCAAGGTGGGATGACAGGAGATCCTGCCCCGGCACTTCGCCCAATAGCAGCCAGT CCCTTCCCGCTTCAGTGACAACGTCGAGCACAGCTGCGCAAGGAACGCCCGTCGTGGCCAGCCACGATAGCCGCGCTGCC TCGTCCTGCAGTTCATTCAGGGCACCGGACAGGTCGGTCTTGACAAAAAGAACCGGGCGCCCCTGCGCTGACAGCCGGAA CACGGCGGCATCAGAGCAGCCGATTGTCTGTTGTGCCCAGTCATAGCCGAATAGCCTCTCCACCCAAGCGGCCGGAGAAC CTGCGTGCAATCCATCTTGTTCAATCATGCGAAACGATCCTCATCCTGTCTCTTGATCAGATCTTGATCCCCTGCGCCAT CAGATCCTTGGCGGCAAGAAAGCCATCCAGTTTACTTTGCAGGGCTTCCCAACCTTACCAGAGGGCGCCCCAGCTGGCAA TTCCGGTTCGCTTGCTGTCCATAAAACCGCCCAGTCTAGCTATCGCCATGTAAGCCCACTGCAAGCTACCTGCTTTCTCT TTGCGCTTGCGTTTTCCCTTGTCCAGATAGCCCAGTAGCTGACATTCATCCGGGGTCAGCACCGTTTCTGCGGACTGGCT TTCTACGTGTTCCGCTTCCTTTAGCAGCCCTTGCGCCCTGAATTTTGTTAAAATTCGCGTTAAATTTTGTTAAATCAGC TCATTTTTAACCAATAGGCCGAAATCGGCAAAATCCCTTATAAATCAAAAGAATAGACCGAGATAGGGTTGAGTGTTGT TCCAGTTTGGAACAAGAGTCCACTATTAAAGAACGTGGACTCCAACGTCAAAGGGCGAAAAACCGTCTATCAGGGCGATG GCCCACTACGTGAACCATCACCCTAATCAAGTTTTTTGGGGTCGAGGTGCCGTAAAGCACTAAATCGGAACCCTAAAGGG AGCCCCCGATTTAGAGCTTGACGGGGAAAGCCGGCGAACGTGGCGAGAAAGGAAGGGAAGAAAGCGAAAGGAGCGGGCGC TAGGGCGCTGGCAAGTGTAGCGGTCACGCTGCGCGTAACCACCACACCCGCCGCGCTTAATGCGCCGCTACAGGGCGCGT CCATTCGCCATTCAGGCTGCGCAACTGTTGGGAAGGGCGATCGGTGCGGGCCTCTTCGCTATTACGCCAGCTGGCGAAAG GGGGATGTGCTGCAAGGCGATTAAGTTGGGTAACGCCAGGGTTTTCCCAGTCACGACGTT

Figure S7. Map and nucleotide sequence of the rPERKex7-17-2cut plasmid.

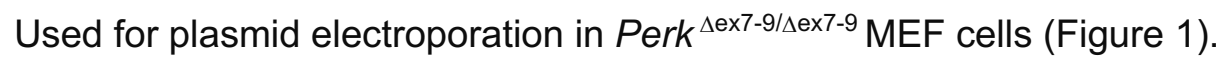


bioRxiv preprint doi: https://doi.org/10.1101/2020.12.17.423314; this version posted December 19, 2020. The copyright holder for this preprint (which was not certified by peer review) is the author/funder, who has granted bioRxiv a license to display the preprint in perpetuity. It is made available under aCC-BY-NC-ND 4.0 International license.

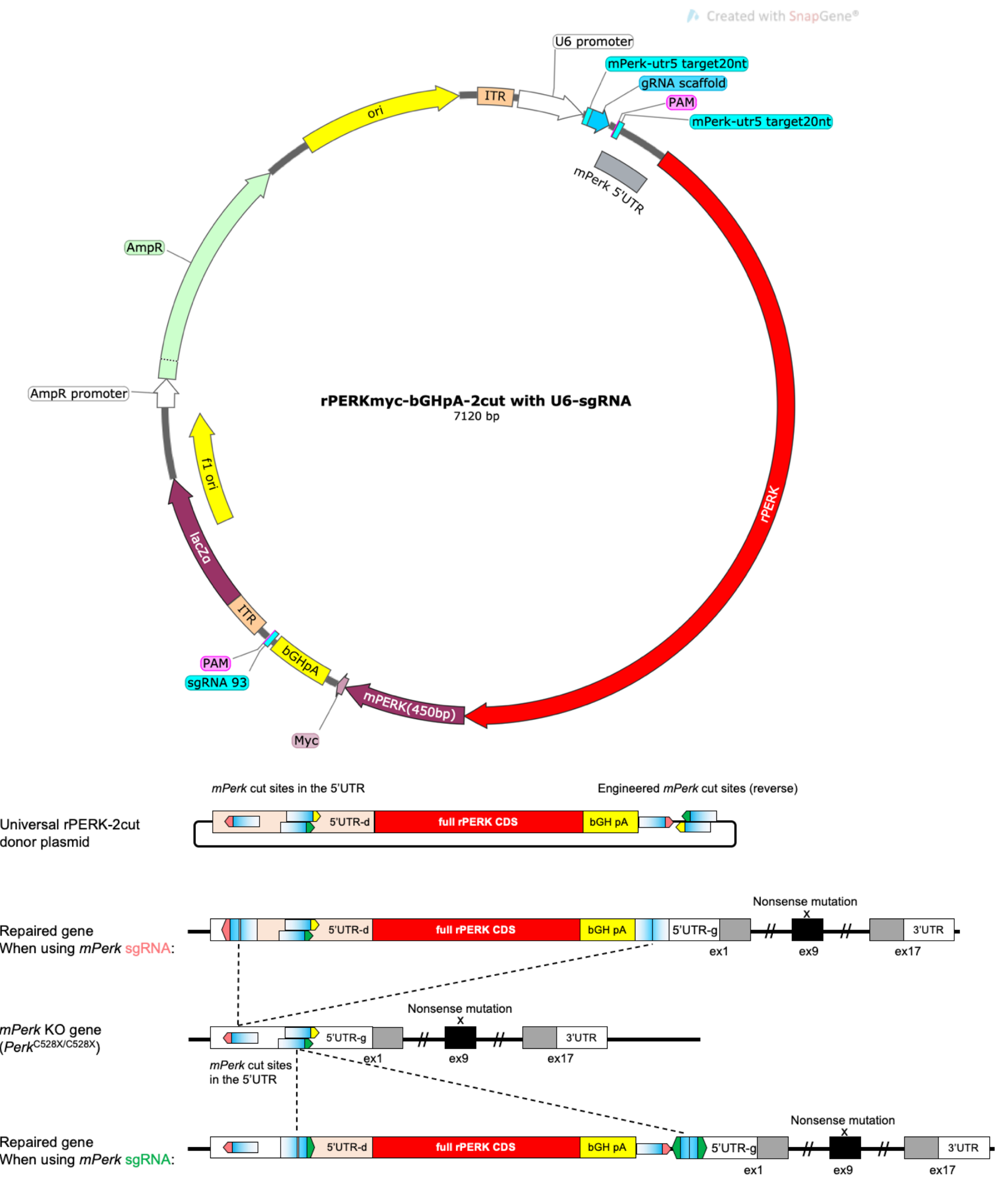


bioRxiv preprint doi: https://doi.org/10.1101/2020.12.17.423314; this version posted December 19, 2020. The copyright holder for this preprint (which was not certified by peer review) is the author/funder, who has granted bioRxiv a license to display the preprint in perpetuity. It is made available under aCC-BY-NC-ND 4.0 International license.

\begin{abstract}
AAAGGACGAAACACCGAGACATCGCCCATTGAGCGAGTTTTAGAGCTAGAAATAGCAAGTTAAAATAAGGCTAGTCCGTTATCAACTTGAAAAAGTGGCACCGAGTCGGTGCTTTTTTTGCTAGCACGCG

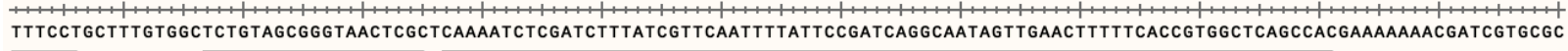
$\overrightarrow{\text { U6 promoter }}$

mPerk-utr5 target20nt

TCGGAACCCTCGCTCAATGGGCGATGTCTGCACAAGGCTGTCACTCAGGTGGCAGTGGCTGAGACGTGGCCGGGAGCTCTGCTGCTGCGGCGCGAGTCGAGAGGCGGGGGGTCCGTGGCGCGCGCTC AGCCTTGGAGCGAGTACCCGCTACAGACGTGTTCCGACAGTGAGTCCACCGTCACCGACTCTGCACCGGCCCGTCGAGACGACGACGCCGCGCTTCAGCTCTCCGCCGCCCCAGGCACCGCGCGCGAG mPerk 5'UTR

PAM mPerk-utr5 target20nt

\author{
mPerk-utr5 target20nt 2 \\ PAM
}

mPerk-utr5 target20nt 3
\end{abstract}

GCAGTGCTCCGAGGCTCCGAGCGGCGAGACGGGCGGGCGCCGACGGCAGGGTCTCCATGCCCGCGCGTGGGGCGGCCGCTGATGGAGCGCGCCACCCAGCCCCGACCGCGCGCGCTGCTGCTGCTGTTC CGTCACGAGGTCCGAGGCTCGCCGCTCTGCCCGCCCGCGGCTGCCGTCCCAGAGGTACGGGCGGCACCCCGCCCGGCGACTACCTCGCGCGGTGGTCGGGGTGGCGCGGCGACGACGACGACAAG

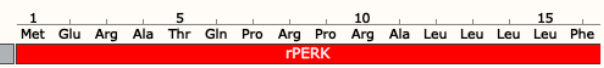

CGGCCTGAAGCCACAGACATCATTGAAAATGCCATATTTGAGAACTTGGAGTTTCCCGGGAAAACGGTTCTGAGACAGCGGTCCCGCTCCATGAGTTCATCTGGAACAAAACATTCCAGACAGCCCAGCT GCCGGACTTCGGTGTCTGTAGTAACTTTTACGGTATAAACTCTTGAACCTCAAAGGCCCTTTTGCCAAGACTCTGTCGCCAGGGCGAGTACTCAAGTAGACCTTGTTTTGTAAGGTCTGTCGGGTCGA

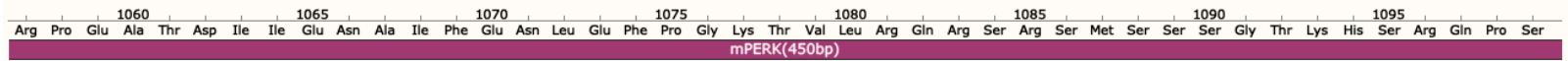

GCTCGTACACGCCACTGCCTGGCGAGCAGAAGCTGATCTCTGAGGAGGATCTGTGACTCGAGTCTAGAGGGCCCGTTTAAACCCGCTGATCAGCCTCGACTGTGCCTTCTAGTTGCCAGCCATCTGTTGT

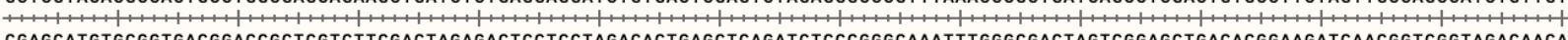
CGAGCATGTGCGGTGACGGACCGCTCGTCTTCGACTAGAGACTCCTCCTAGACACTGAGCTCAGATCTCCCGGGCAAATTGGGCGACTAGTCGGAGCTGACACGGAAGATCAACGGTCGGTAGACAACA 100
Cys Ser Tyr Thr Pro Leu Pro Gly Glu Gin Lys Leu 5 Tle Ser Glu Glu Asp Leu
MycerK(450bp)

BGHPA

TTGCCCCTCCCCCGTGCCTTCCTTGACCCTGGAAGGTGCCACTCCCACTGTCCTTTCCTAATAAAATGAGGAAATTGCATCGCATTGTCTGAGTAGGTGTCATTCTATTCTGGGGGTGGGTGGGGCAG

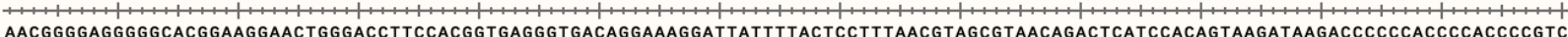
\begin{tabular}{l} 
AACGGGGAGGGGGCACGGAAGGAACTGGGACCTTCCACGGTGAGGGTGACAGGAAAGGATTATTTTACTCCTTTAACGTAGCGTAACAGACTCATCCACAGTAAGATAAGACCCCCCACCCCACCCCGTC \\
\hline
\end{tabular}

GACAGCAAGGGGGGGATTGGGAAGACAATAGCAGGCATGCTGGGGATGCGGTGGGCTCTATGGCACGTGCGGACCGAGACATCGCCCATTGAGCGAGGGCGCCTCTCGACTTCGCGCCGCAGCAGAAT CTGTCGTTCCCCCT, \begin{tabular}{c} 
CTGTCGTTCCCCCTCCTAACCCTTCTGTTATCGTCCGTACGACCCCTACGCCACCCGAGATACCGTGCACGCCTGGCTCTGTAGCGGGTAACTCGCTCCCGGCGGAGAGCTGAAGCGCGGCGTCGT \\
\hline BGHPA \\
\hline
\end{tabular} PAM

PAM

>pBluescriptII-KS (+) -AAV-U6-mPERKutr5sg-mPERK5' UTR-rPERKmyc-bGHpA-2cut (7120 bp) GATATCCCTGCAGGCAGCTGCGCGCTCGCTCGCTCACTGAGGCCGCCCGGGCGTCGGGCGACCTTTGGTCGCCCGGCCTC AGTGAGCGAGCGAGCGCGCAGAGAGGGAGTGGCCAACTCCATCACTAGGGGTTCCTGCGGCCGCACGCGTCAATTGGAGG GCCTATTTCCCATGATTCCTTCATATTTGCATATACGATACAAGGCTGTTAGAGAGATAATTGGAATTAATTTGACTGTA AACACAAAGATATTAGTACAAAATACGTGACGTAGAAAGTAATAATTTCTTGGGTAGTTTGCAGTTTTAAAATTATGTTT TAAAATGGACTATCATATGCTTACCGTAACTTGAAAGTATTTCGATTTCTTGGCTTTATATATCTTGTGGAAAGGACGAA ACACCGAGACATCGCCCATTGAGCGAGTTTTAGAGCTAGAAATAGCAAGTTAAAATAAGGCTAGTCCGTTATCAACTTGA AAAAGTGGCACCGAGTCGGTGCTTTTTTTGCTAGCACGCGTCGGAACCCTCGCTCAATGGGCGATGTCTGCACAAGGCTG TCACTCAGGTGGCAGTGGCTGAGACGTGGCCGGGCAGCTCTGCTGCTGCGGCGCGAAGTCGAGAGGCGGCGGGGTCCGTG GCGCGCGCTCGCAGTGCTCCGAGGCTCCGAGCGGCGAGACGGGCGGGCGCCGACGGCAGGGTCTCCATGCCCGCGCGTGG GGCGGGCCGCTG

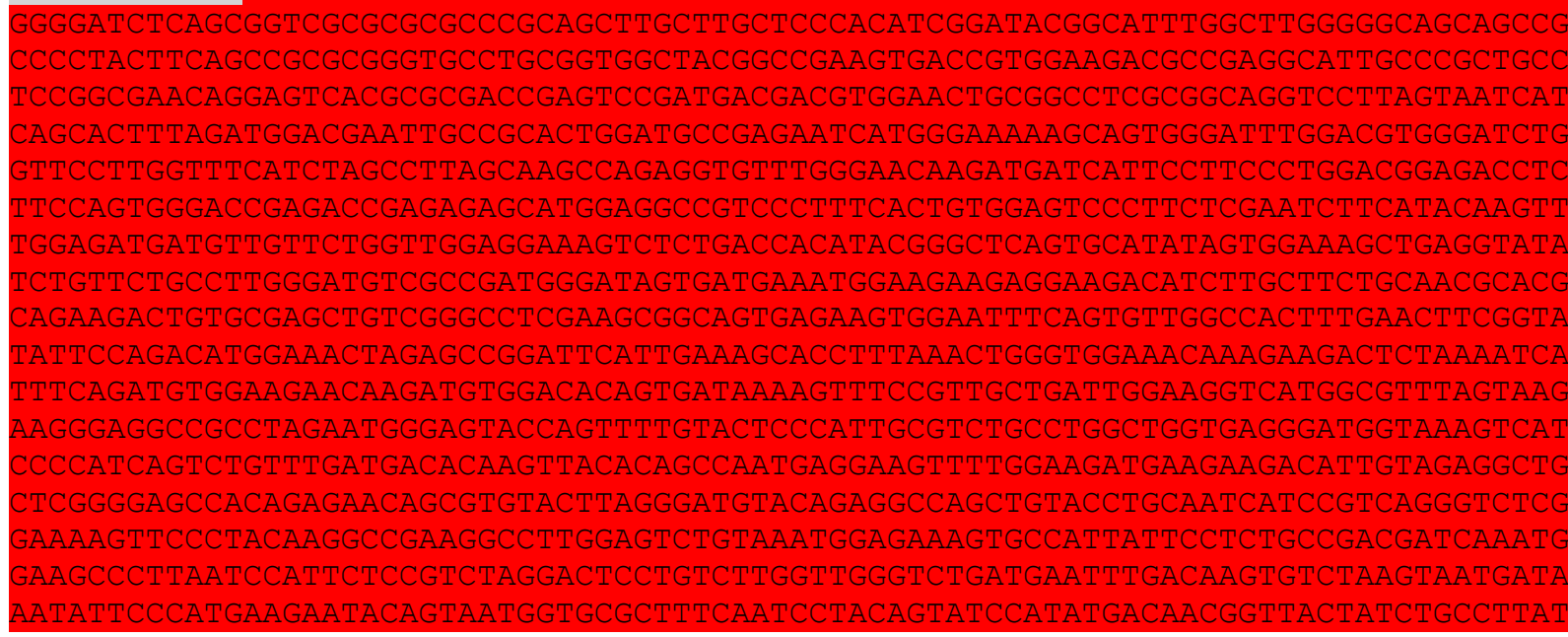


bioRxiv preprint doi: https://doi.org/10.1101/2020.12.17.423314; this version posted December 19, 2020. The copyright holder for this preprint (which was not certified by peer review) is the author/funder, who has granted bioRxiv a license to display the preprint in perpetuity. It is made available under aCC-BY-NC-ND 4.0 International license.

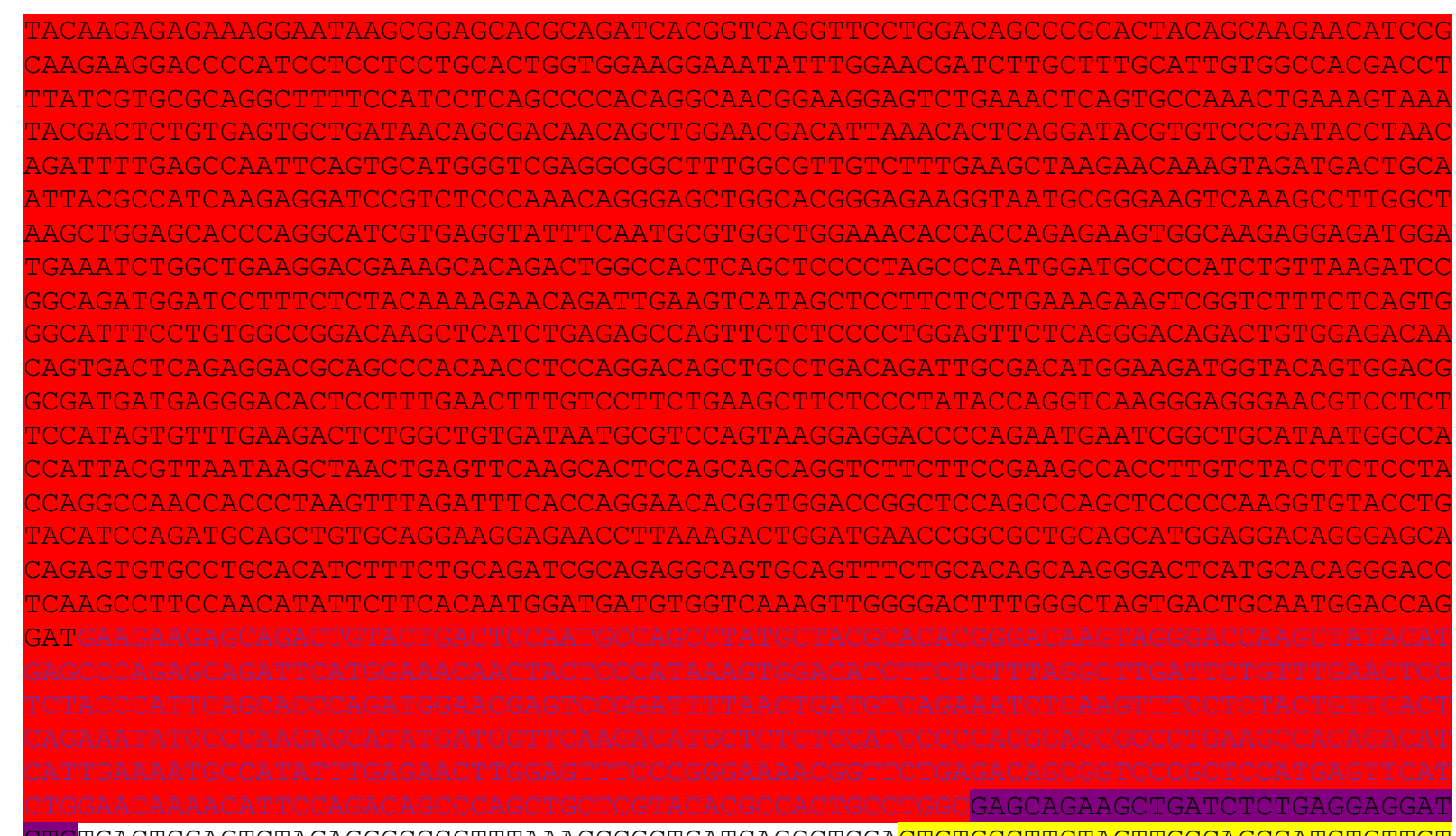

TGACTCGAGTCTAGAGGGCCCGTTTAAACCCGCTGATCAGCCTCGACTGTGCCTTCTAGTTGCCAGCCATCTGTTGT TTGCCCCTCCCCCGTGCCTTCCTTGACCCTGGAAGGTGCCACTCCCACTGTCCTTTCCTAATAAAATGAGGAAATTGCAT CGCATTGTCTGAGTAGGTGTCATTCTATTCTGGGGGGTGGGGTGGGGCAGGACAGCAAGGGGGAGGATTGGGAAGACAAT AGCAGGCATGCTGGGGATGCGGTGGGCTCTATGGCACGTGCGGACCGAGACATCGCCCATTGAGCGAGGGCCGCCTCTCG ACTTCGCGCCGCAGCAGAATTCAGCGGCCGCAGGAACCCCTAGTGATGGAGTTGGCCACTCCСTCTCTGCGCGCTCGCTC GCTCACTGAGGCCGGGCGACCAAAGGTCGCCCGACGCCCGGGCTTTGCCCGGGCGGCCTCAGTGAGCGAGCGAGCGCGCA GCTGCCTGCAGGGTCGACGGTATCGATAAGCTTGATATCGAATTCCTGCAGCCCGGGGGATCCACTAGTTCTAGAGCGGC CGCCACCGCGGTGGAGCTCCAATTCGCCCTATAGTGAGTCGTATTACGCGCGCTCACTGGCCGTCGTTTTACAACGTCGT GACTGGGAAAACCCTGGCGTTACCCAACTTAATCGCCTTGCAGCACATCCCCCTTTCGCCAGCTGGCGTAATAGCGAAGA GGCCCGCACCGATCGCCCTTCCCAACAGTTGCGCAGCCTGAATGGCGAATGGGACGCGCCCTGTAGCGGCGCATTAAGCG CGGCGGGTGTGGTGGTTACGCGCAGCGTGACCGCTACACTTGCCAGCGCCCTAGCGCCCGCTCCTTTCGCTTTCTTCCCT TCCTTTCTCGCCACGTTCGCCGGCTTTCCCCGTCAAGCTCTAAATCGGGGGCTCCCTTTAGGGTTCCGATTTAGTGCTTT ACGGCACCTCGACCCCAAAAAACTTGATTAGGGTGATGGTTCACGTAGTGGGCCATCGCCCTGATAGACGGTTTTTCGCC CTTTGACGTTGGAGTCCACGTTCTTTAATAGTGGACTCTTGTTCCAAACTGGAACAACACTCAACCCTATCTCGGTCTAT TCTTTTGATTATAAGGGATTTTGCCGATTTCGGCCTATTGGTTAAAAAATGAGCTGATTTAACAAAAATTTAACGCGAA TTTTAACAAAATATTAACGCTTACAATTTAGGTGGCACTTTTCGGGGAAATGTGCGCGGAACCCCTATTTGTTTATTTTT CTAAATACATTCAAATATGTATCCGCTCATGAGACAATAACCCTGATAAATGCTTCAATAATATTGAAAAAGGAAGAGTA TGAGTATTCAACATTTCCGTGTCGCCCTTATTCCCTTTTTTGCGGCATTTTGCCTTCCTGTTTTTGCTCACCCAGAAACG CTGGTGAAAGTAAAAGATGCTGAAGATCAGTTGGGTGCACGAGTGGGTTACATCGAACTGGATCTCAACAGCGGTAAGAT CCTTGAGAGTTTTCGCCCCGAAGAACGTTTTCCAATGATGAGCACTTTTAAAGTTCTGCTATGTGGCGCGGTATTATCCC GTATTGACGCCGGGCAAGAGCAACTCGGTCGCCGCATACACTATTCTCAGAATGACTTGGTTGAGTACTCACCAGTCACA GAAAAGCATCTTACGGATGGCATGACAGTAAGAGAATTATGCAGTGCTGCCATAACCATGAGTGATAACACTGCGGCCAA СTTACTTCTGACAACGATCGGAGGACCGAAGGAGCTAACCGCTTTTTTGCACAACATGGGGGATCATGTAACTCGCCTTG ATCGTTGGGAACCGGAGCTGAATGAAGCCATACCAAACGACGAGCGTGACACCACGATGCCTGTAGCAATGGCAACAACG TTGCGCAAACTATTAACTGGCGAACTACTTACTCTAGCTTCCCGGCAACAATTAATAGACTGGATGGAGGCGGATAAAGT TGCAGGACCACTTCTGCGCTCGGCCCTTCCGGCTGGCTGGTTTATTGCTGATAAATCTGGAGCCGGTGAGCGTGGGTCTC GCGGTATCATTGCAGCACTGGGGCCAGATGGTAAGCCCTCCCGTATCGTAGTTATCTACACGACGGGGAGTCAGGCAACT ATGGATGAACGAAATAGACAGATCGCTGAGATAGGTGCCTCACTGATTAAGCATTGGTAACTGTCAGACCAAGTTTACTC ATATATACTTTAGATTGATTTAAAACTTCATTTTTAATTTAAAAGGATCTAGGTGAAGATCCTTTTTGATAATCTCATGA CCAAAATCCCTTAACGTGAGTTTTCGTTCCACTGAGCGTCAGACCCCGTAGAAAAGATCAAAGGATCTTCTTGAGATCCT TTTTTTCTGCGCGTAATCTGCTGCTTGCAAACAAAAAAACCACCGCTACCAGCGGTGGTTTGTTTGCCGGATCAAGAGCT ACCAACTCTTTTTCCGAAGGTAACTGGCTTCAGCAGAGCGCAGATACCAAATACTGTCCTTCTAGTGTAGCCGTAGTTAG GCCACCACTTCAAGAACTCTGTAGCACCGCCTACATACCTCGCTCTGCTAATCCTGTTACCAGTGGCTGCTGCCAGTGGC GATAAGTCGTGTCTTACCGGGTTGGACTCAAGACGATAGTTACCGGATAAGGCGCAGCGGTCGGGCTGAACGGGGGGTTC GTGCACACAGCCCAGCTTGGAGCGAACGACCTACACCGAACTGAGATACCTACAGCGTGAGCTATGAGAAAGCGCCACGC TTCCCGAAGGGAGAAAGGCGGACAGGTATCCGGTAAGCGGCAGGGTCGGAACAGGAGAGCGCACGAGGGAGCTTCCAGGG GGAAACGCCTGGTATCTTTATAGTCCTGTCGGGTTTCGCCACCTCTGACTTGAGCGTCGATTTTTGTGATGCTCGTCAGG GGGGCGGAGCCTATGGAAAAACGCCAGCAACGCGGCCTTTTTACGGTTCCTGGCCTTTTGCTGGCCTTTTGCTCACATGT 


\section{Figure S8. Map and nucleotide sequence of the rPERKmyc-2cut plasmid with U6- mPERKutr5sg.}

Used for plasmid electroporation in Perk ${ }^{\mathrm{C528X/C528X}}$ MEF cell (Figure 2) and microinjection to generate rPERK-CRBR transgenic mice (Figure 3).

Schematic of universal CRBR 2-cut donor design, using Perk ${ }^{\mathrm{C528X} / \mathrm{C528X}}$ genome editing as an example. Multiple Cas9/gRNA target sites can be tested for optimal 5' junction at the 5'UTR region, because context sequence around the 5 ' junction region could favor certain unexpected indels that may introduce unexpected new "ATG" in the 5'UTR region. The universal donor plasmid provides a rPERK-bGHpA cassette that is flanked by a wild-type 5'UTR of mPerk and three Cas9/gRNA target sites engineered together in reverse orientation as identified within the mPerk 5'UTR. It is a universal design to test out three different sgRNAs using one donor to compare the efficiency of CRBR editing at genome level and validate the transcription and translation from the repair cassette of the CRBRedited allele.

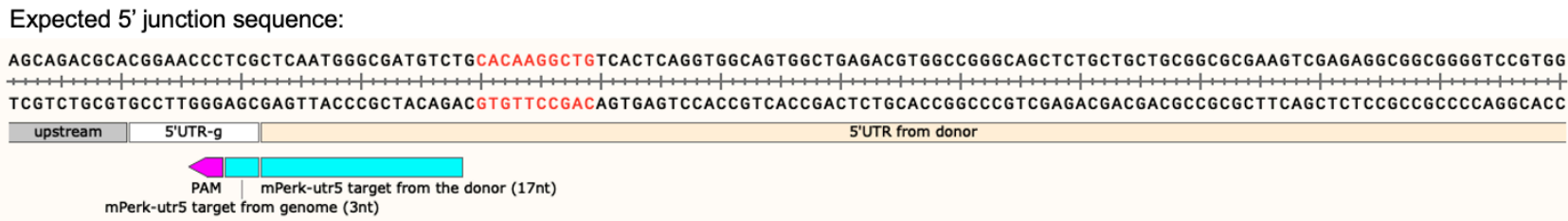
CGCGCGCTCGCAGTGCTCCGAGGCTCCGAGCGGCGAGACGGGGGGCGCCGACGGCAGGGTCTCCATGCCCGCGCGTGGGGCGGCCGCTGATGGAGCGCGCCACCCGGCCCGGGCGCGCGCGCTGCTG GCGCGCGAGCGTCACGAGGCTCCGAGGCTCGCCGCTCTGCCCGCCCGCGGTGCCGTCCCAGAGGTACGGGCGCGACCCCGCCCGGCGACTACCTCGCGCGGTGGCCGGGCCCGGCGCGCGCGACGAC 5'UTR from donor

4bp deletion $(-1$ to +3$)$ and $10 \mathrm{bp}$ repeat/insertion at $(+18)$ at the 5 ' junction of rPERK-CRBR allele in the transgenic mouse model:

AGCAGACGCACGGAACCCTCAATGGGCGATGTCTGCACAAGGCTGCACAAGGCTGTCACTCAGGTGGCAGTGGCTGAGACGTGGCCGGGCAGCTCTGCTGCTGCGGCGCGAAGTCGAGAGGCGGCGGGGT TCGTCTGCGTGCCTTGgGaTTACCCGCTACAGAC GTTTCCGACGTGTTCCGACAGTGAGTCCACCGTCACCGACTCTGCACCGGCCCGTCGAGACGACGACGCCGCGCTTCAGCTCTCCGCCGCCCCA \begin{tabular}{c|c||c|c|}
\hline upstream & 5'UTR-g & \\
\hline
\end{tabular}

5'UTR from donor

mPerk-utr5 target from genome (2nt)

CCGTGGCGCGCGCTCGCAGTGCTCCGAGGCTCCGAGCGGCGAGACGGGCGGGCGCCGACGGCAGGGTCTCCATGCCCGCGCGTGGGGCGGGCCGCTGATGGAGCGCGCCACCCAGCCCCGACCGCGCGCG GGCACCGCGCGCGAGCGTCACGAGGTTCGAGGCTCGCCGCTCTGCCCGCCCGCGGCTGCCGTCCCAGAGGTACGGGCGCGCACCCCGCCCGGCGACTACCTCGCGCGGTGGGTCGGGGCTGGCGCGCGC 5'UTR from donor $\frac{1}{\text { Met Glu Arg Ala Thr Glin Pro Arg Pro Arg Ala }}$

Figure S9. The 5' junction sequence analysis of rPERK-CRBR allele.

The 5' junction sequence of CRBR editing, expected vs rPERK-CRBR allele. Sequencing of 5' junction PCR showed $4 \mathrm{bp}$ deletion occurred at the joint site and a $10 \mathrm{bp}$ repeat sequence was inserted $18 \mathrm{bp}$ downstream of the joint site in the rPERK-CRBR allele from the transgenic mice. 
bioRxiv preprint doi: https://doi.org/10.1101/2020.12 17.423314; this version posted December 19, 2020. The copyright holder for this preprint (which was not certified by peer review) is the author/funder, who has granted bioRxiv a license to display the preprint in perpetuity. It is made available under aCC-BY-NC-ND 4.0 International license.

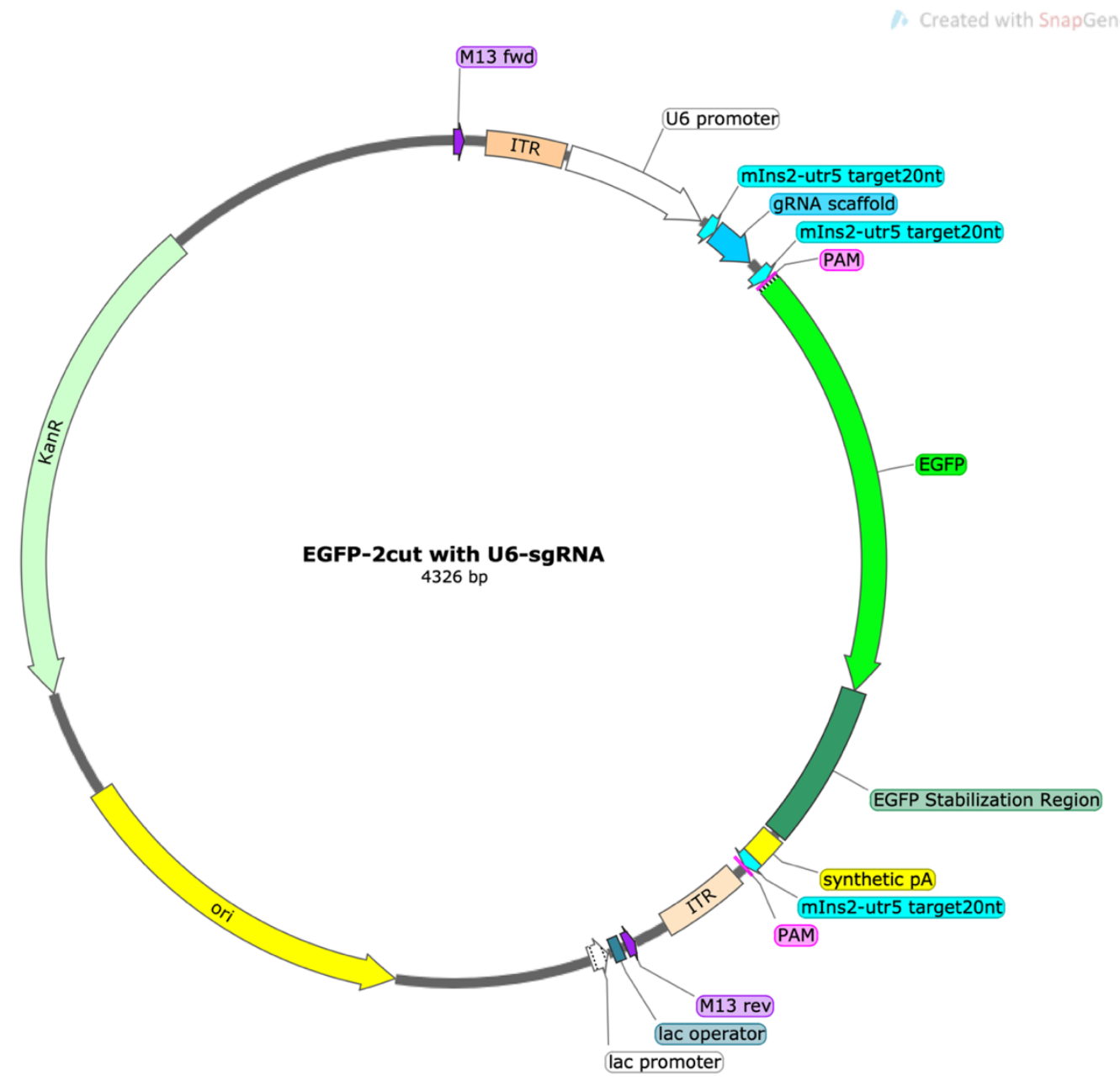

>pUC57-Kan-AAV-U6-mIns2utr5sg-EGFP-pA-2cut (4326 bp)

GTAAAACGACGGCCAGTGAATTGAGCTCGGTACCTCGCGAATGCATCTAGATCCTGCAGGCAGCTGCGCGCTCGCTCGC TCACTGAGGCCGCCCGGGCGTCGGGCGACCTTTGGTCGCCCGGCCTCAGTGAGCGAGCGAGCGCGCAGAGAGGGAGTGGC CAACTCCATCACTAGGGGTTCCTGCGGCCGCGAGGGCCTATTTCCCATGATTCCTTCATATTTGCATATACGATACAAGG CTGTTAGAGAGATAATTGGAATTAATTTGACTGTAAACACAAAGATATTAGTACAAAATACGTGACGTAGAAAGTAATAA TTTCTTGGGTAGTTTGCAGTTTTAAAATTATGTTTTAAAATGGACTATCATATGCTTACCGTAACTTGAAAGTATTTCGA TTTCTTGGCTTTATATATCTTGTGGAAAGGACGAAACACCGTGTAGCGGATCACTTAGGGCGTTTTAGAGCTAGAAATAG CAAGTTAAAATAAGGCTAGTCCGTTATCAACTTGAAAAAGTGGCACCGAGTCGGTGCTTTTTTTCCATGGGCTAGCTGTA GCGGATCACTTAGGGCTGGATGGTGAGCAAGGGCGAGGAGCTGTTCACCGGGGTGGTGCCCATCCTGGTCGAGCTGGACG GCGACGTAAACGGCCACAAGTTCAGCGTGTCCGGCGAGGGCGAGGGCGATGCCACCTACGGCAAGCTGACCCTGAAGTTC ATCTGCACCACCGGCAAGCTGCCCGTGCCCTGGCCCACCCTCGTGACCACCCTGACCTACGGCGTGCAGTGCTTCAGCCG CTACCCCGACCACATGAAGCAGCACGACTTCTTCAAGTCCGCCATGCCCGAAGGCTACGTCCAGGAGCGCACCATCTTCT TCAAGGACGACGGCAACTACAAGACCCGCGCCGAGGTGAAGTTCGAGGGCGACACCCTGGTGAACCGCATCGAGCTGAAG GGCATCGACTTCAAGGAGGACGGCAACATCCTGGGGCACAAGCTGGAGTACAACTACAACAGCCACAACGTCTATATCAT GGCCGACAAGCAGAAGAACGGCATCAAGGTGAACTTCAAGATCCGCCACAACATCGAGGACGGCAGCGTGCAGCTCGCCG ACCACTACCAGCAGAACACCCCCATCGGCGACGGCCCCGTGCTGCTGCCCGACAACCACTACCTGAGCACCCAGTCCGCC CTGAGCAAAGACCCCAACGAGAAGCGCGATCACATGGTCCTGCTGGAGTTCGTGACCGCCGCCGGGATCACTCTCGGCAT GGACGAGCTGTACAAG

GAATTCAATAAAAGATCTTTATTTTCATTAGATCTGT GTGTTGGTTTTTTGTGTGTGTAGCGGATCACTTAGGGCTGGATCGATGTTAACCAATTGAGGAACCCCTAGTGATGGAGT TGGCCACTCCСTCTCTGCGCGCTCGCTCGCTCACTGAGGCCGGGCGACCAAAGGTCGCCCGACGCCCGGGCTTTGCCCGG GCGGCCTCAGTGAGCGAGCGAGCGCGCAGCTGCCTGCAGGATCGGATCCCGGGCCCGTCGACTGCAGAGGCCTGCATGCA AGCTTGGCGTAATCATGGTCATAGCTGTTTCCTGTGTGAAATTGTTATCCGCTCACAATTCCACACAACATACGAGCCGG AAGCATAAAGTGTAAAGCCTGGGGTGCCTAATGAGTGAGCTAACTCACATTAATTGCGTTGCGCTCACTGCCCGCTTTCC AGTCGGGAAACCTGTCGTGCCAGCTGCATTAATGAATCGGCCAACGCGCGGGGAGAGGCGGTTTGCGTATTGGGCGCTCT TCCGCTTCCTCGCTCACTGACTCGCTGCGCTCGGTCGTTCGGCTGCGGCGAGCGGTATCAGCTCACTCAAAGGCGGTAAT 
bioRxiv preprint doi: $\mathrm{https}$ //doi.org/10.1101/2020.1217.423314 this version posted December 19,2020 . The copyright holder for this preprint (which was not certified by peer review) is the author/funder, who has granted bioRxiv a license to display the preprint in perpetuity. It is made available under aCC-BY-NC-ND 4.0 International license.

ACGGTTATCCACAGAATCAGGGGATAACGCAGGAAAGAACATGTGAGCAAAAGGCCAGCAAAAGGCCAGGAACCGTAAAA AGGCCGCGTTGCTGGCGTTTTTCCATAGGCTCCGCCCCCCTGACGAGCATCACAAAAATCGACGCTCAAGTCAGAGGTGG CGAAACCCGACAGGACTATAAAGATACCAGGCGTTTCCCCCTGGAAGCTCCCTCGTGCGCTCTCCTGTTCCGACCCTGCC GCTTACCGGATACCTGTCCGCCTTTCTCCCTTCGGGAAGCGTGGCGCTTTCTCATAGCTCACGCTGTAGGTATCTCAGTT CGGTGTAGGTCGTTCGCTCCAAGCTGGGCTGTGTGCACGAACCCCCCGTTCAGCCCGACCGCTGCGCCTTATCCGGTAAC TATCGTCTTGAGTCCAACCCGGTAAGACACGACTTATCGCCACTGGCAGCAGCCACTGGTAACAGGATTAGCAGAGCGAG GTATGTAGGCGGTGCTACAGAGTTCTTGAAGTGGTGGCCTAACTACGGCTACACTAGAAGAACAGTATTTGGTATCTGCG CTCTGCTGAAGCCAGTTACCTTCGGAAAAAGAGTTGGTAGCTCTTGATCCGGCAAACAAACCACCGCTGGTAGCGGTGGT TTTTTTGTTTGCAAGCAGCAGATTACGCGCAGAAAAAAAGGATCTCAAGAAGATCCTTTGATCTTTTCTACGGGGTCTGA CGCTCAGTGGAACGAAAACTCACGTTAAGGGATTTTGGTCATGAGATTATCAAAAAGGATCTTCACCTAGATCCTTTTAA ATTAAAAATGAAGTTTTAAATCAAGCCCAATCTGAATAATGTTACAACCAATTAACCAATTCTGATTAGAAAAACTCATC GAGCATCAAATGAAACTGCAATTTATTCATATCAGGATTATCAATACCATATTTTTGAAAAAGCCGTTTCTGTAATGAAG GAGAAAACTCACCGAGGCAGTTCCATAGGATGGCAAGATCCTGGTATCGGTCTGCGATTCCGACTCGTCCAACATCAATA CAACCTATTAATTTCCCCTCGTCAAAAATAAGGTTATCAAGTGAGAAATCACCATGAGTGACGACTGAATCCGGTGAGAA TGGCAAAAGTTTATGCATTTCTTTCCAGACTTGTTCAACAGGCCAGCCATTACGCTCGTCATCAAAATCACTCGCATCAA CCAAACCGTTATTCATTCGTGATTGCGCCTGAGCGAGACGAAATACGCGATCGCTGTTAAAAGGACAATTACAAACAGGA ATCGAATGCAACCGGCGCAGGAACACTGCCAGCGCATCAACAATATTTTCACCTGAATCAGGATATTCTTCTAATACCTG GAATGCTGTTTTTCCGGGGATCGCAGTGGTGAGTAACCATGCATCATCAGGAGTACGGATAAAATGCTTGATGGTCGGAA GAGGCATAAATTCCGTCAGCCAGTTTAGTCTGACCATCTCATCTGTAACATCATTGGCAACGCTACCTTTGCCATGTTTC AGAAACAACTCTGGCGCATCGGGCTTCCCATACAAGCGATAGATTGTCGCACCTGATTGCCCGACATTATCGCGAGCCCA TTTATACCCATATAAATCAGCATCCATGTTGGAATTTAATCGCGGCCTCGACGTTTCCCGTTGAATATGGCTCATAACAC CССTGTATTACTGTTTATGTAAGCAGACAGTTTTATTGTTCATGATGATATATTTTTATCTTGTGCAATGTAACATCAG AGATTTTGAGACACGGGCCAGAGCTGCATCGCGCGTTTCGGTGATGACGGTGAAAACCTCTGACACATGCAGCTCCCGGA GACGGTCACAGCTTGTCTGTAAGCGGATGCCGGGAGCAGACAAGCCCGTCAGGGCGCGTCAGCGGGTGTTGGCGGGTGTC GGGGCTGGCTTAACTATGCGGCATCAGAGCAGATTGTACTGAGAGTGCACCATATGCGGTGTGAAATACCGCACAGATGC GTAAGGAGAAAATACCGCATCAGGCGCCATTCGCCATTCAGGCTGCGCAACTGTTGGGAAGGGCGATCGGTGCGGGCCTC TTCGCTATTACGCCAGCTGGCGAAAGGGGGATGTGCTGCAAGGCGATTAAGTTGGGTAACGCCAGGGTTTTCCCAGTCAC GACGTT

Figure S10. Map and nucleotide sequence of the EGFP-2cut plasmid with U6-mINS2utr5sg.

Used for plasmid electroporation in MIN6 cells and AAV intravenous injection (packaged in serotype 8 or DJ, AAV-U6-mINS2utr5sg-EGFP-2cut) in Cas9 or wild-type mice (Figure 4 and 5). 
bioRxiv preprint doi: https://doi.org/10.1101/2020.12.17.423314: this version posted December 19, 2020. The copyright holder for this preprint (which was not certified by peer review) is the author/funder, who has granted bioRxiv a license to display the preprint in perpetuity. It is made available under aCC-BY-NC-ND 4.0 International license.

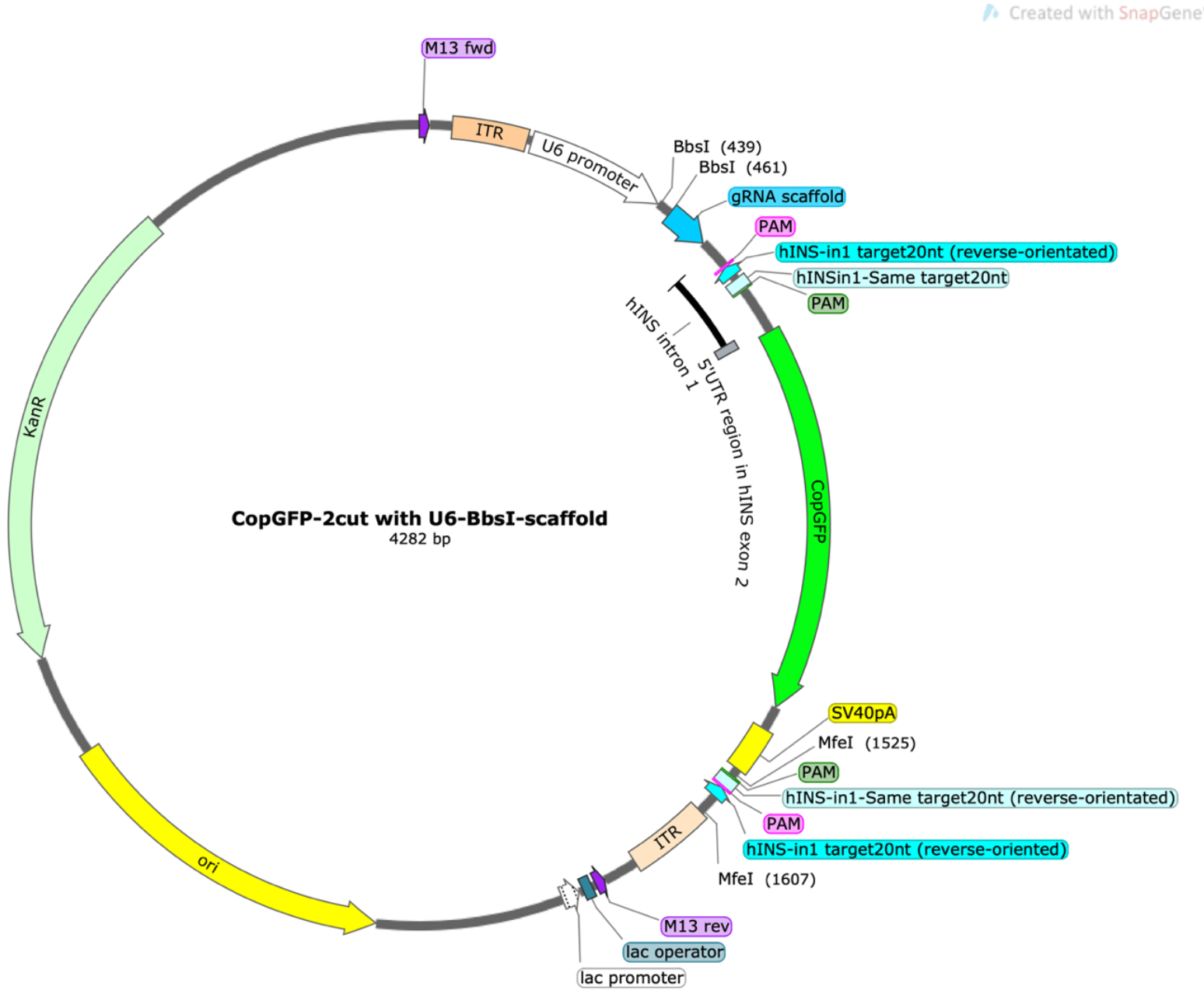

>pUC57-Kan-AAV-U6-BbsI-scaffold-hINSintron1-CopGFP-SV40pA-2cut (4282 bp)

GTAAAACGACGGCCAGTGAATTCGAGCTCGGTACCTCGCGAATGCATCTAGATATCCCTGCAGGCAGCTGCGCGCTCGCT CGCTCACTGAGGCCGCCCGGGCGTCGGGCGACCTTTGGTCGCCCGGCCTCAGTGAGCGAGCGAGCGCGCAGAGAGGGAGT GGCCAACTCCATCACTAGGGGTTCCTGCGGCCGCGAGGGCCTATTTCCCATGATTCCTTCATATTTGCATATACGATACA AGGCTGTTAGAGAGATAATTGGAATTAATTTGACTGTAAACACAAAGATATTAGTACAAAATACGTGACGTAGAAAGTAA TAATTCTTGGGTAGTTTGCAGTTTTAAAATTATGTTTTAAAATGGACTATCATATGCTTACCGTAACTTGAAAGTATTT CGATTTCTTGGCTTTATATATCTTGTGGAAAGGACGAAACACCGGGTCTTCGAGAAGACCTGTTTTAGAGCTAGAAATAG CAAGTTAAAATAAGGCTAGTCCGTTATCAACTTGAAAAAGTGGCACCGAGTCGGTGCTTTTTTTCCATGGGCTAGCGTGG GCTCAGGATTCCAGGGTGGCTGGACCCCAGCCTCCCTGCTGCAGAGCTGGGGCACGTGGCTGGGCTCGTGAAGCATGTGG GGGTGAGCCCAGGGGCCCCAAGGCAGGGCACCTGGCCTTCAGCCTGCCTCAGCCCTGCCTGTCTCCCAGATCACTGTCCT TCTGCCATGCCCGCCATGAAGATCGAGTGCCGCATCACCGGCACCCTGAACGGCGTGGAGTTCGAGCTGGTGGGCGGCGG AGAGGGCACCCCCGAGCAGGGCCGCATGACCAACAAGATGAAGAGCACCAAAGGCGCCCTGACCTTCAGCCCCTACCTGC TGAGCCACGTGATGGGCTACGGCTTCTACCACTTCGGCACCTACCCCAGCGGCTACGAGAACCCCTTCCTGCACGCCATC AACAACGGCGGCTACACCAACACCCGCATCGAGAAGTACGAGGACGGCGGCGTGCTGCACGTGAGCTTCAGCTACCGCTA CGAGGCCGGCCGCGTGATCGGCGACTTCAAGGTGGTGGGCACCGGCTTCCCCGAGGACAGCGTGATCTTCACCGACAAGA TCATCCGCAGCAACGCCACCGTGGAGCACCTGCACCCCATGGGCGATAACGTGCTGGTGGGCAGCTTCGCCCGCACCTTC AGCCTGCGCGACGGCGGCTACTACAGCTTCGTGGTGGACAGCCACATGCACTTCAAGAGCGCCATCCACCCCAGCATCCT GCAGAACGGGGGCCCCATGTTCGCCTTCCGCCGCGTGGAGGAGCTGCACAGCAACACCGAGCTGGGCATCGTGGAGTACC AGCACGCCTTCAAGACCCCCATCGCCTTCGCCAGATCTCGAGCTCGATGAGTTTGGACAAACCACAACTAGAATGCAGTG AAAAAAATGCTTTATTTGTGAAATTTGTATGCTATTGCTTTATTTGTAACCATTATAAGCTGCAATAAACAAGTTAACA ACAACAATTGCCCCCCACATGCTTCACGAGCCCACCTCCCTGCTGCAGAGCTGGGGCCCACCCTGGAATCCTGAGCCCAC ATCGATCAATTGAGGAACCCCTAGTGATGGAGTTGGCCACTCCCTCTCTGCGCGCTCGCTCGCTCACTGAGGCCGGGCGA

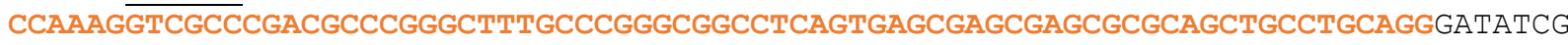
GATCCCGGGCCCGTCGACTGCAGAGGCCTGCATGCAAGCTTGGCGTAATCATGGTCATAGCTGTTTCCTGTGTGAAATTG TTATCCGCTCACAATTCCACACAACATACGAGCCGGAAGCATAAAGTGTAAAGCCTGGGGTGCCTAATGAGTGAGCTAAC TCACATTAATTGCGTTGCGCTCACTGCCCGCTTTCCAGTCGGGAAACCTGTCGTGCCAGCTGCATTAATGAATCGGCCAA CGCGCGGGGAGAGGCGGTTTGCGTATTGGGCGCTCTTCCGCTTCCTCGCTCACTGACTCGCTGCGCTCGGTCGTTCGGCT 
bioRxiv preprint doi: https://doi.org/10.1101/2020.12.17.423314; this version posted December 19, 2020. The copyright holder for this preprint (which was not certified by peer review) is the author/funder, who has granted bioRxiv a license to display the preprint in perpetuity. It is made available under aCC-BY-NC-ND 4.0 International license.

GCGGCGAGCGGTATCAGCTCACTCAAAGGCGGTAATACGGTTATCCACAGAATCAGGGGATAACGCAGGAAAGAACATGT GAGCAAAAGGCCAGCAAAAGGCCAGGAACCGTAAAAAGGCCGCGTTGCTGGCGTTTTTCCATAGGCTCCGCCCCCCTGAC GAGCATCACAAAAATCGACGCTCAAGTCAGAGGTGGCGAAACCCGACAGGACTATAAAGATACCAGGCGTTTCCCCCTGG AAGCTCCCTCGTGCGCTCTCCTGTTCCGACCCTGCCGCTTACCGGATACCTGTCCGCCTTTCTCCCTTCGGGAAGCGTGG CGCTTTCTCATAGCTCACGCTGTAGGTATCTCAGTTCGGTGTAGGTCGTTCGCTCCAAGCTGGGCTGTGTGCACGAACCC CCCGTTCAGCCCGACCGCTGCGCCTTATCCGGTAACTATCGTCTTGAGTCCAACCCGGTAAGACACGACTTATCGCCACT GGCAGCAGCCACTGGTAACAGGATTAGCAGAGCGAGGTATGTAGGCGGTGCTACAGAGTTCTTGAAGTGGTGGCCTAACT ACGGCTACACTAGAAGAACAGTATTTGGTATCTGCGCTCTGCTGAAGCCAGTTACCTTCGGAAAAAGAGTTGGTAGCTCT TGATCCGGCAAACAAACCACCGCTGGTAGCGGTGGTTTTTTTGTTTGCAAGCAGCAGATTACGCGCAGAAAAAAAGGATC TCAAGAAGATCCTTTGATCTTTTCTACGGGGTCTGACGCTCAGTGGAACGAAAACTCACGTTAAGGGATTTTGGTCATGA GATTATCAAAAAGGATCTTCACCTAGATCCTTTTAAATTAAAAATGAAGTTTTAAATCAAGCCCAATCTGAATAATGTTA CAACCAATTAACCAATTCTGATTAGAAAAACTCATCGAGCATCAAATGAAACTGCAATTTATTCATATCAGGATTATCAA TACCATATTTTTGAAAAAGCCGTTTCTGTAATGAAGGAGAAAACTCACCGAGGCAGTTCCATAGGATGGCAAGATCCTGG TATCGGTCTGCGATTCCGACTCGTCCAACATCAATACAACCTATTAATTTCCCCTCGTCAAAAATAAGGTTATCAAGTGA GAAATCACCATGAGTGACGACTGAATCCGGTGAGAATGGCAAAAGTTTATGCATTTCTTTCCAGACTTGTTCAACAGGCC AGCCATTACGCTCGTCATCAAAATCACTCGCATCAACCAAACCGTTATTCATTCGTGATTGCGCCTGAGCGAGACGAAAT ACGCGATCGCTGTTAAAAGGACAATTACAAACAGGAATCGAATGCAACCGGCGCAGGAACACTGCCAGCGCATCAACAAT ATTTTCACCTGAATCAGGATATTCTTCTAATACCTGGAATGCTGTTTTTCCGGGGATCGCAGTGGTGAGTAACCATGCAT CATCAGGAGTACGGATAAAATGCTTGATGGTCGGAAGAGGCATAAATTCCGTCAGCCAGTTTAGTCTGACCATCTCATCT GTAACATCATTGGCAACGCTACCTTTGCCATGTTTCAGAAACAACTCTGGCGCATCGGGCTTCCCATACAAGCGATAGAT TGTCGCACCTGATTGCCCGACATTATCGCGAGCCCATTTATACCCATATAAATCAGCATCCATGTTGGAATTTAATCGCG GCCTCGACGTTTCCCGTTGAATATGGCTCATAACACCCCTTGTATTACTGTTTATGTAAGCAGACAGTTTTATTGTTCAT GATGATATATTTTTATCTTGTGCAATGTAACATCAGAGATTTTGAGACACGGGCCAGAGCTGCATCGCGCGTTTCGGTGA TGACGGTGAAAACCTCTGACACATGCAGCTCCCGGAGACGGTCACAGCTTGTCTGTAAGCGGATGCCGGGAGCAGACAAG CCCGTCAGGGCGCGTCAGCGGGTGTTGGCGGGTGTCGGGGCTGGCTTAACTATGCGGCATCAGAGCAGATTGTACTGAGA GTGCACCATATGCGGTGTGAAATACCGCACAGATGCGTAAGGAGAAAATACCGCATCAGGCGCCATTCGCCATTCAGGCT GCGCAACTGTTGGGAAGGGCGATCGGTGCGGGCCTCTTCGCTATTACGCCAGCTGGCGAAAGGGGGATGTGCTGCAAGGC GATTAAGTTGGGTAACGCCAGGGTTTTCCCAGTCACGACGTT

CTTCGTGGTGGACAGCCACATGCACTTCAAGAGCGCCATCCACCCCAGCATCCTGCAGAACGGGGGCCCCATGTTCGCCTTCCGCCGCGTGGAGGAGCTGCACAGCAACACCGAGCTGGGCATCGTGGAG GAAGCACCACCTGTCGGTGTACGTGAAGTTTCGCGGTAGGTGGGTCGTAGGACGTCTTGCCCCCGGGGTACAAGCGGAAGGCGCGCACCTCCTCGACGTGTCGTTGTGGCTCGACCCGTAGCACCTC

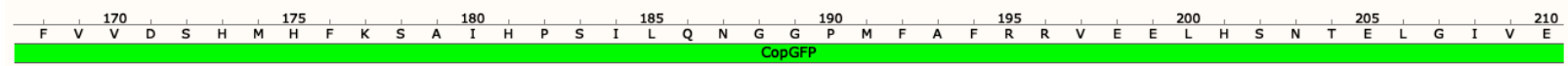

TACCAGCACGCCTTCAAGACCCCCATCGCCTTCGCCAGATCTCGAGCTCGATGAGTTTGGACAAACCACAACTAGAATGCAGTGAAAAAAATGCTTTATTTGTGAAATTTGTGATGCTATTGCTTTATTT ATGGTCGTGCGGAAGTTCTGGGGGTAGCGGAGCGGTCTAGAGCTCGAGCTACTCAAACCTGTTTGGTGTTGATCTTACGTCACTTTTTTTACGAAATAAACACTTTAAACACTACGATAACGAAATAAA

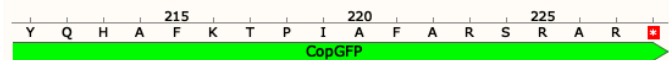

SV40PA

MFel

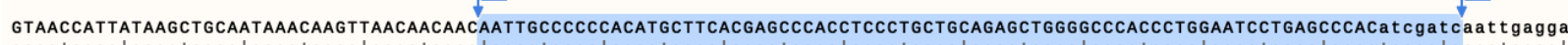
CATTGGTAATATTCGACGTTATTTGTTCAATTGTTGTTGTTAACGGGGGTGTACGAAGTGCTCGGGTGGAGGACGACGTCTCGACCCCGGGTGGACCTTAGGACTCGGGTG agCt agt Iaact tCC \begin{tabular}{cll}
\hline SV40PA & hINS-in1-Same target20nt \\
\hline PAM & hINS-in1 target20nt \\
\hline
\end{tabular}

accctagtgatggagttggccactcctctctgcgcgctcgctcgctcactgaggccgggcgaccaaaggtcgccegacgcceggetttgcceggeggcetcagtgagcgagcgagcgcgcagct gc tggggatcactacctcaaccggtgagggagagacgcgcgagcgagcgagtgactccggccegctggtt tccagcgggctgcgggccegaacgggccegccggagtcactcgctcgctcgcgcgtcgacg ITR

\section{Figure S11. Map and nucleotide sequence of the CopGFP-2cut plasmid.}

This universal donor was used to test sgRNA hINSin1sg-Reverse and hINSin1sg-Same in Figure S4.

hINSin1sg-Reverse showed better CRBR editing in AD293 cells and human islets, so hINSin1sg-

Reverse target(20nt) was chosen to clone into Bbsl site for U6 driven expression in the same donor.

Mfel double digestion on the plasmid removed the two targeted sites from the 3' of the CopGFP

CRBR cassette and generated the CopGFP-1cut donor. 
bioRxiv preprint doi: https://doi.org/10.1101/2020.12 17.423314: this version posted December 19,2020 . The copyright holder for this preprint (which was not certified by peer review) is the author/funder, who has granted bioRxiv a license to display the preprint in perpetuity. It is made available under aCC-BY-NC-ND 4.0 International license.

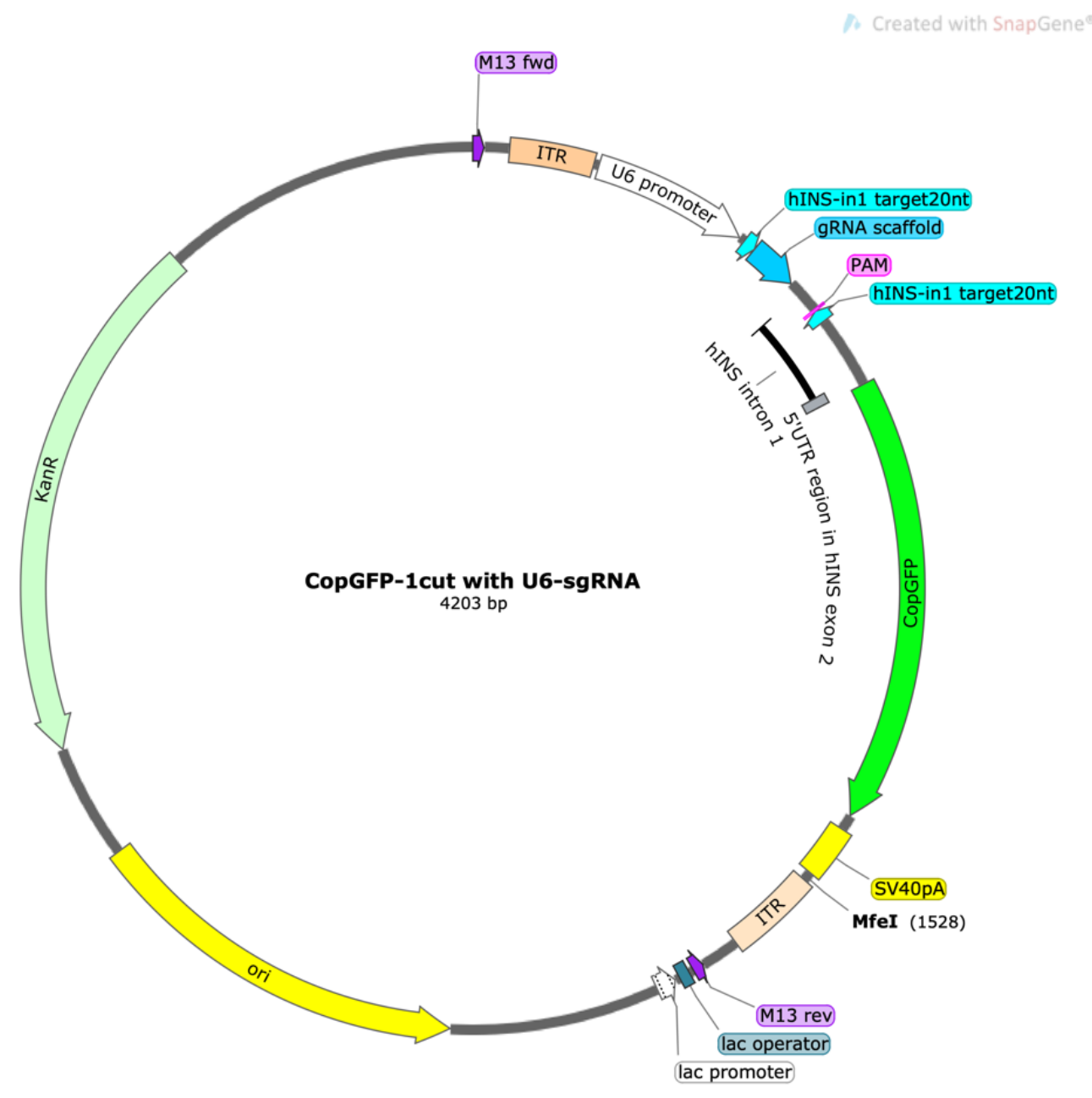

>pUC57-Kan-AAV-U6-hINSin1sg-hINSintron1-CopGFP-SV40pA-1cut (4203 bp)

GTAAAACGACGGCCAGTGAATTCGAGCTCGGTACCTCGCGAATGCATCTAGATATCCCTGCAGGCAGCTGCGCGCTCGCT CGCTCACTGAGGCCGCCCGGGCGTCGGGCGACCTTTGGTCGCCCGGCCTCAGTGAGCGAGCGAGCGCGCAGAGAGGGAGT GGCCAACTCCATCACTAGGGGTTCCTGCGGCCGCGAGGGCCTATTTCCCATGATTCCTTCATATTTGCATATACGATACA AGGCTGTTAGAGAGATAATTGGAATTAATTTGACTGTAAACACAAAGATATTAGTACAAAATACGTGACGTAGAAAGTAA TAATTCTTGGGTAGTTTGCAGTTTTAAAATTATGTTTTAAAATGGACTATCATATGCTTACCGTAACTTGAAAGTATTT СGATTTCTTGGCTTTATATATCTTGTGGAAAGGACGAAACACCGGCCCCAGCTCTGCAGCAGGGGTTTTAGAGCTAGAAA TAGCAAGTTAAAATAAGGCTAGTCCGTTATCAACTTGAAAAAGTGGCACCGAGTCGGTGCTTTTTTTCCATGGGCTAGCG TGGGCTCAGGATTCCAGGGTGGCTGGACCCCAGCCTCCCTGCTGCAGAGCTGGGGCACGTGGCTGGGCTCGTGAAGCATG TGGGGGTGAGCCCAGGGGCCCCAAGGCAGGGCACCTGGCCTTCAGCCTGCCTCAGCCCTGCCTGTCTCCCAGATCACTGT ССTTCTGCCATGCCCGCCATGAAGATCGAGTGCCGCATCACCGGCACCCTGAACGGCGTGGAGTTCGAGCTGGTGGGCGG CGGAGAGGGCACCCCCGAGCAGGGCCGCATGACCAACAAGATGAAGAGCACCAAAGGCGCCCTGACCTTCAGCCCCTACC TGCTGAGCCACGTGATGGGCTACGGCTTCTACCACTTCGGCACCTACCCCAGCGGCTACGAGAACCCCTTCCTGCACGCC ATCAACAACGGCGGCTACACCAACACCCGCATCGAGAAGTACGAGGACGGCGGCGTGCTGCACGTGAGCTTCAGCTACCG CTACGAGGCCGGCCGCGTGATCGGCGACTTCAAGGTGGTGGGCACCGGCTTCCCCGAGGACAGCGTGATCTTCACCGACA AGATCATCCGCAGCAACGCCACCGTGGAGCACCTGCACCCCATGGGCGATAACGTGCTGGTGGGCAGCTTCGCCCGCACC TTCAGCCTGCGCGACGGCGGCTACTACAGCTTCGTGGTGGACAGCCACATGCACTTCAAGAGCGCCATCCACCCCAGCAT CCTGCAGAACGGGGGCCCCATGTTCGCCTTCCGCCGCGTGGAGGAGCTGCACAGCAACACCGAGCTGGGCATCGTGGAGT ACCAGCACGCCTTCAAGACCCCCATCGCCTTCGCCAGATCTCGAGCTCGATGAGTTTGGACAAACCACAACTAGAATGCA GTGAAAAAAATGCTTTATTTGTGAAATTTGTGATGCTATTGCTTTATTTGTAACCATTATAAGCTGCAATAAACAAGTTA ACAACAACAATTGAGGAACCCCTAGTGATGGAGTTGGCCACTCCCTCTCTGCGCGCTCGCTCGCTCACTGAGGCCGGGCG ACCAAAGGTCGCCCGACGCCCGGGCTTTGCCCGGGCGGCCTCAGTGAGCGAGCGAGCGCGCAGCTGCCTGCAGGGATATC GGATCCCGGGCCCGTCGACTGCAGAGGCCTGCATGCAAGCTTGGCGTAATCATGGTCATAGCTGTTTCCTGTGTGAAATT GTTATCCGCTCACAATTCCACACAACATACGAGCCGGAAGCATAAAGTGTAAAGCCTGGGGTGCCTAATGAGTGAGCTAA СTCACATTAATTGCGTTGCGCTCACTGCCCGCTTTCCAGTCGGGAAACCTGTCGTGCCAGCTGCATTAATGAATCGGCCA ACGCGCGGGGAGAGGCGGTTTGCGTATTGGGCGCTCTTCCGCTTCCTCGCTCACTGACTCGCTGCGCTCGGTCGTTCGGC TGCGGCGAGCGGTATCAGCTCACTCAAAGGCGGTAATACGGTTATCCACAGAATCAGGGGATAACGCAGGAAAGAACATG 
bioRxiv preprint doi: $\mathrm{https}$ //doi.org/10.1101/2020.1217.423314 this version posted December 19,2020 . The copyright holder for this preprint (which was not certified by peer review) is the author/funder, who has granted bioRxiv a license to display the preprint in perpetuity. It is made available under aCC-BY-NC-ND 4.0 International license.

TGAGCAAAAGGCCAGCAAAAGGCCAGGAACCGTAAAAAGGCCGCGTTGCTGGCGTTTTTCCATAGGCTCCGCCCCCCTGA CGAGCATCACAAAAATCGACGCTCAAGTCAGAGGTGGCGAAACCCGACAGGACTATAAAGATACCAGGCGTTTCCCCCTG GAAGCTCCCTCGTGCGCTCTCCTGTTCCGACCCTGCCGCTTACCGGATACCTGTCCGCCTTTCTCCCTTCGGGAAGCGTG GCGCTTTCTCATAGCTCACGCTGTAGGTATCTCAGTTCGGTGTAGGTCGTTCGCTCCAAGCTGGGCTGTGTGCACGAACC CCCCGTTCAGCCCGACCGCTGCGCCTTATCCGGTAACTATCGTCTTGAGTCCAACCCGGTAAGACACGACTTATCGCCAC TGGCAGCAGCCACTGGTAACAGGATTAGCAGAGCGAGGTATGTAGGCGGTGCTACAGAGTTCTTGAAGTGGTGGCCTAAC TACGGCTACACTAGAAGAACAGTATTTGGTATCTGCGCTCTGCTGAAGCCAGTTACCTTCGGAAAAAGAGTTGGTAGCTC TTGATCCGGCAAACAAACCACCGCTGGTAGCGGTGGTTTTTTTGTTTGCAAGCAGCAGATTACGCGCAGAAAAAAAGGAT CTCAAGAAGATCCTTTGATCTTTTCTACGGGGTCTGACGCTCAGTGGAACGAAAACTCACGTTAAGGGATTTTGGTCATG AGATTATCAAAAAGGATCTTCACCTAGATCCTTTTAAATTAAAAATGAAGTTTTAAATCAAGCCCAATCTGAATAATGTT ACAACCAATTAACCAATTCTGATTAGAAAAACTCATCGAGCATCAAATGAAACTGCAATTTATTCATATCAGGATTATCA ATACCATATTTTGAAAAAGCCGTTTCTGTAATGAAGGAGAAAACTCACCGAGGCAGTTCCATAGGATGGCAAGATCCTG GTATCGGTCTGCGATTCCGACTCGTCCAACATCAATACAACCTATTAATTTCCCCTCGTCAAAAATAAGGTTATCAAGTG AGAAATCACCATGAGTGACGACTGAATCCGGTGAGAATGGCAAAAGTTTATGCATTTCTTTCCAGACTTGTTCAACAGGC CAGCCATTACGCTCGTCATCAAAATCACTCGCATCAACCAAACCGTTATTCATTCGTGATTGCGCCTGAGCGAGACGAAA TACGCGATCGCTGTTAAAAGGACAATTACAAACAGGAATCGAATGCAACCGGCGCAGGAACACTGCCAGCGCATCAACAA TATTTTCACCTGAATCAGGATATTCTTCTAATACCTGGAATGCTGTTTTTCCGGGGATCGCAGTGGTGAGTAACCATGCA TCATCAGGAGTACGGATAAAATGCTTGATGGTCGGAAGAGGCATAAATTCCGTCAGCCAGTTTAGTCTGACCATCTCATC TGTAACATCATTGGCAACGCTACCTTTGCCATGTTTCAGAAACAACTCTGGCGCATCGGGCTTCCCATACAAGCGATAGA TTGTCGCACCTGATTGCCCGACATTATCGCGAGCCCATTTATACCCATATAAATCAGCATCCATGTTGGAATTTAATCGC GGCCTCGACGTTTCCCGTTGAATATGGCTCATAACACCCCTTGTATTACTGTTTATGTAAGCAGACAGTTTTATTGTTCA TGATGATATATTTTTATCTTGTGCAATGTAACATCAGAGATTTTGAGACACGGGCCAGAGCTGCATCGCGCGTTTCGGTG ATGACGGTGAAAACCTCTGACACATGCAGCTCCCGGAGACGGTCACAGCTTGTCTGTAAGCGGATGCCGGGAGCAGACAA GCCCGTCAGGGCGCGTCAGCGGGTGTTGGCGGGTGTCGGGGCTGGCTTAACTATGCGGCATCAGAGCAGATTGTACTGAG AGTGCACCATATGCGGTGTGAAATACCGCACAGATGCGTAAGGAGAAAATACCGCATCAGGCGCCATTCGCCATTCAGGC TGCGCAACTGTTGGGAAGGGCGATCGGTGCGGGCCTCTTCGCTATTACGCCAGCTGGCGAAAGGGGGATGTGCTGCAAGG CGATTAAGTTGGGTAACGCCAGGGTTTTCCCAGTCACGACGTT

Figure S12. Map and nucleotide sequence of the CopGFP-1cut plasmid with U6-hINSin1sg. Used for plasmid electroporation and AAV transduction (packaged in serotype DJ, AAV-DJ-U6hINSin1sg-CopGFP-1cut) in human islet experiments (Figure 6 and 7). 
bioRxiv preprint doi: https://doi.org/10.1101/2020 12 17.423314; this version posted December 19,2020. The copyright holder for this preprint (which was not certified by peer review) is the author/funder, who has granted bioRxiv a license to display the preprint in perpetuity. It is made available under aCC-BY-NC-ND 4.0 International license.

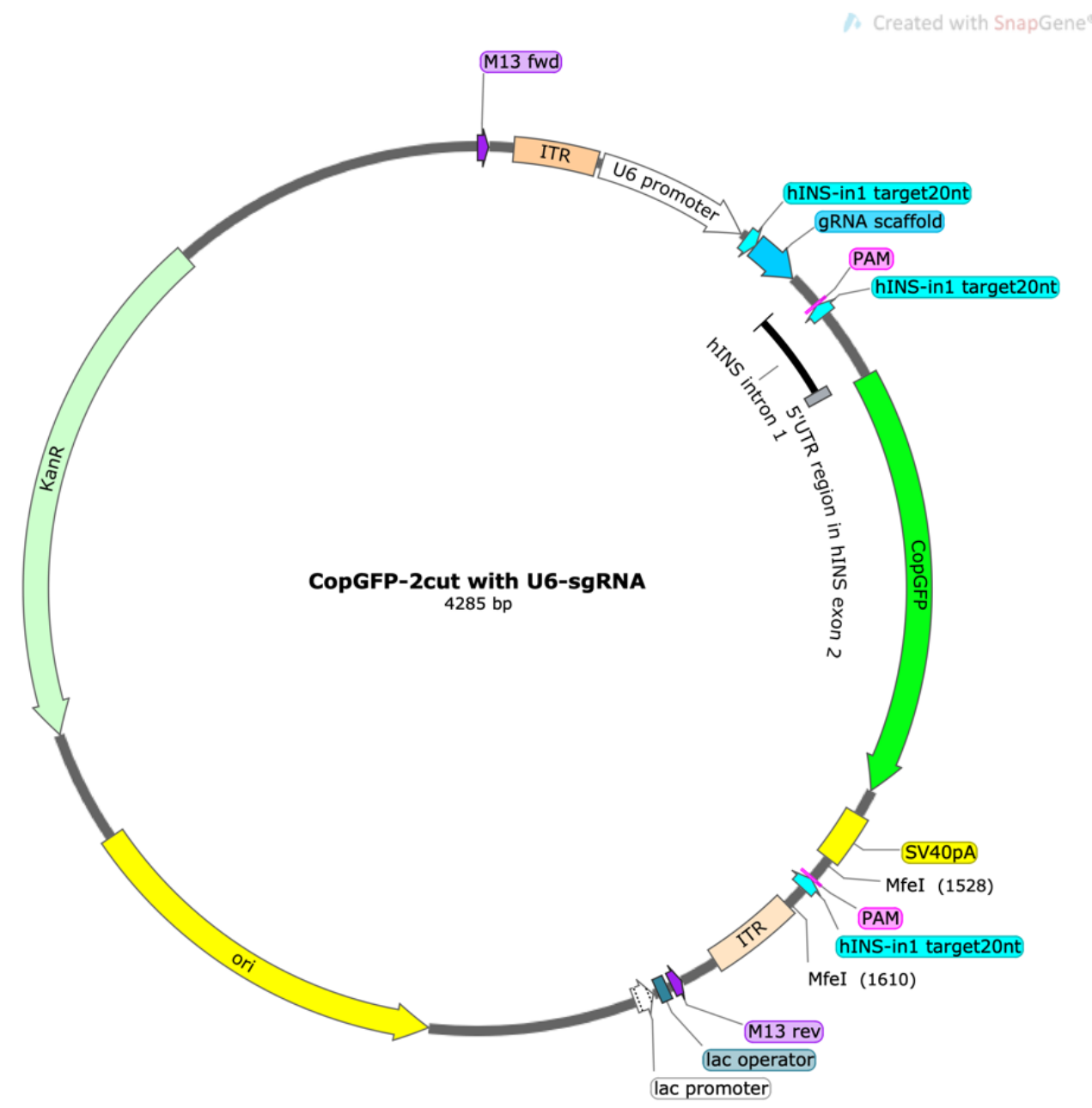

>pUC57-Kan-AAV-U6-hINSin1sg-hINSintron1-CopGFP-SV40pA-2cut (4285 bp)

GTAAAACGACGGCCAGTGAATTCGAGCTCGGTACCTCGCGAATGCATCTAGATATCCCTGCAGGCAGCTGCGCGCTCGCT CGCTCACTGAGGCCGCCCGGGCGTCGGGCGACCTTTGGTCGCCCGGCCTCAGTGAGCGAGCGAGCGCGCAGAGAGGGAGT GGCCAACTCCATCACTAGGGGTTCCTGCGGCCGCGAGGGCCTATTTCCCATGATTCCTTCATATTTGCATATACGATACA AGGCTGTTAGAGAGATAATTGGAATTAATTTGACTGTAAACACAAAGATATTAGTACAAAATACGTGACGTAGAAAGTAA TAATTCTTGGGTAGTTTGCAGTTTTAAAATTATGTTTTAAAATGGACTATCATATGCTTACCGTAACTTGAAAGTATTT СGATTTCTTGGCTTTATATATCTTGTGGAAAGGACGAAACACCGGCCCCAGCTCTGCAGCAGGGGTTTTAGAGCTAGAAA TAGCAAGTTAAAATAAGGCTAGTCCGTTATCAACTTGAAAAAGTGGCACCGAGTCGGTGCTTTTTTTCCATGGGCTAGCG TGGGCTCAGGATTCCAGGGTGGCTGGACCCCAGCCTCCCTGCTGCAGAGCTGGGGCACGTGGCTGGGCTCGTGAAGCATG TGGGGGTGAGCCCAGGGGCCCCAAGGCAGGGCACCTGGCCTTCAGCCTGCCTCAGCCCTGCCTGTCTCCCAGATCACTGT ССTTCTGCCATGCCCGCCATGAAGATCGAGTGCCGCATCACCGGCACCCTGAACGGCGTGGAGTTCGAGCTGGTGGGCGG CGGAGAGGGCACCCCCGAGCAGGGCCGCATGACCAACAAGATGAAGAGCACCAAAGGCGCCCTGACCTTCAGCCCCTACC TGCTGAGCCACGTGATGGGCTACGGCTTCTACCACTTCGGCACCTACCCCAGCGGCTACGAGAACCCCTTCCTGCACGCC ATCAACAACGGCGGCTACACCAACACCCGCATCGAGAAGTACGAGGACGGCGGCGTGCTGCACGTGAGCTTCAGCTACCG CTACGAGGCCGGCCGCGTGATCGGCGACTTCAAGGTGGTGGGCACCGGCTTCCCCGAGGACAGCGTGATCTTCACCGACA AGATCATCCGCAGCAACGCCACCGTGGAGCACCTGCACCCCATGGGCGATAACGTGCTGGTGGGCAGCTTCGCCCGCACC TTCAGCCTGCGCGACGGCGGCTACTACAGCTTCGTGGTGGACAGCCACATGCACTTCAAGAGCGCCATCCACCCCAGCAT CCTGCAGAACGGGGGCCCCATGTTCGCCTTCCGCCGCGTGGAGGAGCTGCACAGCAACACCGAGCTGGGCATCGTGGAGT ACCAGCACGCCTTCAAGACCCCCATCGCCTTCGCCAGATCTCGAGCTCGATGAGTTTGGACAAACCACAACTAGAATGCA GTGAAAAAAATGCTTTATTTGTGAAATTTGTGATGCTATTGCTTTATTTGTAACCATTATAAGCTGCAATAAACAAGTTA ACAACAACAATTGCCCCCCACATGCTTCACGAGCCCACCTCCCTGCTGCAGAGCTGGGGCCCACCCTGGAATCCTGAGCC CACATCGATCAATTGAGGAACCCCTAGTGATGGAGTTGGCCACTCCCTCTCTGCGCGCTCGCTCGCTCACTGAGGCCGGG CGACCAAAGGTCGCCCGACGCCCGGGCTTTGCCCGGGCGGCCTCAGTGAGCGAGCGAGCGCGCAGCTGCCTGCAGGGATA TCGGATCCCGGGCCCGTCGACTGCAGAGGCCTGCATGCAAGCTTGGCGTAATCATGGTCATAGCTGTTTCCTGTGTGAAA TTGTTATCCGCTCACAATTCCACACAACATACGAGCCGGAAGCATAAAGTGTAAAGCCTGGGGTGCCTAATGAGTGAGCT AACTCACATTAATTGCGTTGCGCTCACTGCCCGCTTTCCAGTCGGGAAACCTGTCGTGCCAGCTGCATTAATGAATCGGC CAACGCGCGGGGAGAGGCGGTTTGCGTATTGGGCGCTCTTCCGCTTCCTCGCTCACTGACTCGCTGCGCTCGGTCGTTCG 
bioRxiv preprint doi: https://doi.org/10.1101/2020.12.17.423314; this version posted December 19,2020 . The copyright holder for this preprint (which was not certified by peer review) is the author/funder, who has granted bioRxiv a license to display the preprint in perpetuity. It is made available under aCC-BY-NC-ND 4.0 International license.

GCTGCGGCGAGCGGTATCAGCTCACTCAAAGGCGGTAATACGGTTATCCACAGAATCAGGGGATAACGCAGGAAAGAACA TGTGAGCAAAAGGCCAGCAAAAGGCCAGGAACCGTAAAAAGGCCGCGTTGCTGGCGTTTTTCCATAGGCTCCGCCCCCCT GACGAGCATCACAAAAATCGACGCTCAAGTCAGAGGTGGCGAAACCCGACAGGACTATAAAGATACCAGGCGTTTCCCCC TGGAAGCTCCCTCGTGCGCTCTCCTGTTCCGACCCTGCCGCTTACCGGATACCTGTCCGCCTTTCTCCCTTCGGGAAGCG TGGCGCTTTCTCATAGCTCACGCTGTAGGTATCTCAGTTCGGTGTAGGTCGTTCGCTCCAAGCTGGGCTGTGTGCACGAA CCCCCCGTTCAGCCCGACCGCTGCGCCTTATCCGGTAACTATCGTCTTGAGTCCAACCCGGTAAGACACGACTTATCGCC ACTGGCAGCAGCCACTGGTAACAGGATTAGCAGAGCGAGGTATGTAGGCGGTGCTACAGAGTTCTTGAAGTGGTGGCCTA ACTACGGCTACACTAGAAGAACAGTATTTGGTATCTGCGCTCTGCTGAAGCCAGTTACCTTCGGAAAAAGAGTTGGTAGC TCTTGATCCGGCAAACAAACCACCGCTGGTAGCGGTGGTTTTTTTGTTTGCAAGCAGCAGATTACGCGCAGAAAAAAAGG ATCTCAAGAAGATCCTTTGATCTTTTCTACGGGGTCTGACGCTCAGTGGAACGAAAACTCACGTTAAGGGATTTTGGTCA TGAGATTATCAAAAAGGATCTTCACCTAGATCCTTTTAAATTAAAAATGAAGTTTTAAATCAAGCCCAATCTGAATAATG TTACAACCAATTAACCAATTCTGATTAGAAAAACTCATCGAGCATCAAATGAAACTGCAATTTATTCATATCAGGATTAT CAATACCATATTTTTGAAAAAGCCGTTTCTGTAATGAAGGAGAAAACTCACCGAGGCAGTTCCATAGGATGGCAAGATCC TGGTATCGGTCTGCGATTCCGACTCGTCCAACATCAATACAACCTATTAATTTCCCCTCGTCAAAAATAAGGTTATCAAG TGAGAAATCACCATGAGTGACGACTGAATCCGGTGAGAATGGCAAAAGTTTATGCATTTCTTTCCAGACTTGTTCAACAG GCCAGCCATTACGCTCGTCATCAAAATCACTCGCATCAACCAAACCGTTATTCATTCGTGATTGCGCCTGAGCGAGACGA AATACGCGATCGCTGTTAAAAGGACAATTACAAACAGGAATCGAATGCAACCGGCGCAGGAACACTGCCAGCGCATCAAC AATATTTTCACCTGAATCAGGATATTCTTCTAATACCTGGAATGCTGTTTTTCCGGGGATCGCAGTGGTGAGTAACCATG CATCATCAGGAGTACGGATAAAATGCTTGATGGTCGGAAGAGGCATAAATTCCGTCAGCCAGTTTAGTCTGACCATCTCA TCTGTAACATCATTGGCAACGCTACCTTTGCCATGTTTCAGAAACAACTCTGGCGCATCGGGCTTCCCATACAAGCGATA GATTGTCGCACCTGATTGCCCGACATTATCGCGAGCCCATTTATACCCATATAAATCAGCATCCATGTTGGAATTTAATC GCGGCCTCGACGTTTCCCGTTGAATATGGCTCATAACACCCCTTGTATTACTGTTTATGTAAGCAGACAGTTTTATTGTT CATGATGATATATTTTTATCTTGTGCAATGTAACATCAGAGATTTTGAGACACGGGCCAGAGCTGCATCGCGCGTTTCGG TGATGACGGTGAAAACCTCTGACACATGCAGCTCCCGGAGACGGTCACAGCTTGTCTGTAAGCGGATGCCGGGAGCAGAC AAGCCCGTCAGGGCGCGTCAGCGGGTGTTGGCGGGTGTCGGGGCTGGCTTAACTATGCGGCATCAGAGCAGATTGTACTG AGAGTGCACCATATGCGGTGTGAAATACCGCACAGATGCGTAAGGAGAAAATACCGCATCAGGCGCCATTCGCCATTCAG GCTGCGCAACTGTTGGGAAGGGCGATCGGTGCGGGCCTCTTCGCTATTACGCCAGCTGGCGAAAGGGGGATGTGCTGCAA GGCGATTAAGTTGGGTAACGCCAGGGTTTTCCCAGTCACGACGTT

Figure S13. Map and nucleotide sequence of the CopGFP-2cut plasmid with U6-hINSin1sg. Used for plasmid electroporation and AAV transduction (packaged in serotype DJ, AAV-DJ-U6hINSin1sg-CopGFP-2cut) in human islet experiments (Figure 6 and 7).

Table S1. RRID of human cadaveric islets used for experiments.

\begin{tabular}{|l|l|l|l|}
\hline Figure & RRID & Endocrine Tissue (\%) & Beta Cells (\%) \\
\hline Fig. S4B-E & SAMN13254972 & 92 & 45 \\
\hline Fig. S5A & SAMN13515839 & 95 & 43 \\
\hline Fig. 6C-F, S5B & SAMN14255441 & 97 & 68 \\
\hline Fig. 7D & SAMN15314807 & 71 & 59 \\
\hline Fig. 7B-C & SAMN15518672 & 96 & 67 \\
\hline
\end{tabular}

Table S2. Oligonucleotides for BbsI site cloning into sgRNA expression constructs.

\begin{tabular}{|l|l|l|}
\hline Target site & \multicolumn{2}{|l|}{ Oligonucleotide sequences $\left(5^{\prime} \rightarrow 3^{\prime}\right)$} \\
\hline mPerk-ex9 & $\begin{array}{l}\text { Top oligo } \\
\text { Bottom oligo }\end{array}$ & $\begin{array}{l}\text { 5'-CACCgCCTGCGCACGATGAAGGTCG-3' } \\
\text { 5'AACEACCTTCATCGTGCGCAGGc-3' }\end{array}$ \\
\hline
\end{tabular}


bioRxiv preprint doi: $\mathrm{https}$ //doi.org/10.1101/2020.1217.423314 this version posted December 19,2020 . The copyright holder for this preprint (which was not certified by peer review) is the author/funder, who has granted bioRxiv a license to display the preprint in perpetuity. It is made available under aCC-BY-NC-ND 4.0 International license.

\begin{tabular}{|l|l|l|}
\hline mPerk-in6 & $\begin{array}{l}\text { Top oligo } \\
\text { Bottom oligo }\end{array}$ & $\begin{array}{l}\text { 5'-CACCgIAGTTCGGGATCGCCACATG-3' } \\
\text { 5'-AAACCATGTGGCGATCCCGAACTAC-3' }\end{array}$ \\
\hline mPerk-utr5 & $\begin{array}{l}\text { Top oligo } \\
\text { Bottom oligo }\end{array}$ & $\begin{array}{l}\text { 5'-CACCgAGACATCGCCCATTGAGCGA-3' } \\
\text { 5'-AAACICGCTCAATGGGCGATGTCTc-3' }\end{array}$ \\
\hline mIns2-utr5 & $\begin{array}{l}\text { Top oligo } \\
\text { Bottom oligo }\end{array}$ & $\begin{array}{l}\text { 5'-CACCgTGTAGCGGATCACTTAGGGC-3' } \\
\text { 5'-AAACGCCCTAAGTGATCCGCTACAc-3' }\end{array}$ \\
\hline hINS-in1 & $\begin{array}{l}\text { Top oligo } \\
\text { (hINS-in1 Reverse) }\end{array}$ & $\begin{array}{l}\text { 5'-CACCgGCCCCAGCTCTGCAGCAGGG-3' } \\
\text { 5'-AAACCCCTGCTGCAGAGCTGGGGCC-3' }\end{array}$ \\
\hline hINS-in1-Same & $\begin{array}{l}\text { Top oligo } \\
\text { Bottom oligo }\end{array}$ & $\begin{array}{l}\text { 5'-CACCgIGGGCTCGTGAAGCATGTGG-3' } \\
\text { 5'AACCCACATGCTTCACGAGCCCAC-3' }\end{array}$ \\
\hline
\end{tabular}


Table S3. PCR primers for junction PCR on genomic DNA.

\begin{tabular}{|c|c|c|}
\hline Cassette, target, junction & Primer location & Oligonucleotide sequences $\left(5^{\prime} \rightarrow 3^{\prime}\right)$ \\
\hline $\begin{array}{l}\text { rPERKex7-17-2cut, mPerk-in6, } \\
\text { 5' junction }\end{array}$ & $\begin{array}{l}\text { mP-intron6-F } \\
\text { m/rP-exon7-R }\end{array}$ & $\begin{array}{l}\text { CACAAGTTAGAAAGGCTCA } \\
\text { TGCAGGTACAGCTGGCCTCT }\end{array}$ \\
\hline $\begin{array}{l}\text { rPERKex7-17-2cut, mPerk-in6, } \\
\text { 3' junction }\end{array}$ & $\begin{array}{l}\text { rP-exon15-F } \\
\text { mP-intron9-R }\end{array}$ & $\begin{array}{l}\text { CATTCAGCACTCAGATGGAACG } \\
\text { GAAGGCAGATAGGAAAGTC }\end{array}$ \\
\hline $\begin{array}{l}\text { rPERKex7-17-2cut, mPerk-in6, } \\
\text { flanking }\end{array}$ & $\begin{array}{l}\mathrm{mP} \text {-intron6-F } \\
\mathrm{mP} \text {-intron9-R }\end{array}$ & $\begin{array}{l}\text { CACAAGTTAGAAAGGCTCA } \\
\text { GAAGGCAGATAGGAAAGTC }\end{array}$ \\
\hline $\begin{array}{l}\text { rPERKex7-17-2cut, mPerk-in6, } \\
\text { flipped 5' junction }\end{array}$ & $\begin{array}{l}\mathrm{mP} \text {-intron6-F } \\
\text { rP-exon15-F }\end{array}$ & $\begin{array}{l}\text { CACAAGTTAGAAAGGCTCA } \\
\text { CATTCAGCACTCAGATGGAACG }\end{array}$ \\
\hline $\begin{array}{l}\text { rPERKmyc-2cut, mPerk-utr5, } \\
5^{\prime} \text { junction }\end{array}$ & $\begin{array}{l}\text { upstream-mP-utr5-F } \\
\text { rP-exon1-R }\end{array}$ & $\begin{array}{l}\text { CTTCCTAGCCACAAATTGGGC } \\
\text { CCCAAGCCAAATGCCGTATC }\end{array}$ \\
\hline $\begin{array}{l}\text { rPERKmyc-2cut, mPerk-utr5, } \\
\text { 3' junction }\end{array}$ & $\begin{array}{l}\text { Myc-F } \\
\text { mP-intron1-R }\end{array}$ & $\begin{array}{l}\text { AGCAGAAGCTGATCTCTGAGG } \\
\text { GGTGCCCCGACCCTAGTTC }\end{array}$ \\
\hline $\begin{array}{l}\text { EGFP-2cut, mlns2-utr5, } \\
5^{\prime} \text { junction }\end{array}$ & $\begin{array}{l}\text { upstream-mlns2-utr5-F } \\
\text { EGFP-R }\end{array}$ & $\begin{array}{l}\text { AGCCAAGGACAAAGAAAGCA } \\
\text { TTCAGGGTCAGCTTGCCGTAG }\end{array}$ \\
\hline $\begin{array}{l}\text { EGFP-2cut, mlns2-utr5, } \\
\text { 3' junction }\end{array}$ & $\begin{array}{l}\text { EGFP-F } \\
\text { mlns2-exon2-R }\end{array}$ & $\begin{array}{l}\text { CACTACCTGAGCACCCAGTC } \\
\text { GTGGGACTCCCAGAGGAAG }\end{array}$ \\
\hline $\begin{array}{l}\text { EGFP-2cut, mlns2-utr5, } \\
\text { flanking }\end{array}$ & $\begin{array}{l}\text { upstream-mlns2-utr5-F } \\
\text { mlns2-exon2-R }\end{array}$ & $\begin{array}{l}\text { AGCCAAGGACAAAGAAAGCA } \\
\text { GTGGGACTCCCAGAGGAAG }\end{array}$ \\
\hline $\begin{array}{l}\text { EGFP-2cut, mIns2-utr5, } \\
\text { whole plasmid integration }\end{array}$ & $\begin{array}{l}\text { U6-F } \\
\text { mIns2-in1ex2-R }\end{array}$ & $\begin{array}{l}\text { GAGGGCCTATTTCCCATGATT } \\
\text { CTGGAAGATAGGCTGGGTTG }\end{array}$ \\
\hline $\begin{array}{l}\text { CopGFP-1cut(or 2cut), hINS-in1, } \\
5 \text { ' junction }\end{array}$ & $\begin{array}{l}\text { upstream-hINS-utr5-F2 } \\
\text { CopGFP-R }\end{array}$ & $\begin{array}{l}\text { GTGCTGACGACCAAGGAGAT } \\
\text { GAAGATCACGCTGTCCTCGG }\end{array}$ \\
\hline $\begin{array}{l}\text { CopGFP-1cut(or 2cut), hINS-in1, } \\
\text { 2cut 3' junction }\end{array}$ & $\begin{array}{l}\text { CopGFP-F } \\
\text { hINS-exon2-R }\end{array}$ & $\begin{array}{l}\text { CCGAGGACAGCGTGATCTTC } \\
\text { CCCCGCACACTAGGTAGAGA }\end{array}$ \\
\hline $\begin{array}{l}\text { CopGFP-1cut(or 2cut), hINS-in1, } \\
\text { 1cut 3' junction }\end{array}$ & $\begin{array}{l}\text { U6-F } \\
\text { hINS-exon2-R }\end{array}$ & $\begin{array}{l}\text { GAGGGCCTATTTCCCATGATT } \\
\text { CCCCGCACACTAGGTAGAGA }\end{array}$ \\
\hline $\begin{array}{l}\text { CopGFP-1cut(or 2cut), hINS-in1, } \\
5^{\prime} \text { junction (for AAV constructs) }\end{array}$ & $\begin{array}{l}\text { upstream-hINS-utr5-F1 } \\
\text { CopGFP-qR2 }\end{array}$ & $\begin{array}{l}\text { GAGGAAGAGGTGCTGACGAC } \\
\text { TGATGCGGCACTCGATC }\end{array}$ \\
\hline
\end{tabular}


Table S4. Quantitative realtime PCR primers for mRNA expression.

\begin{tabular}{|c|c|c|}
\hline Gene & Primer location & Oligonucleotide sequences $\left(5^{\prime} \rightarrow 3^{\prime}\right)$ \\
\hline mActin (Actb) & $\begin{array}{l}\text { exon4-qF } \\
\text { exon5-qR }\end{array}$ & $\begin{array}{l}\text { GCCCTGAGGCTCTTTTCC } \\
\text { TGCCACAGGATTCCATACCC }\end{array}$ \\
\hline rPERKex10 & $\begin{array}{l}\text { rP-exon10-qF } \\
\text { rP-exon10-qR }\end{array}$ & $\begin{array}{l}\text { GTGAGTGCTGATAACAGCG } \\
\text { CGTATCCTGAGTGTTTAATGTCG }\end{array}$ \\
\hline rPERKex12-13 & $\begin{array}{l}\text { rP-exon12-qF } \\
\text { rP-exon13-qR }\end{array}$ & $\begin{array}{l}\text { TGGATGAAATCTGGCTGAAGG } \\
\text { GGGAGCTGAGTGGCCAGTC }\end{array}$ \\
\hline EGFP & $\begin{array}{l}\text { EGFP-qF } \\
\text { EGFP-qR }\end{array}$ & $\begin{array}{l}\text { GCAAAGACCCCAACGAGAAG } \\
\text { TCACGAACTCCAGCAGGACC }\end{array}$ \\
\hline nascent mlns2 & $\begin{array}{l}\text { intron2-qF } \\
\text { intron2-qR }\end{array}$ & $\begin{array}{l}\text { CCTAGGTGTGGAGGGTCTCG } \\
\text { CCAGAAACGTGTCCCCACTC }\end{array}$ \\
\hline mature mlns2 & $\begin{array}{l}\text { exon2-qF } \\
\text { exon3-qR }\end{array}$ & $\begin{array}{l}\text { GGGGAGCGTGGCTTCTTCTA } \\
\text { AGTGCCAAGGTCTGAAGGTC }\end{array}$ \\
\hline $\begin{array}{l}\text { mINS2utr5-F - EGFP-R1, } \\
\text { mINS2utr5-F - EGFP-R2 }\end{array}$ & $\begin{array}{l}\text { exon1(utr5)-qF } \\
\text { EGFP-qR1 } \\
\text { EGFP-qR2 }\end{array}$ & $\begin{array}{l}\text { GGGACCCAGTAACCACCAG } \\
\text { CGGTGAACAGCTCCTCG } \\
\text { GTTTACGTCGCCGTCCAG }\end{array}$ \\
\hline hActin (ACTA1) & $\begin{array}{l}\text { exon5-qF } \\
\text { exon5-qR }\end{array}$ & $\begin{array}{l}\text { CGCGACATCAAGGAGAAGCT } \\
\text { CTCGTTCTCGAAGTCCAGGG }\end{array}$ \\
\hline $\begin{array}{l}\text { hINSutr5-F - CopGFP-R1, } \\
\text { hINSutr5-F - CopGFP-R2 }\end{array}$ & $\begin{array}{l}\text { exon1(utr5)-qF } \\
\text { CopGFP-qR1 } \\
\text { CopGFP-qR2 }\end{array}$ & $\begin{array}{l}\text { GCATCAGAAGAGGCCATCAA } \\
\text { CGGCACTCGATCTTCATG } \\
\text { TGATGCGGCACTCGATC }\end{array}$ \\
\hline hINS & $\begin{array}{l}\text { exon2-qF } \\
\text { exon2-qR }\end{array}$ & $\begin{array}{l}\text { CAGCCTTTGTGAACCAACAC } \\
\text { GGTCTTGGGTGTGTAGAAGAAG }\end{array}$ \\
\hline mPERKex1-2 & $\begin{array}{l}\text { mP-exon1-qF } \\
\text { mP-exon2-qR }\end{array}$ & $\begin{array}{l}\text { GTCACGCGCGACGGAGC } \\
\text { CTCGGCATCCAGTGCAGCG }\end{array}$ \\
\hline rPERKex1 & $\begin{array}{l}\text { rP-exon1-qF } \\
\text { rP-exon1-qR }\end{array}$ & $\begin{array}{l}\text { CCACATCGGATACGGCA } \\
\text { CCCGCGCGGCTGAAGTA }\end{array}$ \\
\hline
\end{tabular}

